\title{
DO YOU STAND BY OR STAND UP? BYSTANDER CHARACTERISTICS IN SOCIAL \\ BULLYING AND CYBERBULLYING
}

\author{
By
}

Nicole Summers

\begin{abstract}
A thesis submitted to
the Faculty of Graduate and Postdoctoral Affairs

in partial fulfillment of the requirements for the degree of
\end{abstract}

\author{
Master of Arts \\ in \\ Psychology \\ Carleton University \\ Ottawa, Canada
}

(C)2015, Nicole Summers 


\begin{abstract}
The aim of the current study was to investigate how moral disengagement and defender selfefficacy were related to bystander behaviour in social and cyberbullying. Four hundred and ninety-five emerging adults completed an online survey consisting of two measures of moral disengagement, a measure of defender self-efficacy and an adapted version of the Student Bystander Behaviour Scale. Regression analyses revealed that moral disengagement for the whole sample was positively associated with pro-bully behaviour and that defender self-efficacy was positively related to defender behaviour in both the social and cyberbullying contexts. The findings revealed that in order to better explain bystander behaviours, researchers should consider multiple cognitive mechanisms involved in bullying across various contexts. This study demonstrated the necessity of investigating social bullying and cyber bullying across various developmental periods and in turn may inform intervention efforts on how to encourage individuals to defend others when confronted with various forms of bullying.
\end{abstract}




\section{Acknowledgements}

I would like to express my sincere appreciation to a number of people, without whom this dissertation would not have been possible. I would like to thank my supervisor, Dr. Tina Daniels, for her endless support, advice, and guidance throughout this degree. I have learned so much from you, and am truly grateful to have had the opportunity to work with you. I would also like to thank my committee member, Dr. Kevin Nunes and external examiner Dr. Virginia Caputo for their efforts, insights, and constructive advice. I am grateful to have had your input in this process. I would also like to thank Dr. Andrea Howard for providing her expertise on the statistical analyses.

Thank you to both past and present members of the Healthy Relationships Lab and all of the others who helped me out along the way. I greatly appreciate all that you have done to help me get to this point. I would like to express my sincere gratitude to Christine for your endless advice, support, assistance, and friendship throughout the past 4 years.

Thank you to my family and friends for your love, support, and encouragement throughout. Knowing I have a very powerful team of amazing people standing behind me is what drives my success; I could not do this without all of your love.

Finally, to Devon, I am so grateful to have you by my side throughout this entire process; this would not have been possible without you. Thank you for always being there to listen and push me a little harder. I cannot express how much I appreciate your unwavering patience, understanding, and support ... and for always making me laugh. You are amazing.

Thank you, again, to all who have made this a positive experience, I can't wait to celebrate with all of you. 


\section{Table of Contents}

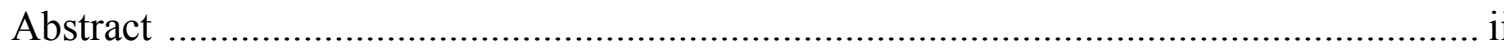

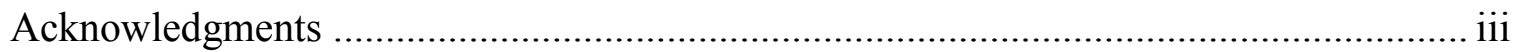

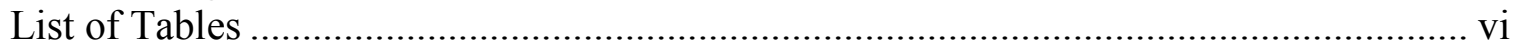

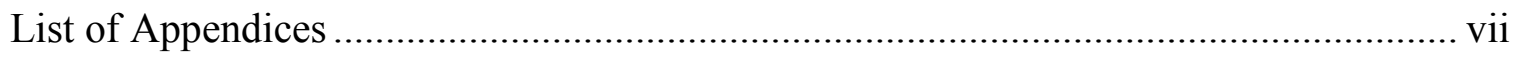

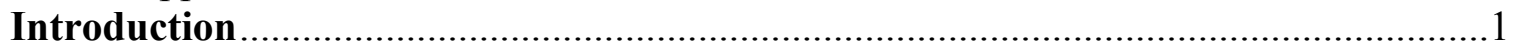

Bullying and the Audience: A Group Process. .....................................................

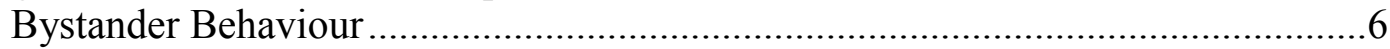

Age and gender affects on bystander behaviour ................................................6

Social Cognitive Theory of Moral Agency.....................................................................

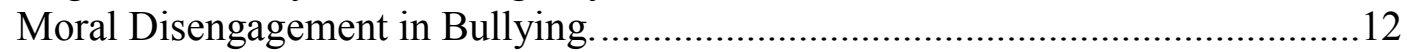

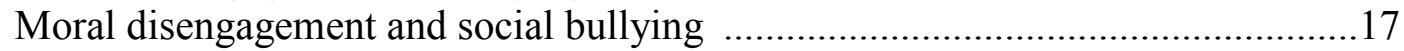

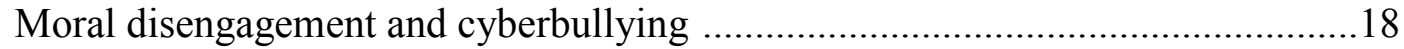

Moral Disengagement in Bystanders of Bullying ..............................................23

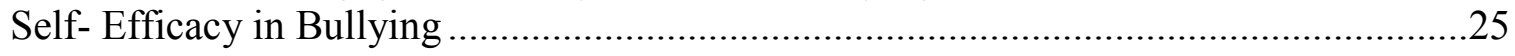

Self-Efficacy and moral disengagement in bullying behaviour.........................26

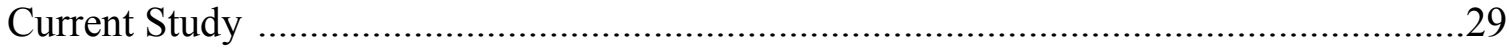

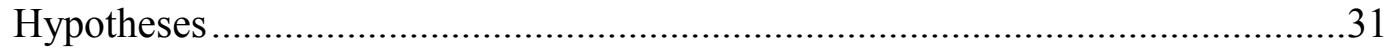

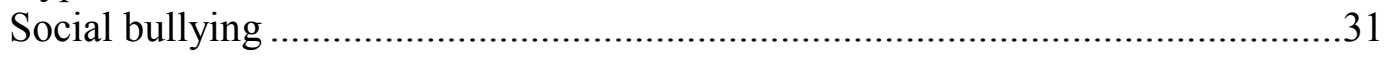

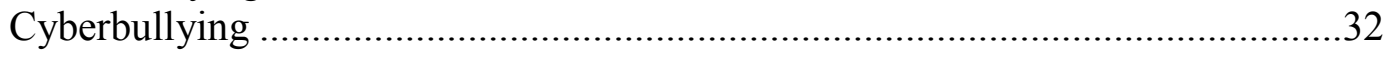

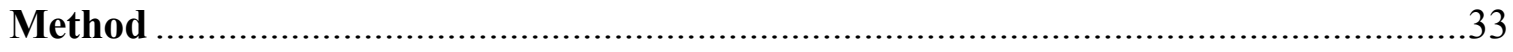

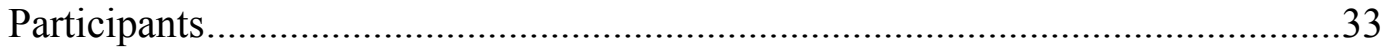

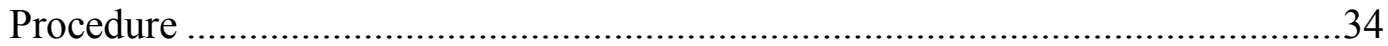

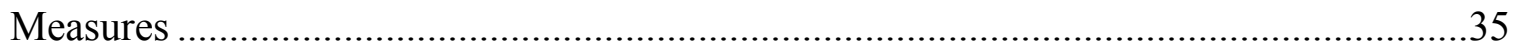

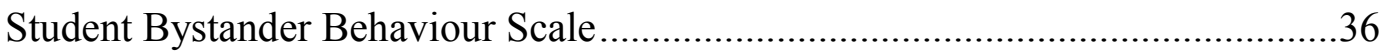

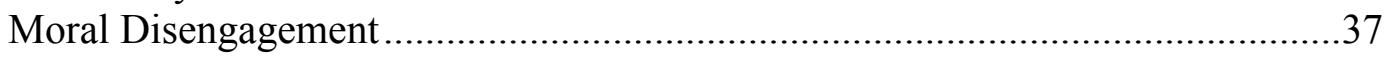

Moral Disengagement in Using Social Aggression (MODUSA) ..............37

Moral Disengagement in Using Cyber Aggression (MDCA)....................38

Defender Self-Efficacy ....................................................................39

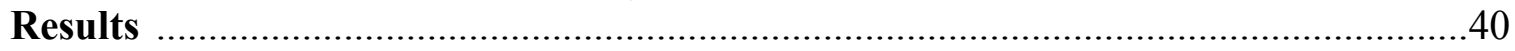

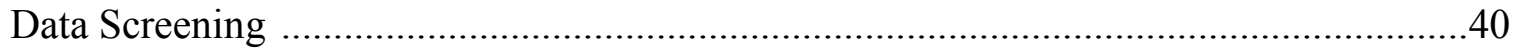

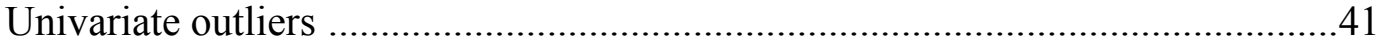

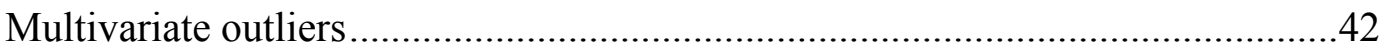

Missing data for all variables ......................................................................42

Development of the Moral Disengagement in Using Social Aggression Scale................42

Development of the Moral disengagement in Using Cyber Aggression Scale.................45

Development of The Social Aggression Student Bystander Behaviours Scale ................47

Development of the Cyberbullying Student Bystander Behaviour Scale .........................52

Development of the Defender Self-Efficacy Scale .................................................58

Exploring Sex Differences for all Variables .............................................................61

Moral disengagement, Defender Self-Efficacy, and Bystander Behaviour .....................61

Linear regression models for social bullying and bystander behaviour ..............63

Pro-bully bystander behaviour ................................................65

Outsider bystander behaviour ...............................................65

Defender bystander behaviour ..............................................67 
Logistic regression models for cyberbullying bystander behaviour .....................70

Pro-bully bystander behaviour ...................................................71

Defender bystander behaviour ........................................................73

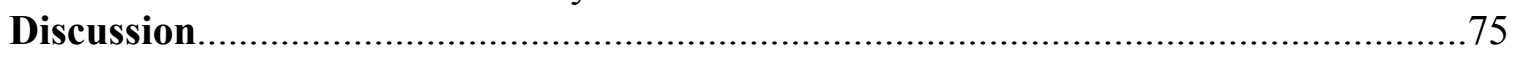

Development of Moral Disengagement Scales for Social and Cyberbullying ...................75

Moral disengagement in using social aggression..................................................75

Moral disengagement in using cyber aggression ..............................................76

Development of the Student Bystander Behaviour Scale ...............................................77

Social bullying bystander behaviour.................................................................77

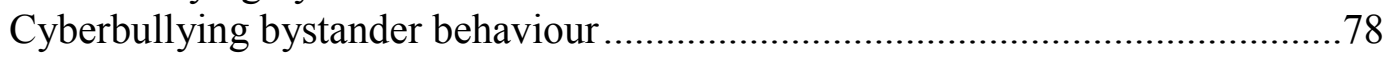

Sex Differences in Moral Disengagement and Bystander Behaviour .............................79

Moral Disengagement Defender Self-Efficacy and Social Bystander Behaviours ............81

Moral Disengagement Defender Self-Efficacy and Cyber Bystander Behaviours.............81

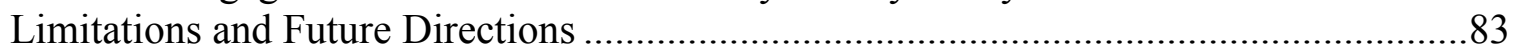

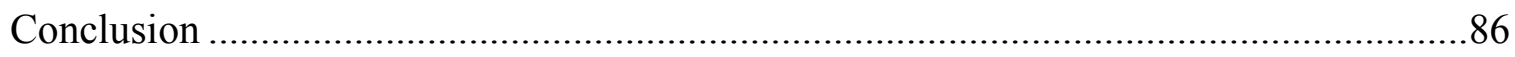

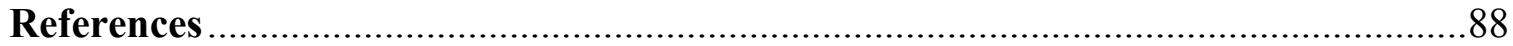

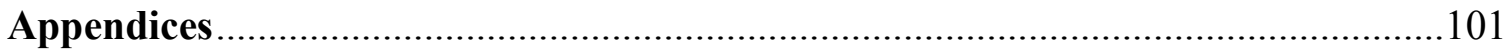




\section{List of Tables}

Table 1 Confirmatory Factor Analysis for Moral Disengagement in using Social Aggression... 44

Table 2 Exploratory Factor Analysis for Moral Disengagement in using Cyber Aggression..... 46

Table 3 Confirmatory Factor Analysis for Moral Disengagement in using Cyber Aggression... 48

Table 4 Factor Loadings for Exploratory Factor Analysis for Bystander Behaviour of Social Aggression................................................................... 50

Table 5 Factor Loadings for Confirmatory Factor Analysis for Bystander Behaviour in Social Bullying......................................................................... 51

Table 6 Means and Standard Deviations for the Student Bystander Behaviour in Cyberbullying Scale......................................................... 54

Table 7 Factor Loadings for Exploratory Factor Analysis for Bystander Behaviour in Cyberbullying.............................................................. 55

Table 8

Factor Loadings for Confirmatory Factor Analysis for Bystander Behaviour in

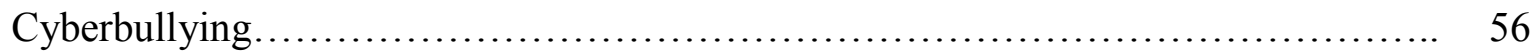

Table $9 \quad$ Confirmatory Factor Analysis for Bystander Behaviour in Cyberbullying.............. 57

Table 10 Means and Standard Deviations for the Defender Self-Efficacy in Bullying Scale ...... 60

Table 11 Factor Loadings for Confirmatory Factor Analysis for Defender Self-Efficacy Scale... 60

Table 12 Means and Standard Deviations for all Variables for Males and Females............... 62

Table 13 Means, Standard Deviations and Inter-Correlations Between all Variables............. 64

Table 14 Hierarchical Regression Predicting Pro-Bully Bystander Behaviour in Social Bullying....................................................................... 66

Table 15 Hierarchical Regression Predicting Outsider Bystander Behaviour in Social Bullying................................................................. 68

Table 16 Hierarchical Regression Predicting Defender Bystander Behaviour in Social Bullying...................................................................... 69

Table 17 Risk (Odds Ratio) for Pro-Bully Cyber Bystander Behaviour predicted from Moral Disengagement and Defender Self-Efficacy ................................... 72

Table 18 Risk (Odds Ratio) for Defender Cyber Bystander Behaviour predicted from Moral Disengagement and Defender Self-Efficacy 


\section{List of Appendices}

Recruitment Poster ............................................................................Appendix A

Informed Consent Form ......................................................................... Appendix B

Student Bystander Behaviour Scale ....................................................... Appendix C

MODUSA Moral Disengagement in Using Social Aggression ......................Appendix D

Moral Disengagement in Cyberbullying ................................................... Appendix E

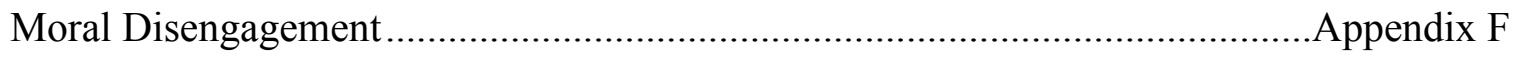

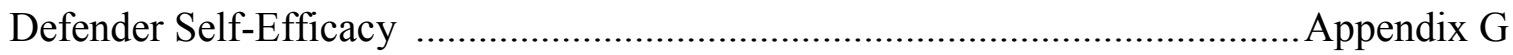

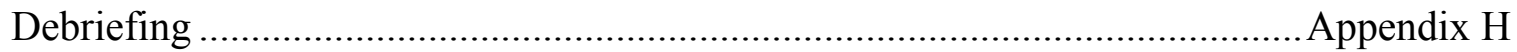

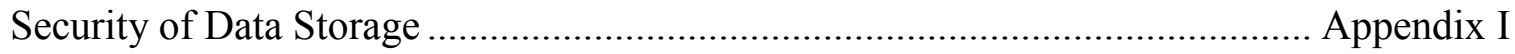

Supplementary Results Tables................................................................. Appendix J 


\section{Do You Stand By or Stand Up? Bystander Characteristics in Social Bullying and Cyberbullying}

Conflict exhibited between peers emerges at a young age (Crick et al., 1997) and continues throughout elementary school and into emerging adulthood (Boulton \& Smith, 1994; Olweus, 1993; Whitney \& Smith, 1993). Youth in today's society have multiple ways in which they are able to hurtfully engage with their peers, from face-to-face interactions, to indirect actions such as exclusion, to the vastly expanding cyber world. In order to effectively study and build an understanding of the those involved in bullying behaviours, a definition of this behaviour is essential. Bullying was first defined as "being ... exposed, repeatedly, and over time, to negative actions ... when someone intentionally inflicts injury or discomfort upon another" (Olweus, 1994, p. 27). Over time the definition of bullying has solidified to include three central aspects: intentionality, repetition and power imbalance (Hymel, Schonert-Reichl, Bonanno, Vaillancourt, \& Rocke Henderson, 2005; Nansel et al., 2001; Olweus, 1994; 2010; Vaillancourt et al., 2008). Bullying can be further broken down into two types of aggression; physical forms of aggression (e.g. acts that cause harm to the physical body such as hitting, kicking, punching etc.) and non-physical forms of aggression where the intent is to cause social or emotional injury to the individual (e.g. gossip, exclusion, non-verbal body language). The current study focused on understanding non-physical forms of bullying, specifically social bullying and cyberbullying behaviours.

Currently there is little known about the individuals involved in witnessing bullying episodes and how they may contribute to the impact of these hurtful behaviours. In the past bullying has been perceived as a conflict between two people, the perpetrator and the target; however, recent research suggests that a large number of other people are usually present when 
bullying occurs (e.g. Craig \& Pepler, 1997; O’Connell, Pepler, \& Craig, 1999; Trach, Hymel, Waterhouse, \& Neale, 2010). In research on Canadian playgrounds it has been found that in $85 \%$ of bullying episodes there are other children who witness or are drawn into bullying behaviour (O'Connell et al., 1999). These individuals, referred to as bystanders, may contribute substantially to both the nature and impact of bullying behaviour (Trach et al., 2010).

Researchers have suggested that bystanders may be the most important resource available if we wish to alter the power dynamic present in bullying episodes (Vaillancourt, McDougall, Hymel, \& Sunderani, 2010) and many current approaches to bullying intervention have focused on bystander engagement. Research has consistently shown that when others are present the magnitude and severity of the bullying episode increase (Pepler, Craig, \& O'Connell, 2010; O’Connell et al., 1999; Salmivalli, 2010; Salmivalli, Lagerspetz, Björkqvist, Österman, \& Kaukiainen, 1996) and the more people that are present the less likely others are to intervene. Given the substantial role that bystanders play in supporting bullying behaviour (e.g. O'Connell et al., 1999) and the evidence suggesting that attitudes, values and beliefs influence behaviour (e.g. Bandura, 1996; 1999; Almedia, Correia, \& Marinho, 2010; Hymel, Rocke-Henderson, \& Bonnano, 2005) the current study proposed to examine the underlying cognitive processes of bystanders.

There is little known about the underlying beliefs and cognitive processes of those who do not intervene when they witness bullying behaviour compared to those who do. One important area of study that has received attention is the use of cognitive justifications that allow those who witness harmful acts to both justify the immoral behaviours and reduce their sense of responsibility to intervene. This underlying cognitive process is known as moral disengagement (Bandura, 1999, 2002). 
Moral disengagement (Bandura, 1999; 2002) refers to the process of perceiving some types of antisocial behaviour as reasonable or justified. This process is important to consider when studying bullying behaviour as research has shown that even if individuals have internalized moral rules that prohibit bullying behaviours, in certain circumstances they have the ability to justify engaging in such harmful behaviour (Hymel et al., 2005). The theory of moral disengagement has been used to explain the different roles an individual may play when witnessing an incident of bullying (i.e. the perpetrator, who initiates the hurtful behaviour; the victim, who is the target of the hurtful behaviour; and/or the bystander, who is witness to the hurtful act). A small body of research exists which addresses the role of moral disengagement in bystander behaviours (Gini, 2006; Menesini, Fonzi, Ortega, Costabile, \& Lo Feudo, 2003; Obermann, 2011; Thornberg \& Jungert 2013) but only in relation to witnessing traditional forms of bullying (i.e. physical). Given that social/relational bullying and cyberbullying have been identified to be as harmful as physical aggression (Bauman \& Newman, 2013), the role of moral disengagement for bystanders involved in these common forms of peer bullying should be considered. The primary goal of this study was to examine the relationship between moral disengagement and bystander behaviours for those who witness social bullying (e.g. rumour spreading, gossip, dirty looks, cold shoulder) and cyberbullying (e.g. spreading gossip, embarrassing pictures, excluding others online).

In addition to moral disengagement other possible cognitive mechanisms may be related to bystander behaviour. The term self-efficacy, introduced by Bandura (1986; 1997), refers to the belief in one's capabilities to successfully execute a required action in order to produce the desired results. Recent bullying research has found that defender self-efficacy is positively associated with defender behaviour (Barchia \& Bussey, 2011; Thornberg \& Jungert, 2013). 
Given these findings, the current study examined how personal beliefs in one's ability to intervene (defender self-efficacy) were related to reports of bystander behaviour.

The scope of the present study was to better explain the full range of possible bystander behaviours in bullying situations by investigating how moral disengagement and defender selfefficacy were related to bystander behaviours in social bullying and cyberbullying among a sample of emerging adults. The following review examines recent research and the relevant theories of bullying, moral disengagement, and defender self-efficacy in order to provide a context for the current study.

\section{Bullying and the Audience: A Group Process}

Bullying behaviour has been recognized to be a group process involving more than the victim and the perpetrator (Gini, 2006; Gini et al., 2008; Obermann 2011; Salmivalli, 1999). In the past bullying has been perceived as a conflict between two people, the perpetrator and the target; however, recent research suggests that a large number of other children are usually present when bullying occurs (Craig \& Pepler, 1997; O'Connell et al., 1999; Trach et al., 2010). To further understand bullying behaviour and how it operates within the peer group and how it is supported by the social context, a more sophisticated view must be taken to understand how bystander behaviours impact the nature, duration, and severity of the bullying episode (Trach et al., 2010). Bystanders are an important part of the group process as they are present and witness bullying behaviour; however, they are not directly acting in the role of the bully or victim (Twemlow, Fonagy, Sacco, 2010). Bullying episodes may be affected by the bystanders as the behaviour is often maintained by the presence and the indirect involvement of bystanders (Gini, 2006; Gini et al., 2008; Obermann 2011; Salmivalli, 1999). This may indirectly encourage and support the bullying behaviour by providing an audience for the bully (Trach et al., 2010). 
Bystanders may also become directly involved as they get drawn into the bullying behaviours by laughing and provoking the bullying behaviour or they may actively intervene to support the victim (Salmivalli, 1999).

The important presence of peers in incidents of bullying was demonstrated by O'Connell, Pepler, and Craig (1999) in a study using Toronto playground observations of 120 elementary school children. O'Connell and colleagues found that of the students who were present across 53 different bullying episodes, many members of the peer group witnessed bullying and in fact as many as $85 \%$ of peers were present and aware of the behaviour. The largest majority of the time (54\%) bystander's reinforced the bully behaviour in a passive manner by watching and not intervening. Peers were found to discourage the bully or defend the victim only $25.4 \%$ of the time, while $20 \%$ of the time they were actively involved in encouraging the bullying behaviour. This study was the first to bring to light the high prevalence of bystanders in bullying episodes and the scarcity of incidents that involved someone in the peer audience intervening to help the victim. These findings emphasize the importance of considering the role of the larger peer group in understanding the process of bullying. It is important that researchers continue to examine the variables that predict higher rates of defending bystander behaviour.

More recent studies of bullying have continued to demonstrate that there are a large number of peers present when bullying incidents occur. A study conducted by Rivers, Poteat, Noret, and Ashurst (2009) with a sample of 2002 students between the ages of 12 and 16 years old found that $63 \%$ of peers reported witnessing bullying behaviour, and more recently Trach, Hymel, Waterhouse and Neale (2010) found in a large Canadian sample of 9397 students in grades 4 to 11 , that $68 \%$ of peers witness bullying on a regular basis. Bystanders to peer bullying have the unique and important ability to stop the behaviour or engage in pro-social 
behaviours to assist the victim, which is an imperative consideration for bullying intervention programs.

Bystander behaviour. Much of the recent research on bystander behaviour has focused on identifying the different possible behaviours that individuals who witness bullying may engage in and what characteristics are associated with bystander behaviours (Craig \& Pepler, 1997; Rivers et al., 2009; Salmivalli et al., 1996; 1999). In particular, researchers have examined those who do nothing (described by researchers as outsiders or witnesses) versus those who take an active role in attempting to stop the bullying behaviour described as defenders (Twemlow et al., 2010; Thornberg \& Jungert 2013).

Outsider bystander behaviour contributes to the bullying social structure as individuals who engage in this behaviour participate indirectly in the victimization process when they fail to respond to the perpetration of bullying behaviour. Positive feedback is given to the perpetrator when witnesses stand and watch (O'Connell et al., 1999; Salmivalli et al., 1996; Rigby \& Johnson, 2006) and the negative effects experienced by the victim can increase, such that they experience higher anxiety, depression and lower self-esteem (Salmivalli, 2010). Therefore it is important to address the group dynamics supporting bullying behaviour. Research has suggested that there are two important considerations in understanding these individual differences; age and gender (Craig \& Pepler, 1997; Rivers et al., 2009; Salmivalli et al., 1996; 1999).

Age and gender affects on bystander behaviour. In an effort to examine the effect of age and gender on an individual's type of response to bullying behaviour an observational study by Craig and Pepler (1997) found that boys were more likely to be witnesses rather than defenders in bullying situations in comparison to girls. In peer nominated and self-report studies, girls were rated more often as outsiders by peers and rated themselves as witnesses of bullying 
who passively watched or did not respond to the incident as compared to boys (Rivers et al., 2009; Salmivalli et al., 1996; 1999). When examining intervention behaviour, girls were shown to react on behalf of the victim when they witness bullying significantly more than boys (Gini, Pozzoli, Borghi, \& Franzoni, 2008). Gini and colleagues (2008) found that girls endorsed defending behaviours, while assistive and passive bullying behaviours were not endorsed. Boys on the other hand, were more likely to endorse behaviours that assisted the bully (Gini et al., 2008).

A cross sectional study by Trach and colleagues (2010) examined the experiences of bullying and victimization among students in grades 4 to 7 from 38 Canadian elementary and secondary schools. An examination of sex differences found that, regardless of age, females and males were equally likely to report they walked away from the bullying behaviour and avoided or ignored the behaviour. The prevalence of passive and aggressive bystander behaviour was found to increase with grade level. Importantly, $20 \%$ of peers were identified as reinforcing the bully and $7 \%$ were named assistants or followers of the bully. Only a small proportion of peers (17\%) were identified as defenders, those who intervened in the bullying behaviour on behalf of the victim. However, younger elementary students in grades 4 and 5 reported higher intervention on behalf of the victim and intervened using more positive, recommended strategies (i.e. telling the bully to stop, helping the victim, talking to an adult) than older students. Older students (Grade 8 - 10) were more likely to report walking away and/or doing nothing to intervene (Trach et al., 2010).

Developmental trends have been well documented in research concerning bullying victimization and perpetration. Findings suggest that physical aggression tends to peak in early childhood, then to gradually decline with age, with a brief upswing during adolescence 
(Tremblay \& Nagin, 2005). Research has indicated that verbal aggression, unlike physical aggression, tends to increase with age, from childhood through adolescence before declining in later adulthood (Archer \& Côté, 2005). Finally, research has indicated that indirect forms of peer aggression including social aggression, tend to increase with age during this period, particularly among girls (Vaillancourt, 2005; Zimmer-Gembeck, Geiger \& Crick, 2005). Overall, researchers have reported that intervening to support the victim decreases with age), yet little is known about what happens as youth move beyond adolescence and into adulthood (Menesini et al., 2003;

O’Connell et al., 1999; Salmivalli, 1999). In considering bystanders' responses to acts of bullying much research has been conducted in order to understand the thoughts these individuals may use to justify their behaviour.

\section{Social Cognitive Theory of Moral Agency}

The theoretical foundations underpinning bullying research have been adapted from the more substantial research based on aggression. Among the most influential models of aggression, and thus of bullying, is the social cognitive theory of the moral self (Bandura, 1986, 1991). In the development of a moral self, individuals adopt standards of right and wrong that serve as guides and deterrents for conduct. This self-regulatory process allows individuals to monitor their conduct, judge it in relation to their moral standards and perceived circumstances, and regulate their actions. Bullying may take the form of ignoring or rejecting moral values, and intentionally turning to aggression to meet social goals or secure social or material gains. One avenue for further exploring the role of moral reasoning in bullying and aggression can be found in Bandura's (1991) conceptualization of moral disengagement.

Bandura's research has focussed on the moral thoughts and justifications of adults who engage in hurtful behaviours (Bandura, 1999; 2002). He was interested in how seemingly good 
people could engage in harmful aggressive acts. His research was focused around how immoral behaviours were achieved, not by altering their personality structures or moral standards, but rather by cognitively redefining the morality of the harmful act so that it can be done free from negative emotional consequences. Bandura described this process as moral disengagement.

Research by Bandura (1999; 2002) demonstrates that moral disengagement is a process by which people use psychological mechanisms to justify engaging in harmful acts towards others and that high levels of moral disengagement protect one from experiencing negative emotions (e.g. shame, guilt) and prevent negative behaviours from being stressful as the individual is able to rid themselves of cognitive dissonance and potential guilt (Bandura, 1999; 2002). This allows the individual to engage in negative and harmful acts with little to no negative emotional consequences. Social conditions also play an important role in supporting these behaviours as they can lead ordinary people to engage in harmful behaviour. Moral internal justifications are used to close the gap between social pressures and personal moral standards (Bandura, 1990) such that the ability to justify a hurtful behaviour leads to the ability to engage in hurtful actions. In conclusion, it has been demonstrated that among adults, cognitive justifications can allow individuals to disengage from their moral compass and participate in acts against others that are hurtful and damaging without experiencing negative emotions such as guilt (Bandura, 1999; 2002).

Bandura has identified four possible cognitive strategies that may allow individuals to rid themselves of any cognitive dissonance that arises when engaging in or witnessing immoral behaviour. These strategies include: 1) cognitive restructuring of the event 2) internal justifications for the behaviour to diminish personal responsibility 3) distortion of the negative impact caused by the behaviour, 4) and blaming or dehumanizing the victim). Considering these 
cognitive justifications is important for understanding the variables that may be related to behaviours such as those exhibited by bystanders of bullying behaviour. Presented below is an explanation of the four categories of justifications developed by Bandura.

Internal cognitive restructuring for engaging in harmful behaviour can occur when one interprets the harmful behaviour as morally acceptable in order to justify the act. This allows the individual to avoid negative emotions like guilt and shame. An important technique used to justify this behaviour is euphemistic labeling, a term which refers to the process of sanitizing language in order to detract from the emotional intensity of the reality being referenced (Bandura, 2001). For example the use of the term "friendly fire" is used to refer to death or injury caused by one's own military in order to sound more socially acceptable.

Another mechanism that Bandura has argued can be used to reduce responsibility for one's actions involves minimizing personal responsibility in order to reduce the perceived harmful consequences of the behaviour. For example, saying "I am sorry you are so sensitive" in response to hurting someone's feelings. Diffusion or displacement of responsibility leads to a reduction of the presumed personal responsibility for the behaviour.

The third mechanism hypothesized by Bandura involves justifications that disregard or distort the negative impact of the behaviour. Distortion is the term used to refer to situations where an individual utilizes previous information about the potential benefits of the hurtful behaviour in order to minimize the impact. For example, when someone justifies hurtful behaviour by arguing that it will "make the person stronger".

The final method of moral disengagement described by Bandura involves dehumanizing and blaming the victim. This can be achieved by reinterpreting the role of the victim as having been actively responsible for and ultimately deserving of the harm they received. For example, 
this is commonly seen in references to minority groups as non-human or less than human (i.e. likening individuals to animals). Bandura argued that these four methods of moral disengagement may work separately or together in such a way as to increase an individual's ease with and ability to engage in immoral behaviour without personally experiencing negative cognitive consequences or emotions.

Bandura (1990) has argued that cognitive justifications leading to moral disengagement are gradual and begin with small acts that are easily tolerated. Individuals who commit intentional hurtful acts over time justify their behaviours and may no longer experience negative cognitive and emotional outcomes such as stress or guilt. According to Bandura (2002)

Disengagement practises will not instantly transform considerate persons into cruel ones. Rather, the change is achieved by progressive disengagement of self-censure. Initially, individuals perform mildly harmful acts they can tolerate with some discomfort. After their self reproof has been diminished through repeated enactments, the level of ruthlessness increases, until eventually acts originally regarded as abhorrent can be performed with little anguish or self-censure. Inhumane practices become thoughtlessly routinized. The continuing interplay between moral thought, affect, action, and its social reception is personally transformative. People may not even recognize the changes they have undergone as a moral self (p. 110).

Understanding the justifications used when engaging in immoral, hurtful behaviour is an important consideration for the field of bullying research. Although Bandura's research focused on adults' use of aggressive behaviour and their justifications for such acts, recently researchers have applied his theories to the use of bullying behaviours in childhood and adolescence 
(Almeida et al., 2010; Gini, 2006; Hymel et al., 2005; Menesini et al., 2003; Obermann, 2011a, 2011b; Thornberg, 2010).

\section{Moral Disengagement in Bullying}

Individuals who perpetrate bullying behaviours report higher levels of moral disengagement (Gini, 2006; Hymel et al., 2005, Obermann, 2011) than victims and those who are not involved. Some of the first researchers to look at moral disengagement and bullying were Menesini and colleagues (2003) who focused on the emotions associated with moral disengagement. They interviewed grade 4 and grade 8 students after they were presented with a typical bullying situation using illustrated cartoons. Each child having been nominated by their peers as a bully, victim, or outsider was compared on their emotional reactions. This study emphasized emotions associated with moral responsibility and moral disengagement such as guilt, shame, indifference and pride. Findings were consistent with Bandura's construct of moral disengagement in that peer nominated bullies reported more morally disengaging emotions and more egocentric explanations than victims or outsiders. Children who were identified by peers as bullies reported less emotional concern for victims and more emotions related to moral disengagement such as indifference and pride. Although this study examined moral disengagement utilizing hypothetical bullying scenarios and peer nominations, there have been numerous other studies that have also found a link between direct engagement in bullying behaviour and high levels of moral disengagement (Barchia \& Bussey, 2011; Gini, 2006; Obermann, 2011; 2013; Pornari \& Wood, 2010; Pozzoli et al., 2012; Robson \& Witenberg, 2013).

In order to determine whether initial levels of moral disengagement were related to changes in peer aggression over time, Barchia and Bussey (2011) examined the relationships between 
moral disengagement (Bandura et al., 1996) and relational and physical bullying as identified by Crick and Grotpeter (1995) over time. The study consisted of 1,167 participants in grades 7 to 10 and examined the relationship between moral disengagement and aggression over an 8-month period. Moral disengagement was measured using 13 items from the Moral Disengagement Scale (Bandura et al., 1996) which measures justifications used to legitimize the use of delinquent or immoral behaviours. It was found that when accounting for stability of aggressive behaviour over time, children with high moral disengagement scores reported more aggressive behaviour over time compared to children with low moral disengagement scores. This relationship was not found to be bidirectional as there was no significant effect of aggression at time 1 or change in aggression efficacy on moral disengagement at time 2. These results illustrate the important role cognitive justifications may play in the ability to engage in aggression and the use of more aggressive behaviour over time (Bandura, 2002). This study provides evidence of the relationship between high levels of aggressive behaviour and higher moral disengagement justifications in children.

The previous study did not find a bidirectional relationship between aggression and moral disengagement, but rather found evidence to support the argument that moral disengagement strategies lead to more aggression over time. In contrast, Obermann (2013) examined the role of aggressive behaviour in maintaining and increasing reported levels of moral disengagement over time. The theory of moral disengagement states that individuals involved in repeated immoral behaviour may experience escalation in their ability to disengage from their moral standards (Bandura, 1999; Tsang, 2002). Obermann (2013) hypothesized that repeated aggressive behaviour over time would produce a tolerance and resistance to negative emotional consequences experienced by individuals. Specifically it was hypothesized that stable bullies 
would show significant increases in moral disengagement over time. Moreover, it was hypothesized that consistent aggression over time would lead to an escalation in moral disengagement due to the constant exposure and use of disengaging strategies that degrade feelings of remorse and guilt (Bandura, 2002). Obermann (2013) examined the temporal relationship between aggression and moral disengagement in a sample of 567 students in grades 6-8 over a one-year span. Participants completed questionnaires on self-reported bullying, peernominated bullying, and moral disengagement as measured using the Moral Disengagement Scale (Bandura et al., 1996) at two time points over the course of one year. Obermann found that the change in self-reported bullying behaviour over one year was significantly related to a change in levels of moral disengagement. Results indicated that levels of moral disengagement of the aggressive adolescents did not decrease significantly over time and levels of moral disengagement of the bullies at $\mathrm{T} 1$ who were no longer reporting aggression at $\mathrm{T} 2 \mathrm{did}$ not increase. Participants who reported bullying behaviour at T1 and who either experienced no changes or an increase in bullying behaviour from $\mathrm{T} 1$ to $\mathrm{T} 2$ were assigned to the position of stable bullies. Results indicated stable bullies reported a higher level of moral disengagement compared to those who were not bullies or desisted bullies (i.e. those who reported less bullying at T2). These results provided some support for the theory (Bandura, 1999, 2002) that people involved in aggressive behaviour consistently over time report higher levels of moral disengagement compared to those who do not commit immoral behaviour. This study provided evidence to support the developmental relationship that exists between moral disengagement and aggression as those who were identified as perpetrators who demonstrated stable aggressive behaviour over the two time points showed significantly higher levels of moral disengagement compared to non-bullies. 
These two studies have taken different approaches in establishing the nature of the relationship between moral disengagement and bullying behaviour; however, currently it is not clear the direction of this relationship. Both studies used only two time points across a short period of time ( 8 months and 12 months). Longer time periods and more time periods are needed to better understand the relationship between moral disengagement and aggressive behaviour. Obermann's (2013) study did not take into account the environmental influences of the bullying episodes, which has been shown to have a significant relationship (Barchia \& Bussey, 2011). Both researchers recommended that the importance of early intervention to aid in the prevention of long-term bullying, and related increases in moral disengagement, be considered given the findings of their studies.

Pozzoli and colleagues (2012) examined the role of moral disengagement in bullying at an individual and classroom level. Moral disengagement is influenced by the surrounding moral values, the strategy of diffusion of responsibility, group norms, and other group processes within the classroom. Class moral disengagement is the degree of disengagement processes at the class level. A 14 item version of the Moral Disengagement Scale (Caprara et al., 1995) based on Bandura et al. (1996) measured classroom and individual moral disengagement using a sample of 663 children ranging from 8 to 10 years old. The role of class moral disengagement was tested using a multilevel modeling technique of hierarchical linear modeling. A positive association between moral disengagement and bullying was found at an individual level and the most effective cognitive justification mechanism utilized was cognitive restructuring of negative events (e.g. It's okay to insult a classmate because beating him/her is worse). Interestingly, cognitive restructuring was not associated with the classroom level of moral disengagement, however distorting negative consequences (e.g. Teasing someone does not really hurt them), 
blaming/dehumanizing the victim and minimizing agents' role was associated with pro bully behaviour at the class level. Pozzoli et al. (2012) demonstrated a significant relationship between specific mechanisms of moral disengagement and individual pro-bully behaviour. Based on these findings they argued that it was through cognitive restructuring that children became more accepting of their own use of aggressive bullying behaviours, which resulted in their ability to interpret bullying as an acceptable way to communicate.

The majority of studies examining the use of moral disengagement in bullying have used Bandura's measure of moral disengagement, which focuses on the legitimacy of engaging in delinquent and immoral behaviour but not specifically bullying behaviour. Hymel et al. (2005) have developed a measure of moral disengagement that specifically refers to bullying behaviours. Hymel and colleagues (2005) examined moral disengagement justifications in bullying behaviour and experiences with bullying and victimization as well as attitudes towards bullying behaviour. The study consisted of 494 participants from American secondary schools from the grades of 8 and 10. A measure was created to assess the level of moral disengagement that is specific to bullying behaviour. This measure is more relevant for the study of bullying as items address physical and verbal bullying behaviours (e.g. "Some kids need to be picked on just to teach them a lesson", "If you're angry with someone, it's okay to keep them out of your group of friends").

Hymel and colleagues (2005) found that $38 \%$ of the variance in self-reports of bullying was explained by moral disengagement attitudes and the status of the individual, whether they were a victim or a bully. This is important as it demonstrates that children who reported frequent bullying behaviour also exhibited the highest level of moral disengagement; in contrast to those who never bullied displayed the lowest level, regardless if they had been victimized. Children 
who sometimes bullied and had never been victimized showed high levels of moral disengagement. However, those who bullied sometimes and had been victimized showed fairly low levels of moral disengagement. These researchers speculated that experiencing both bullying and victimization (bully-victims) was found to act as a buffer from moral disengagement justifications. This could be due to the fact that those who have experienced forms of victimization have trouble justifying their harmful behaviours. Importantly, this was the first study that utilized a measure that addressed moral justifications specific to bullying behaviours (Hymel et al., 2005). Although research has examined the relationship between moral disengagement and physical bullying behaviours, little is known about the relationship between moral disengagement and social bullying behaviours.

Moral disengagement and social bullying. To date the largest majority of research in the area of moral disengagement has focused on the use of physical bullying (Hymel et al., 2005). However, more current definitions of bullying define it as any behaviour intended to cause harm (Li, 2005). This would include not only physical acts of aggression but also non-physical forms directed towards harming peer relationships or self-esteem (i.e. social/relational bullying) as well as acts of aggression perpetrated online (i.e. cyberbullying). The term relational aggression was created to include non-physical forms of aggression (Crick \& Grotpeter, 1995) such as gossip, group exclusion, threats to withdraw from the friendship, and threats to harm peer relationships (Crick, Bigabee, \& Howes, 1996). Social aggression, a term developed by Galen and Underwood in 1997, refers to behaviours used to inflict harm on one's reputation or relationships such as malicious rumours, social exclusion, and harming an individual's self-concept. Social aggression is a more encompassing term that includes relationally aggressive behaviours as well as non verbal behaviours such as eye rolling, hair flipping, and the cold shoulder that are directed 
at the victim to cause harm (Coyne et al., 2006). The term social bullying will be used in the current study to describe both verbal and non-verbal social behaviours utilized to harm the victim's reputation and relationships. Currently there is no published research in the area of social bullying and moral disengagement.

Polihronis, Daniels, Quigley, Magner, and Trant (2012) created a measure of moral disengagement that uses the justifications for socially aggressive behaviour that can include spreading rumors, gossip, and non-verbal behaviours such as dirty looks and hair flipping, all of which are used to harm another person. This measure was created as a revision of Hymel et al. (2005) moral disengagement justification in bully behaviour but specifically focused on the uses of socially aggressive justifications. It was used in a pilot study of 104 young adults (29 male and 75 female) between the ages of 18 and 30 years old. This scale examined the endorsement and justifications of socially aggressive acts using items such as "If a rumour is being spread about someone, there is nothing I can do to stop it" and "It's okay to give someone the silent treatment in order to teach that person a lesson". To date there is little research that addresses moral disengagement justifications of socially aggressive behaviours, thus, an examination of the role of moral disengagement in the perpetration of socially aggressive bullying behaviours is warranted. In addition to expanding the research on moral disengagement to the use of social bullying behaviours it is also important to consider the use of cyberbullying behaviours.

Moral disengagement and cyberbullying. Social aggression among youth has advanced into more discrete and accessible behaviours that are often carried out in online forums and social media sites. Although similar to social forms of aggression (Li, 2010; 2007; Smith et al., 2008) cyberbullying is defined as "willful and repeated harm inflicted through the medium of electronic text" (Patchin \& Hinduja, 2006, p. 152). Cyberbullying encompasses a broad scope of 
behaviours that include sending harmful emails, text messages or posts, creating offensive websites, posting embarrassing photos or videos of another person online, and excluding or insulting the victim via online forums, blogs or social media cites (Campbell, 2005). Cyberbullying is a very accessible tool to inflict harmful acts that quickly affects all environments (e.g. home, school, work) and reaches a much larger audience.

Cyberbullying has been argued to be similar to traditional bullying in intent to harm, and behaviours used to cause harm; however, it differs from traditional bullying in three main ways. It can reach the victims without requiring face-to face interaction, it can be much more far reaching and because of the perceived anonymity youth report that they would perpetrate more hurtful and harmful behaviours than they would face-to-face (Li, 2005). The vast majority of behaviours exhibited in cyberbullying are acts that are similar to social/relational bullying in that the behaviours do not involve physical harm but rather are directed at the manipulation of friendships, spreading rumours, and calling names (Li, 2010; 2007; Smith et al., 2008).

While cyberbullying has been found to be very similar to traditional forms of bullying in terms of the type of behaviours perpetrated (Smith et al., 2008) it is important to examine if there are differences exhibited in the moral cognitive justifications utilized when engaging in cyberbullying versus traditional bullying. With the internet, social media, and personal electronic devices, the means to target others anonymously, with no constraints of physical location, are easily accessible. Although similar to traditional bullying, the anonymity of cyberbullying creates an especially dangerous opportunity for adolescents to harm one another.

With growing concern for online bullying, it has become critical to understand the cognitive processes involved. Often, cyberbullying does not involve the opportunity for the perpetrator to see the emotional impact of their actions on the victim and this may make it easier for someone 
to harm another without feeling guilty or ashamed (Slonje \& Smith, 2008). This may also impact the type and form of cognitive strategies used in order to disengage from moral responsibility (Almeida et al., 2008). Although research has found significant empirical and conceptual overlap between traditional and cyberbullying (Dooley et al., 2009; Smith et al., 2008), further investigation is warranted to understand the cognitive processes involved in the perpetration of each form of aggression.

Pornari and Wood (2010) investigated the unique relationship between cyberbullying and moral disengagement, and compared this to the relationship between moral disengagement and traditional bullying. With a sample of 339 students between the age of 7 and 9 years old, moral disengagement was measured using the original scale of Bandura and colleagues (1996) and selfreports assessed the frequency of traditional bullying and cyberbullying. The prevalence of cyber victimization was high with $55 \%$ of all students reported that they had experienced cyberbullying at least once in the past 6 months, while 37\% had experienced cyberbullying frequently in the past six months. The remaining $31 \%$ of participants reported harming others at least once using electronic forums. It is important to note the high prevalence of cyberbullying in such a young sample, and that more females reported cyberbullying than boys. This finding is supported by previous research that has found that girls tend to engage in more indirect and covert forms of social aggression than do boys (Crick, 1996; Crick \& Grotpeter, 1995; Li, 2006). Furthermore these findings reinforce the importance of understanding the process of cyberbullying as over half the sample reported having been victimized by this form of bullying. Pornari and Wood (2010) found that high levels of traditional bullying and victimization were related to high frequencies of cyberbullying and becoming a victim of cyberbullying. 
A positive but weaker relationship was found between moral disengagement and cyberbullying than between moral disengagement and traditional bullying. Researchers speculated that due to the anonymity and distance cyberbullying presents, the consequences of the harmful acts may not elicit strong negative feelings (i.e. guilt, shame) and that the use of moral disengagement justifications may not be required as much as in situations of face-to-face bullying. A limitation of this study was the use of the original moral disengagement scale that inquires about general aggression and delinquent behaviours rather than behaviours that are specific to cyberbullying. Using a scale developed to measure justifications specific to cyberbullying behaviours might result in a more accurate depiction of the level of moral disengagement.

These distinct characteristics of cyberbullying may lessen inhibition to engage in hurtful behaviours as the lack of responsibility and inability to see the victim's emotions results in the lack of feeling remorse or guilt. A study conducted by Perran and Gutzwiller-Helfenfinger (2012) examined the moral disengagement justifications used when engaging in cyberbullying and traditional bullying in a sample of 564 adolescents between the ages of 12 and 19 years old. Moral disengagement was measured through two hypothetical aggression scenarios, one scenario described an adolescent intentionally misinforming another adolescent about a meeting and the other scenario described a student sending out embarrassing photos of a peer. Moral disengagement was measured based on the written responses regarding how the participant felt about the above scenarios. It was found that higher levels of moral disengagement were associated with higher levels of traditional bullying. Using regression analyses they found that low levels of moral values and high levels of disengaged justifications were associated with higher levels of traditional bullying. Low levels of moral values also related to higher levels of 
cyberbullying when controlling for traditional bullying. Although previous research has found significant overlap between traditional and cyberbullying in many aspects including harm (Smith et al., 2008), a significant correlation between cyberbullying and moral disengagement has not been found. It was found that higher levels of disengaged justifications related to higher levels of traditional bullying, but with respect to moral disengagement, higher levels of disengaged justifications did not relate to higher levels of cyberbullying. It is hypothesized that this may be due to the distance and lack of face-to-face interaction, which is a unique characteristic of cyberbullying. Researchers speculated that this absence of direct contact between perpetrator and victim may inhibit the perpetrators emotional engagement and therefore the use of cognitive distancing strategies becomes unnecessary (Almeida et al., 2008); however, the correlational nature of the data does not allow for such a conclusion.

Robson and Witenberg (2013) investigated the use of moral disengagement strategies in relation to traditional and cyberbullying in a sample of 210 adolescents concerning traditional and cyberbullying. Moral disengagement was measured using the original 32 item Moral Disengagement Scale (Bandura et al., 1996) and a relationship was found between moral disengagement and cyberbullying. This relationship was significantly weaker than found between moral disengagement and traditional bullying.

To date, studies that examine the relationship between moral disengagement and cyberbullying show that there is either no relationship (Perran \& Gutzwiller-Helfenfinger, 2012) or a relatively weak relationship (Robson \& Witenberg, 2013). This may be due to the lack of a concrete measure of cyberbullying and a lack of a measure that addresses moral disengagement strategies used in relation to cyberbullying and social bullying behaviours. All of the studies to date have examined moral disengagement in relation to physical and verbal bullying behaviour 
(Bandura, 1996). The development of a measure that examines moral disengagement specifically in relation to cyberbullying behaviours and further clarification of the relationship between cyberbullying and moral disengagement is warranted.

To date the majority of the research on moral disengagement has focused on perpetrators of hurtful acts of aggression and bullying behaviours. However, research has shown that those individuals who are standing by witnessing these harmful acts may also be morally disengaged. What follows is a review of the current literature examining the relationship between moral disengagement and the larger peer group who may witness these acts.

\section{Moral Disengagement in Bystanders of Bullying}

Bullying has been demonstrated to be a group process that involves the broader peer group and research has moved beyond focussing on solely the perpetrator and the victim (Cowie, 2000; Craig \& Pepler, 1995; O’Connell et al., 1999; Salmivalli et al., 1996), yet a very limited amount of research has addressed the cognitive processes of bystanders. Gini (2006) studied the levels of moral disengagement exhibited by youth who experienced different roles in bullying situations. Participants were 204 elementary school children who were classified as either bullies, those who reinforced the bullies, assistants of the bullies, defenders of the victim, victims or outsiders based on per nominations. Gini (2006) found higher levels of the moral disengagement in all the aggressive roles, especially in bullies. Those who reinforced and assisted the bully reported higher levels of moral disengagement than victims and outsiders. Defenders of the victim reported the lowest levels of moral disengagement. Additionally, outsiders (individuals who witness bullying and remain outside of the situation) also displayed a lower level of moral disengagement than those that engaged in bullying behaviours. Much research has focussed on the levels of disengagement exhibited by those that play a direct role in 
bullying situations, specifically the target victim and the perpetrator, but there has been little research examining the relationship between moral disengagement and bystander behaviour; however, one recent study to examine this issue has been Obermann (2011).

Obermann (2011) examined moral disengagement (Bandura et al., 1996) among 660 children in grades 6 through 7. Discrete groups of bystanders were examined and participants were categorized as a type of bystander based on their responses to a single item self-report measure. The types of bystanders were unconcerned bystanders who do not intervene and just watched the bullying incident, guilty bystanders who did not intervene but felt personally responsible to intervene, and defenders who felt personally responsible and intervened on behalf of the victim. Obermann (2011) found that defenders had lower levels of moral disengagement compared to unconcerned bystanders. Unconcerned bystanders showed higher levels of moral disengagement than did guilty bystanders. Guilty bystanders and defenders had lower levels of moral disengagement compared to unconcerned bystanders. One important limitation of this study was the procedure that was used to categorize individuals into discrete groups was based on their self-reported behaviour. This is problematic as bullying is a fluid process and individuals may take on different roles and engagement levels depending on the situation.

Summers, Polihronis, and Daniels (2014) examined bystander behaviour when witnessing socially aggressive behaviours and the relation to moral disengagement in a sample of 435 participants between the ages of 18-25 using self-report measures. Participants rated how much they endorsed using three types of bystander behaviours including guilty (do not intervene but feel they should), defender (intervene on behalf of the victim), and unconcerned (feel as if it is not their responsibility or concern to intervene). Results indicated that participants who reported feeling unconcerned for the victim demonstrated the highest level of moral disengagement. 
Importantly, this study found that very few participants reported endorsing a single type of bystander behaviour, supporting the notion that bystander behaviour is influenced by many other factors and individuals are unlikely to fit into a discrete 'type' of bystander.

It is imperative that researchers make attempts to examine bystander behaviour of more indirect forms of bullying such as social bullying and cyberbullying as the nature of this behaviour may result in weaker feelings of responsibility to intervene. As first introduced by Bandura (1999; 2002), moral disengagement was found to be correlated to engagement in harmful delinquent and physically aggressive behaviours, and in the case of witnessing behaviours, bystanders must justify their behaviour to determine whether they feel they are morally responsible to intervene and assist the victim. When bystanders witness bullying, it is proposed that they assess the risk of intervening and if they are able to justify why they will not intervene and morally disengage from the negative emotional consequences, they will continue to be an outsider and not assist the victim. However, some may witness the behaviour but feel morally responsible and unable to morally disengage, leading them to intervene and assist the victim. Although research has shown the important relationship between moral disengagement and the use of bullying behaviour, there are still unanswered questions as to why bystanders who identify the behaviour as morally wrong do not intervene to assist a victim. A possible explanation is that the bystander may not believe they possess the necessary tools and ability to intervene; this is referred to as self-efficacy.

\section{Self-Efficacy in Bullying}

The contribution of defender self-efficacy in explaining bullying behaviour has only recently been examined and has so far been shown to have a significant effect on the frequency of defender behaviour (Barchia \& Bussey, 2011; Rigby \& Johnson, 2006; Thornberg \& Jungert, 
2013). Bandura (1997) defined self-efficacy as "beliefs in one's capabilities to organize and execute the courses of action required to produce given attainments" and is centered on the idea that "unless people believe that they can produce desired effects by their actions, they have little incentive to act" (p. 120). Self-efficacy functions as a multilevel set of beliefs. The current study focuses on the domain of defender self-efficacy, the belief in one's ability to successfully intervene, by executing a particular action that is effective in stopping bullying behaviour (Bandura, 1986, 1997).

\section{Self-efficacy and moral disengagement in bystanders of bullying behaviour. Rigby} and Johnson (2006) conducted one of the first studies to examine the role of self-efficacy in bystanders of bullying behaviour in a sample of 400 primary and secondary school children. Using self-report measures, they found that $43 \%$ of the sample indicated that they certainly or probably would intervene. Importantly, self-efficacy was not significantly associated with intervention behaviour. It is possible that the measure of self-efficacy used in this study was too general in nature to find a relationship with defending bystander behaviour. Rigby and Johnson (2006) suggested that future studies employ a more specific measure of self-efficacy that is relevant to the behaviours of bullying self-efficacy. A more appropriate measure may aid in explaining the self-efficacy beliefs of bystanders who witness bullying. Research is needed to clarify relationships between self-efficacy, moral disengagement, and bystander intervention when witnessing bullying behaviour.

Barchia \& Bussey (2011) examined the association between self-efficacy for aggression, moral disengagement, and collective efficacy beliefs on peer aggression in young adolescents. Self-efficacy for aggression refers to the belief in one's ability to engage in aggressive acts. It was hypothesized that bystanders with high self-efficacy for aggression would not intervene to 
stop bullying behaviour unless they were high on moral disengagement and were able to justify the aggressive behaviour. They had a sample of 1285 participants between grades 7 and 10 complete self-report measures at the beginning and end of the school year ( 8 month span) in order to examine the unique influence of moral disengagement, self-efficacy, and collective efficacy on defender behaviour over time. Collective efficacy was measured by asking about how well students and teachers could work together to stop a range of aggressive behaviours. Defender self-efficacy was measured with a 3 item scale, one item for each type of aggression (physical, verbal, and relational) and moral disengagement was measured using an adapted version of Bandura et al. (1996) with items applicable to peer aggressive behaviours.

Interestingly, they found that there was no association between defender self-efficacy or moral disengagement with bystanders who reported defending victims of peer aggression. However, collective efficacy was associated with higher rates of defending 8 months later. It is speculated that in a younger sample, collective efficacy beliefs are more important in accounting for defending behaviour over time than individual self-efficacy beliefs as children may not intervene unless they feel they are supported by their surrounding social group. Moral disengagement was not associated with defending behaviour, in contrast to previous research (Gini, 2006; Obermann, 2011). This may be due to the measure of moral disengagement that was used (Bandura et al., 1996) as it was not being specific to bullying behaviours. In addition it may have been the younger age of the subjects that contributed to the lack of relationship between self-efficacy and defender behaviour. It is expected that with maturity, individuals rely less on the collective effect of peers and teachers, and become more reliant on individual moral standards and self-efficacy beliefs. 
Thornberg and Jungert (2013) examined pathways that linked emerging adults' moral disengagement in bullying and defender self-efficacy to different bystander behaviours (probully, outsider, or defender behaviour) in traditional bullying situations. A sample of 347 students between the ages of 15-20 years completed self-report measures on moral sensitivity, moral disengagement and defender self-efficacy. Moral disengagement was measured using six items based on the original scale (Bandura et al., 1996) and defender self-efficacy was measured with two items ("If I saw bullying, I'm sure I would be able to stop it"; "I have a high confidence in my ability to intervene in bullying situations and help the victim"). Eight items in the survey asked about previous behaviours that participants engaged in when witnessing bullying behaviours. A total of three bystander behaviours from the participant role approach (Salmivalli, 1999; Salmivalli et al., 1996) were examined including a) outsider (“I didn’t do anything but I was quiet and passive instead") b) defender ("I tried to get the bully/bullies to stop") and c) probully ("I laughed and cheered the bullies on"). Moral disengagement was positively correlated with pro-bully behaviour and negatively associated with both outsider and defender behaviours. Results indicated a strong negative relationship between defender self-efficacy and outsider behaviour. The strong positive relationship between defender self-efficacy and defender behaviour suggests that self-efficacy is an important factor to consider when examining individuals with low moral disengagement in bullying and their behaviours to either help a victim or to remain passive.

Gender differences were found where defender self-efficacy was much higher in males, and females were more likely to report outsider behaviour. However, females reported much lower moral disengagement than males regardless of their bystander behaviour. This is surprising as previous research has found that females engage in more pro-social intervention strategies 
(Barchia \& Bussey, 2011; O’Connell et al., 1999; Poyhonen et al., 2010; Salmivalli et al., 1996). Males were found to be significantly more likely to engage in pro-bully behaviour. Furthermore, a negative relationship between defender self-efficacy and outsider behaviour, and a positive relationship between defender self-efficacy and defender behaviour, was found for both males and females.

The well-established occurrence of bullying in adolescence (e.g. Perran, 2012; Smith, 2009) and the similarities between emerging adulthood and adolescence (Arnett, 2004) provides support that exploring the developmental period of emerging adulthood is an especially important area of research. As children grow older, bullying behaviour becomes less direct and it is therefore imperative for researchers to study indirect forms of aggression including social bullying and cyberbullying in emerging adulthood. Not only are the majority of individuals entering postsecondary education emerging adults, but a large number of these students also transition straight from high school where indirect aggression is a well documented problem (Renda, Vassallo, \& Edwards, 2011). When children and young adults learn to engage in aggressive behaviour as a way to deal with conflict in their lives, they are at an increased risk to continue this behaviour into adulthood (Smith, 2009).

\section{Current Study}

The aim of the current study was to investigate how moral disengagement and defender selfefficacy were related to three forms of bystander behaviour. A total of three bystander behaviours from the participant role approach (Salmivalli, 1999; Salmivalli et al., 1996) were used: pro-bully (directly engages in bullying behaviours), outsider (knows of the behaviours but does not engage) and defender (actively intervene to assist the victim) to assess the behaviours of those who witness social bullying and cyberbullying. The current study expands on this field of 
research by examining bystander behaviour in response to more indirect and sophisticated forms of bullying behaviours (e.g. rumour spreading, exclusion), as these issues have only previously been examined in reference to physical aggression or general forms of bullying. Behaviours that are more covert and indirect often go unnoticed by authorities therefore it is important that those peers who witness such behaviours are capable and willing to intervene. Although cyberbullying is a growing phenomenon in today's youth, where $81 \%$ have access to the Internet at home and $60 \%$ own a cell phone (Law, Shapka, Domene, \& Gagne, 2012), only recently research and educators have begun to take steps to address cyberbullying.

A large sample size of emerging adults was used to address the gaps in the research concerning the behaviours of those who witness social bullying and cyberbullying. Emerging adulthood is a recently defined developmental period that refers to those in late adolescence through early adulthood. Research has argued that emerging adulthood and young adulthood should be distinguished as separate developmental periods (Arnett 2001;2011). Emerging adults do not see themselves as adolescents, but many of them also do not see themselves entirely as adults. The characteristics that matter most to emerging adults are not demographic transitions but individualistic qualities of character including accepting responsibility for one's self and making independent decisions (Arnett, 2001; 2011). The majority of research to date has examined bullying behaviours in samples of children through adolescence; however, little is known about these behaviours in emerging adulthood. This study was the first to look at bystander behaviours specific to cyber and social bullying and the relationships between moral disengagement and self-efficacy, and reported bystander behaviours in this age range 


\section{Hypotheses}

Social bullying. In examining three types of bystander behaviour (pro-bully, outsider and defender) when witnessing incidents of social bullying, it was hypothesized that moral disengagement would be positively related to the self-reported use of pro-bully behaviours. This is supported by Thornberg and Jungert (2013) who found that individuals who actively engaged in bullying behaviours when witnessing bullying episodes reported significantly higher levels of moral disengagement. It was also hypothesized that self-reported defender self-efficacy would be negatively related to pro-bully behaviour, as this bystander behaviour involves actively encouraging harmful acts (Thornberg \& Jungert, 2013).

Outsider behaviour refers to those who do not engage in bullying behaviours but instead seemingly stand and watch. It was hypothesized that moral disengagement would be positively associated with outsider bystander behaviour. This hypothesis is based on research that has shown that individuals who feel personally responsible are less likely to commit actions that are inconsistent with their moral expectations for acceptable behaviour (Bandura, 1990; Obermann, 2011). Thus it is further hypothesized that self-reported defender self-efficacy would be negatively related to the endorsement of outsider behaviour (Thornberg \& Jungert, 2013).

It was hypothesized that a strong negative relationship would be found between moral disengagement and defender bystander behaviour. It was also hypothesized that a strong positive relationship between defender self-efficacy and defender behaviour would be found. Previous research has found that, consistent with the self-efficacy framework, defender self-efficacy was positively associated with defender behaviour in bystanders of bullying (Barchia \& Bussey, 2011; Pöyhönen et al., 2012). 
Cyberbullying. The current study also addressed the question of whether there were significant relationships between moral disengagement, defender self-efficacy and bystander behaviours of cyberbullying. Although these relationships were expected for social bullying behaviours, previous research has demonstrated that the relationship between moral disengagement and cyberbullying behaviour is not as clear (Perran \& Gutzwiller-Helfenfinger, 2012; Pornari \& Wood, 2010; Robson \& Witenberg, 2013). It was hypothesized that moral disengagement would be positively related to pro-bully behaviour and negatively related to outsider and defender behaviour. Furthermore, it was hypothesized that defender self-efficacy would be positively associated only with defender behaviour (Thornberg \& Jungert, 2013) and negatively associated with outsider behaviour.

Finally, it was of interest to determine the possible differences in moral disengagement and defender self-efficacy in bystander behaviours of both cyber and social bullying. Witnessing indirect forms of bullying may also inhibit ones belief in their ability to intervene and assist the victim, especially in the case of cyberbullying. Therefore, it was hypothesized that significant differences would be observed in moral disengagement and defender self-efficacy between cyberbullying and social bullying. Specifically, moral disengagement and defender self-efficacy were hypothesized to be lower in cyberbullying due to the nature of the behaviour (Perran \& Gutzwiller-Helfenfinger, 2012; Pornari \& Wood, 2010). Cyberbullying is a relatively new challenge youth face and therefore youth may not feel as equipped to intervene and may feel less responsible to stop the bullying, making it more likely that bystanders stay passive to online bullying behaviour. Regardless of the type of bullying, it was hypothesized that females would report lower levels of moral disengagement (Gini, 2006; Menesini et al., 2003; Pozzoli et al., 2012; Thornberg \& Jungert 2013) and higher levels of defender self-efficacy compared to males. 


\section{Method}

A power analysis was conducted in order to determine the appropriate sample size. With regard to multiple regressions, Tabachnick and Fidell (2007) suggested that the minimum number of participants should be larger than $50+8(\mathrm{~m})$, where $m$ is the number of predictor variables, with a medium effect size and power of .80 . The minimum sample size for the current study was calculated based on the hypotheses proposed using the $\mathrm{N} \geq 50+8(\mathrm{~m})$ formula. The current study includes 12 predictor variables (two descriptive variables, three moral disengagement variables, six bystander behaviour variables, and one defender self-efficacy variable). When all variables are included, the minimum number of participants required is 146 .

The secondary purpose of the current study was to examine the psychometric properties of newly developed measures. The current study conducted multiple confirmatory factor analyses and required a larger dataset to achieve adequate power. According to Tabachnick and Fidell (2007) a sample size of 300 is regarded as good and a sample size closer to 500 is recommended for conducting factor analyses. The number of participants in the current study is 495, which is consistent with the number estimated (Tabachnick \& Fidell, 2007).

\section{Study Participants}

Study participants included 495 undergraduate students [390 females (79.1\%), 103 males $(20.9 \%)]$ between the ages of $17-20$ years old $(M=18.39, S D=.91)$ at a large urban university registered in the first year psychology or neuroscience classes who received extra credit for participating in this study. The gender distribution is representative of the female-male ratio in Social Sciences at the university where the data was collected, which was $61.5 \%$ female in the latest university survey (Carleton University, 2014). Participants were required to be between seventeen and twenty years of age in order to complete the survey. The ethnicity of the sample 
was primarily Caucasian (63.1\%) and racial minorities included 6\% Asian, 8.9\% Black, 6.9\%

South Asian and $12.6 \%$ other.

\section{Procedure}

Data collection occurred across 2 school semesters, during the months of September 2014 until January 2015. Participants were required to login to SONA, and were asked to click the link from the recruitment page and were directed to the external site Qualtrics.com, where the survey was hosted. Participants received compensation of .50 bonus percent for qualifying university courses. Prior to participation, students were provided with an informed consent form, which students were required to accept the terms of as part of the electronic survey. The consent forms (Appendix A and B) informed each of the participants about the purpose of the study, their task requirements, any potential risks/discomfort, confidentiality/anonymity and their right to withdraw at any given time for any reason, with no penalty. Participants were not given an opportunity to go back and complete it once they signed off, rather they were required to complete the survey in one sitting. Once they had read the informed consent, those who choose to continue with the survey were provided with all of the measures described below and were presented with a debriefing form.

There was a possibility that thinking about peer relationships and reflecting on one's own behaviour could have caused some mild psychological discomfort. Although this potential was no more of a risk than what could be encountered on a daily basis when discussing conflicts with friends, a list of local support services were provided (see Appendix F for the debriefing form). Participants were able to decide to withdraw or end their survey at any time by pressing the button at the bottom of every page which then directed them to the debriefing form page (see Appendix $\mathrm{H}$ for the debriefing form). 
The approximate time for completing this survey was 45 minutes. After participation was completed, all of the participants were forwarded to an online written debriefing form (Appendix H), explaining the purpose of the current research, why it was important to conduct this study, what the hypotheses and predictions were, as well as contact information.

\section{Measures}

Students were asked about their experiences with witnessing social and cyberbullying behaviours as well as their moral justifications and personal self-efficacy beliefs in this regard. Prior to completing the questionnaires subjects were given a definition of bullying behaviour in order to ensure that all participants were responding to the surveys in reference to the same behaviours. The following definition was provided:

We say a student is being bullied when another student, or group of students say nasty and unpleasant things to him or her. It is also bullying when a student is hit, kicked, threatened, or locked inside a room, sent nasty notes, when people don't talk to him or her and things like that. These things may take place frequently, and it is difficult for the student being bullied to defend him/herself. It is also bullying when a student is teased repeatedly in a negative way. But it is not bullying when students of the same strength quarrel or fight (Olweus, 1993, p. 7). The following five measures were administered online: 1) An adapted version of the Student Bystander Behaviour Scale (Thornberg \& Jungert, 2013) (Appendix C), 2) The Moral Disengagement in Using Social Aggression Scale (Appendix D), 4) The Moral Disengagement in Using Cyber Aggression Scale (Appendix E), 5) The Moral Disengagement Scale (Bandura 1996; Paceiello et al., 2008) (Appendix F), 5) and an adapted version of the Defender SelfEfficacy Scale (Barchia \& Bussey, 2011) (Appendix G). 
Student Bystander Behaviour Scale (SBBS). A modified version of the Student Bystander Behaviour Scale (Thornberg \& Jungert, 2013) was used. The Student Bystander Behaviour Scale (Thornberg \& Jungert, 2013) assessed bystander behaviour in response to general bullying situations. This measure consisted of eight items that identify three forms of bystander behaviour. Defender behaviour refers to when a bystander actively intervenes to assist the victim and is assessed with two items. Pro-Bully behaviour is when the bystander encourages the bully by laughing at or engaging in the aggressive behaviour and is assessed with two items. Outsider behaviour is when a witness of the behaviour stays passive or avoids the situation is assessed with four items.

For the purposes of the current study, this questionnaire was modified by the addition of 16 items that asked specifically about bystander behaviour in response to social (i.e. gossip, rumours, dirty looks) and cyber (i.e. online posts, electronic images, websites) bullying. The final revised version of the SBBS includes a total of twenty-four items (including the original 8 items specific to general bullying). Of the 24 items, 12 items assess pro-bully behaviour (i.e., 3 items referring to general bullying, 3 to social bullying and 3 to cyberbullying), six items assess outsider behaviour (i.e., 2 items referring to general bullying, 2 to social bullying and 2 to cyberbullying) and six items assess defender behaviour (i.e., 2 items referring to general bullying, 2 to social bullying and 2 to cyberbullying) (Appendix C). Students were asked how often they exhibit each of these behaviours, using a 5-point scale Likert scale from 1) Never to 5) Often. For each of the three types of bystander behaviour, items were summed and higher scores indicated higher levels of reported bystander behaviour.

Thornberg and Jungert (2013) ran a factor analysis on their original 8 item scale and found that a three-factor model which explained $73 \%$ of variance. The first factor with four 
items assessed pro-bully behaviour (Cronbach's $\alpha=.82$ ), the second factor containing two items assessed outsider behaviour $(r=.49)$, and the third factor with two items assessed defender behaviour $(r=.46)$. It was expected that these three factors would be replicated in the current study. An exploratory factor analysis was conducted to determine if these factors hold with the addition of the new items. These findings are presented in the Results section that follows.

\section{Moral Disengagement}

The original moral disengagement scale (Bandura et al., 1996) was used in the current study to validate newly adapted measures included in the current study. This measure assessed moral disengagement and justifications used when engaging in delinquent and physically aggressive behaviours. Similar high internal consistency values were reported for the original 32 item uni-dimensional Mechanisms of Moral Disengagement scale by Bandura et al. (1996) at .85. To create a total score all items on the scale were summed, with higher scores representing higher levels of endorsement of the use of aggressive and delinquent behaviours (see Appendix F).

Moral Disengagement in Using Social Aggression (MODUSA). This scale was comprised of 13 questions that were adapted from the MDS created by Hymel et al. (2005) (Appendix D). The original scale by Hymel et al. (2005) included 18 items, 13 of which loaded on a single factor for moral disengagement. It was reported to have high internal consistency, $\alpha$ $=.81$. Almeida et al. (2010) also used this scale in a more age diverse sample of 292 students, 10-18 years-old from Portugal, and also reported high internal consistency of $\alpha=.86$ on a single factor model. This Moral Disengagement measure (Hymel et al., 2005) was adapted for use in the present study in order to be able to assess moral disengagement justifications specific to 
social and cyberbullying behaviours rather than to bullying behaviour in general as the original measure did.

Each item from the Hymel et al. questionnaire was modified to ask specifically about social bullying. The MODUSA (Polihronis et al., 2012) was constructed to assess the endorsement and justifications used when engaging in social bullying behaviours such as: rumour spreading, gossip, and non-verbal socially aggressive behaviours. Participants were asked to rate the extent to which they agree with the statements on a five-point scale that included 0 (Completely disagree) to 4 (Totally agree). To create a total score all items on the scale were summed. Higher scores represented higher levels of endorsement of the use of social bullying behaviours (high moral disengagement).

The MODUSA was piloted on a sample of 435 young adults between the ages of $18-20$ years old (Summers, Polihronis, \& Daniels, 2014) and was found to have good concurrent validity $(r=.73)$ with the MDS by Hymel et al. (2005). Consistent with the MDS, all items on the MODUSA were found to load on a single factor. Cronbach's alpha for the overall MODUSA scale was $\alpha=.85$, which is similar to other moral disengagement measures $(\alpha=.86$; Bandura et al., 2001; $\alpha=.85$; Hymel et al., 2005).

Moral Disengagement in Using Cyber Aggression (MDCA). This scale was newly developed for the current study in order to assess justifications and endorsement of cyberbullying behaviours (Appendix E) as previous research has suggested that moral disengagement measures should be specific to the behaviours of interest (Hymel et al., 2005). Questions were adapted from the MDS created by Hymel et al. (2005) and were constructed to represent the endorsement of rumor spreading, gossiping, exclusion and posting embarrassing hurtful messages or images via electronic devices and social media. Participants were asked to rate the extent to which they 
agreed with the statements such as 'Posting mean comments online about another person is okay when all your friends are doing it' on a five point scale that included 0 (Completely disagree) to 4 (Totally agree) across a total of sixteen items (Appendix E). To create a total score all items on the scale were summed. Higher scores represented higher levels of endorsement of the use of cyberbullying behaviours (high moral disengagement). An exploratory factor analysis was conducted to determine if the current measure was consistent with previous scales of moral disengagement that have revealed a one-factor structure (Bandura et al., 1996; Hymel et al., 2005). The findings are reported in the Results section that follows.

\section{Defender Self Efficacy}

An adapted version of the defender self-efficacy scale validated by Barchia and Bussey (2011) was created. The original version consisted of three items that assessed perceived capability to intervene and defend victims of bullying. The revised measure built on the original to include a total of nine items that address multiple bullying behaviours (including cyberbullying and social bullying). A total of six items were developed in addition to the original three that assessed students' confidence in addressing bullying behaviour, both social and cyber when they witnessed it. This included items asking students how well they can "Tell $a$ student or friend who sends nasty message to another person that it is not okay" or "Tell a student or friend who sends embarrassing pictures of someone via online or electronic device to stop?" (Appendix G). Participants were asked to rate their personal beliefs about their defender self-efficacy on a 7-point Likert scale ranging from 1 (Not well) to 7 (Very well). Higher scores represented a higher reported belief of one's capability of intervening and defending a victim of bullying. 
Barchia and Bussey (2011) conducted a factor analysis and found that their original three items loaded on one factor with loadings ranging from .75-.84 and reliability of $r=.87$ in a sample of adolescents in grades 7 to 10 . The current study conducted an exploratory factor analysis on the adapted version of the Defender Self-Efficacy scale. The findings are reported in the Results section which follows.

\section{Results}

A variety of preliminary analyses including descriptive statistics and bivariate correlations were conducted. The measures of moral disengagement in using social aggression, moral disengagement in using cyberbullying, student bystander behaviour scales in social and cyberbullying, and the defender self-efficacy scale were examined and modified using SAS version 9.4. Finally, hierarchical and logistic regression models with the modified measures were conducted in order to answer the research questions regarding the associations between moral disengagement, defender self-efficacy and bystander behaviours.

\section{Data Screening}

Normality of the distribution of the data was explored. The majority of variables were positively skewed, as there were low reports of cyber and social moral disengagement, low reports of pro-bully behaviour, and high reports of outsider and defender bystander behaviour. The skewed variables with skewness and kurtosis values that were above $-/+3.29$ were transformed as suggested by Tabachnick and Fidell (2007) to improve normality of the data. Logarithm transformations were performed on all variables that were significantly positively skewed, but did not significantly improve the normality of the data. Variables that were negatively skewed and contained a zero were transformed appropriately using reflect and inverse transformation. Transformations were completed for all variables and produced only marginal 
improvements (Tabachnick \& Fidell, 2007). Theoretically it was expected that variables would be skewed and because the transformed data did not provide significant improvements, the original data was used for all subsequent analyses.

To accommodate for severe skew in the dependent variables, cyber pro-bully behaviour and cyber defender behaviour, were dichotomized to create groups of those who reported bystander behaviour (1) and compared to those who exhibited low to no endorsement of bystander behaviours (0). The cut off criteria are explained in the analyses below.

Univariate outliers. Data screening was undertaken to examine all measures in the study. First univariate outliers were examined followed by outliers for the total scores. Finally multivariate outliers were examined and all analyses were conducted with the outliers taken into range and compared to the original data. The results of these analyses are explained below.

Univariate outliers are cases that have an unusual value for a single variable. Univariate outliers were noted in fewer than 3 cases on single items and these cases were reduced to be within range of a $\mathrm{z}$ score of $+/-3.29$, as cases with standardized scores higher than 3.29 were considered potential outliers (Tabachnick \& Fidell, 2007). Total scores for each variable were then screened for outliers. At least one univariate outlier above the $\mathrm{z}$ score of $-/+3.29$ was found for each of the following variables: moral disengagement in using social aggression $(n=2)$, moral disengagement in using cyber aggression $(n=3)$, moral disengagement as measured by Bandura ( $n=2)$, and pro-bully bystander behaviour $(n=1)$. In our analyses, we were concerned with univariate outliers for the dependent variable, thus the dependent variable for cyber bystander behaviour was dichotomized to address the violation of normality. None of these values were outside of the expected range, thus transformations offered only marginal improvements (Tabachnick \& Fidell, 2007). All analyses were run comparing the adjusted 
transformed total scores and the original data, and as only marginal improvements were noted with the transformed data the original data was used for all subsequent analyses.

Multivariate outliers. Mahalanobis distance was used to screen the data for multivariate outliers and all cases had a Mahalanobis distance less than the critical value of $\chi^{2}=34.53$ (critical value obtained from Tabachnick \& Fidell, 2007, p. 949), indicating that there was no evidence of multivariate outliers.

All items were retained, as the extreme scores did not distort the data. It should be noted that outlier removal does not contribute substantially to variance in the distributions of a given measurement, but might increase effect sizes in overall findings (Orr, Sackett, \& Dubois, 1991). It was decided that these outliers were legitimate and not based on data entry or other errors made by the researcher and therefore outliers were retained in the dataset for all further analyses. In conclusion, screening of this data revealed no major concerns.

Missing data for all variables. Subscale scores were examined for patterns of missing data and across all variables to be included in the models. Some variables were missing up to $4.6 \%$ of data. A missing value analysis (MVA) was conducted with SPSS version 22 and Little's MCAR test was not significant, $\chi^{2}(89)=175.94, p=.79$, indicating that the data was missing at random. The majority of missing data was a function of a single missing item, discontinuing after the first few measures, or stopping the survey before the end. The amount of missing data was not of great concern as it was missing at random and below a value of 5\%; therefore no subsequent procedures were done to address this issue.

\section{Development of the Moral Disengagement in Using Social Aggression Scale (MODUSA)}

Exploratory factor analyses (EFA) were used to examine latent factors for the Moral Disengagement in Using Social Aggression Measure (MODUSA). Bivariate correlations 
between items were conducted to determine if there was an issue with local dependence. A cutoff of $r=0.8$ was used as suggested by Tabachnick and Fidell (2007). All items were retained as all correlations were below $0.8(r=0.2-0.58)$ indicating no issues with multicollinearity. The MODUSA is a newly developed measure created based on the original moral disengagement measure by Bandura et al. (1996). It was expected that the modified scale would contain a single factor structure similar to the original measure (Bandura et al., 1996). An exploratory factor analysis (EFA) using maximum likelihood extraction and promax rotation was conducted as a first step to examine this new measure and to determine the appropriate factor structure for this scale.

The complete 13 items were factor analyzed and factor loadings of at least 0.35 were considered good indicators of the underlying concept based on recommendations by Tabachnick and Fidell (2007). After examining the eigenvalues provided in the output, it was clear that the first two components had an eigenvalue of 1 or above. According to the guidelines of the Kaiser-Guttman Rule, this is a good starting point when deciding how many factors to maintain (Kaiser,1991). The first two factors were greater than 1; however, factor 2 was just above a value of 1 and was drastically smaller than the single factor value of 9.33. A single factor model accounted for $85 \%$ of the variance in the full item set. Further, the scree plot was examined to determine the number of components to maintain. There was a clear 'bend' and flatness beginning at eigenvalue number 2 therefore it was concluded that it was appropriate to maintain 1 or 2 factors.

A single factor model was pursued based on previously established measures (Bandura et al., 1996; Hymel et al., 2005; Thornberg \& Jungert, 2013) and was tested by conducting a confirmatory factor analyses on all 13 items (see Table 1 for CFA factor loadings). 
Table 1

Confirmatory Factor Analysis for Moral Disengagement in Social Aggression

Items

Factor

Loadings

1. Gossiping isn't that bad if all of your friends do it.

2. It's not my responsibility to include someone if my friends ignore that person.

3. If a rumour is being spread about someone, there is nothing I can do to stop it.

4. It's okay to give someone a dirty look because hitting them is worse.

5. It's okay to talk behind someone's back if they don't know who is doing it.

6. It's okay to tell a rumour about someone that my friends don't like.

7. It's okay to give someone the silent treatment in order to teach that person a lesson.

8. Rolling your eyes at someone gets them to know what is not appropriate in the group.

9. A rumour doesn't hurt if the person doesn't know about it.

10. Some people deserve to be left out from certain activities.

11. It's okay to give the cold shoulder to (or to turn away from) a person no one likes.

12. Most people who get gossiped about bring it on themselves.

13. Some people have rumours spread about them because they deserved it. 
This model produced adequate fit indices. Hu and Bentler (1999) suggest the following guidelines for acceptable model fit: (a) SRMR values are close to .08 or below; (b) RMSEA values are close to .06 or below; and (c) CFI and TLI values are close to .95 or greater). The SRMR was .06, and the RSMEA was 0.08 (CI: [0.06 - 0.11]) and the Comparative Fit Index (CFI) was 0.867 , which taken together are considered evidence of an adequate fit (Bentler, 1990).

In conclusion, a single factor model was established and is consistent with established measures of moral disengagement (Bandura et al., 1996; Hymel et al., 2005; Thornberg \& Jungert, 2013). All items were retained and the internal consistency was .87 for the 13 -item scale. This was similar to that of the original measure of moral disengagement (Bandura et al., 1996) and had good concurrent reliability $(r=.68)$.

\section{Development of the Moral disengagement in Using Cyber Aggression Scale (MDC)}

The Moral Disengagement in Using Cyber Aggression (MDC) was a newly developed measure created for the purposes of this study based on the original moral disengagement measure by Bandura et al. (1996). An exploratory factor analysis (EFA) was conducted on this new measure to determine the most appropriate factor structure for this scale and it was expected that the newly developed scale would contain a single factor, representing the concept measure by Bandura et al. (1996).

Bivariate correlations between items were conducted to see if there was multicollinearity. A cut-off of 0.8 was used (Tabachnick \& Fidell, 2007). All items were retained as all correlations were below $r=0.8(r=0.2-0.59)$. An EFA was then used to explore latent factors for the items (See Table 2). The complete 16 items were factor analyzed with maximum 
Table 2

Exploratory Factor Analysis for Moral Disengagement in Cyberbullying

Items

Factor

Loadings

1. Posting mean comments online about another person is okay when all your friends are doing it.

2. If an embarrassing picture or video is being posted online of another person, there is nothing I can do to stop it.

3. If my friends are texting mean things to someone else, there is nothing I can do to stop them.

4. It is not my fault if someone gets upset about something funny I posted about them online.

5. It's okay to post a mean comment online about someone because saying it to the person face to face is worse.

6. It's okay to post a nasty comment online about someone if they don't know who is doing it.

7. It's okay to post an embarrassing picture or video of someone else online if they don't know who is doing it.

8. It is okay to forward someone an embarrassing picture or video of someone nobody likes.

9. When you post a status update online (via Facebook, Twitter, etc.) that includes all the friends you are with, it's not your fault if others feel excluded.

10. Posting something mean about someone online is okay if they did it to you first.

11. Posting nasty comments online or through text messages is okay if they don't know who is doing it

12. It's okay to send a nasty comment to someone in order to teach that person a lesson.

13. A mean or hurtful online post about someone doesn't hurt if that person doesn't know about it.

14. Some people deserve to have mean comments posted online about them. $\quad .56$

15. It is okay to send mean messages to friends about a person no one likes. $\quad .72$

16. People who have hurtful comments posted about them online bring it on themselves 
likelihood extraction and promax rotation. Factor loadings of at least 0.35 were considered good indicators of the underlying concept. One item failed to reach these criteria with loading of .11, and was removed from further analyses ("When you post a status update online [via Facebook, Twitter, etc.] that includes all the friends you are with, it's not your fault if others feel excluded"). It was expected that a one-factor model would best fit the model. There was one factor with an eigenvalue greater than 1 and this factor accounted for $91.48 \%$ of the variance in the full item set. Examination of the scree plot suggested a single factor solution. A single factor model was deemed most appropriate based on these examinations and prior research (Bandura et al., 1996; Hymel et al., 2005; Thornberg \& Jungert, 2013).

After removing the item of concern, a confirmatory factor analysis (CFA) was performed with the recommended single factor structure for the remaining 15 items (see Table 3 ). The fit indices were adequate. The Comparative Fit Index (CFI) was 0.89 which indicated a moderate fit (Bentler, 1990), the SRMR was .07 and the RSMEA was 0.07 (CI: [0.06-0.1]). In conclusion, a single factor model was deemed appropriate for this measure and was consistent with and had good concurrent reliability $(r=.78)$ with the original measure of moral disengagement (Bandura et al., 1996) and internal consistency reliability was .92 for the 15-item scale.

\section{Development of The Social Aggression Student Bystander Behaviours Scale}

The Student Bystander Behaviours Scale (Salmivalli, 1999; Salmivalli et al., 1996) was modified for the current study to create measures to separately address social bullying and cyberbullying bystander behaviours. 
Table 3

Confirmatory Factor Analysis for Moral Disengagement in Cyberbullying

Items

Factor

Loadings

1. Posting mean comments online about another person is okay when all your friends are doing it.

2. If an embarrassing picture or video is being posted online of another person, there is nothing I can do to stop it.

3. If my friends are texting mean things to someone else, there is nothing I can do to stop them.

4. It is not my fault if someone gets upset about something funny I posted about them online.

5. It's okay to post a mean comment online about someone because saying it to the person face to face is worse.

6. It's okay to post a nasty comment online about someone if they don't know who is doing it.

7. It's okay to post an embarrassing picture or video of someone else online if they don't know who is doing it.

8. It is okay to forward someone an embarrassing picture or video of someone nobody likes.

9. Posting something mean about someone online is okay if they did it to you first.

10. Posting nasty comments online or through text messages is okay if they don't know who is doing it

11. It's okay to send a nasty comment to someone in order to teach that person a lesson.

12. A mean or hurtful online post about someone doesn't hurt if that person doesn't know about it.

13. Some people deserve to have mean comments posted online about them.

14. It is okay to send mean messages to friends about a person no one likes.

15. People who have hurtful comments posted about them online bring it on themselves 
The social aggression bystander items were first examined for bivariate correlations between items to determine if multicollinearity was an issue. An EFA was used to explore the latent factors for the scale. A cut-off of 0.8 was used (Tabachnick \& Fidell, 2007). All items were retained as all correlations were below $0.8(r=0.2-0.52)$, indicating no issues with multicollinearity.

The complete set of 10 items was analyzed with an EFA using maximum likelihood extraction and promax rotation. It was predicted that a three-factor model would best fit as it was expected that three types of bystander behaviour would emerge (Thornberg \& Jungert, 2013). There were 4 factors with eigenvalues greater than 1; however, cumulatively 3 factors accounted for $93.37 \%$ of the variance in the full item set and was consistent with theoretical development. Examination of the scree plot suggested a 3 or 4 factor solution. Based on the previously established measure (Thornberg \& Jungert, 2013), a three-factor model was examined (see Table 4). Factor loadings of at least 0.35 on one, but not more than one factor, were considered good indicators of the underlying concept. Observing high negative loadings associated to specific factors means that these variables contribute negatively to this component. A negative value indicates an inverse impact on the factor an is expected when observing types of bystander behaviours. One item cross-loaded high on two factors and was removed ('I watched and did nothing when my friends excluded another person'). This item was deemed complex, as it theoretically overlapped with the three expected factors that represented bystander behaviour.

A confirmatory factor analysis (CFA) was performed with the recommended three-factor structure for the remaining 9 items to further differentiate between the three forms of bystander behaviour (see Table 5 for factor loadings). The fit indices were adequate. 
Table 4

Factor Loadings for Exploratory Factor Analysis for Bystander Behaviour of Social Aggression

Items

F1:

F2:

F3:

Pro-Bully Outsider Defender

1. I laughed at the embarrassing gossip my friends told me.

.72

.80

$-.03$

someone from our group, I excluded them too.

4. I told the rumour I heard to another friend.

5. I watched and did nothing when my friends excluded another person.

6. When I heard friends talking about other people, I didn't do anything but I was quiet instead.

7. When my friends gossiped about others, I didn't do anything but I was quiet instead.

8. I didn't do anything but I was quiet instead when my friends told rumours about others.

9. When I have heard nasty rumours about someone, I have told people "it is not okay to talk like that".

10. When my friends have left someone out of the group on purpose, I asked them to join us and included them.
.11

$-.13$

$\begin{array}{lll}.46 & .11 & -.13\end{array}$

$\begin{array}{lll}.71 & -.05 & .01\end{array}$

$\begin{array}{lll}.41 & .22 & -.21\end{array}$

.05

.77

.83

.01

$.1 \quad .59$

$-.22$

.09

.41

.06

$-.01$

Note. Bolded values indicate significant loading on the factor $(p<.001)$ 
Table 5

Factor Loadings for Confirmatory Factor Analysis for Bystander Behaviour of Social Bullying

Items

F1:

F2:

F3:

Pro-Bully Outsider Defender

1. I laughed at the embarrassing gossip my friends told me.

2. I joined in when friends gossiped because it was fun and entertaining

3. When my friends ignored or excluded someone from our group, I excluded them too.

4. I told the rumour I heard to another friend.

5. When I heard friends talking about other people, I didn't do anything but I was quiet instead.

6. When my friends gossiped about others, I didn't do anything but I was quiet instead.

7. I didn't do anything but I was quiet instead when my friends told rumours about others.

8. When I have heard nasty rumours about someone, I have told people "it is not okay to talk like that".

9. When my friends have left someone out of the group on purpose, I asked them to join us and included them.

Note. Bolded values indicate significant loading on the factor $(p<.001)$ 
The Comparative Fit Index (CFI) was 0.85, which indicated a moderate fit (Bentler, 1990), SRMR was 0.03 and the RSMEA was 0.04 (CI: [0.01 - 0.06]) indicating good fit.

Three factors corresponding to those established by Thornberg and Jungert's (2013) measure were identified. A factor that corresponded to pro-bully behaviour included four items (e.g., When my friends ignored or excluded someone from our group, I excluded them too.), representing the behaviours of bystanders who engage in assisting the bully. The second factor corresponded to outsider bystander behaviour, including 3 items (e.g. When my friends gossiped about others, I didn't do anything but I was quiet instead), representing behaviours that characterized standing by and doing nothing to assist the victim. Finally, the third factor, defender bystander behaviour, was composed of 2 items (e.g., When my friends have left someone out of the group on purpose, I asked them to join us and included them) indicating that the items were reflective of bystanders intervening to assist the victim.

Rotated solutions were produced and oblique rotation was used to enhance the simple structure of the results given the correlations between the items within each measure (Henson \& Roberts, 2006). For the sake of comparison, an orthogonal rotation was used (varimax method) and the same factor structures emerged.

In conclusion, three factors were identified and were used to classify three bystander behaviours of social bullying: pro-bully (Cronbach's $\alpha=.78)$, outsider (Cronbach's $\alpha=.78$ ), and defender (Cronbach's $\alpha=.61$ ). This was consistent with the previous measure established to examine bystander behaviour in general bullying (Thornberg \& Jungert, 2013).

\section{Development of the Cyberbullying Student Bystander Behaviour Scale}

The cyberbullying bystander items were first examined for bivariate correlations between items to determine if multicollinearity was an issue. An EFA was then used to explore the 
number of latent factors for the remaining items. A cut-off of 0.8 was used (Tabachnick \& Fidell, 2007). All items were retained as all correlations were below $0.8(r=0.2-0.52)$.

The complete set of 8 items were factor analyzed with maximum likelihood extraction and promax rotation. It was expected that a three-factor model would best fit the model representing the three bystander behaviours (Thornberg \& Jungert, 2013). Three factors were examined to see which model best fit the present scale based on the eigenvalues examined (refer to Table 6 for descriptive statistics of all items). Factor loadings of at least 0.35 on one, but not more than one factor, were considered good indicators of the underlying concept (see Table 7 for EFA factor loadings of the three factor model). Observing high negative loadings associated to specific factors means that these variables contribute negatively to this component. Two items did not load properly (See Table 8) due to high response rates and these items were removed from further analyses ('When I have read mean or offensive posts online, I did not respond or comment on the post' and 'When I saw the embarrassing online post, I did not pass it on or show others.'). The exploratory factor analysis was run after removing the two items of concern and only two eigenvalues greater than one emerged; therefore a two-factor model was examined. These items theoretically were representative of the 'outsider' bystander behaviour construct, and the removal of these items resulted in a 2-factor model. A confirmatory factor analysis (CFA) was performed with the two-factor structure for the remaining 6 items to differentiate between the two forms of bystander behaviours as shown in Table 9. The fit indices were good. The Comparative Fit Index (CFI) was 0.96, which indicates a good fit (Bentler, 1990) and the SRMR was .03 and the RSMEA was 0.06 (CI: [0.04 - 0.09]) further indicating a good fit. Rotated solutions were produced for both and oblique rotation (direct oblimin method) to enhance the simple structure of the results given the correlation between the items within each 
Table 6

Means and Standard Deviations for the Student Bystander Behaviour in Cyberbullying Scale

\begin{tabular}{|c|c|c|c|c|}
\hline Items & & $\mathrm{N}$ & $M$ & $S D$ \\
\hline & I forwarded an embarrassing online post that was sent to me. & 428 & .61 & .98 \\
\hline & $\begin{array}{l}\text { I enjoyed reading mean online posts about others as it was fun } \\
\text { and entertaining. }\end{array}$ & 466 & .75 & .94 \\
\hline & $\begin{array}{l}\text { I laughed and showed other friends the embarrassing online post } \\
\text { of someone else. }\end{array}$ & 457 & 1.05 & 1.09 \\
\hline & $\begin{array}{l}\text { I forwarded a message to my friend about another person that I } \\
\text { had received. }\end{array}$ & 450 & 1.09 & 1.13 \\
\hline 5. & $\begin{array}{l}\text { When I have read mean or offensive posts online, I did not } \\
\text { respond or comment on the post. }\end{array}$ & 455 & 2.74 & 1.35 \\
\hline & $\begin{array}{l}\text { When I saw the embarrassing online post, I did not pass it on or } \\
\text { show others. }\end{array}$ & 437 & 2.61 & 1.35 \\
\hline 7. & $\begin{array}{l}\text { When I have seen an embarrassing online post or text message } \\
\text { of someone, I tried to stop it from circulating. }\end{array}$ & 425 & 1.65 & 1.21 \\
\hline & $\begin{array}{l}\text { When I have seen a mean message posted about someone, I } \\
\text { reported the message or online post as 'inappropriate' or } \\
\text { 'offensive'. }\end{array}$ & 455 & 1.29 & 1.296 \\
\hline
\end{tabular}


Table 7

Factor Loadings for Exploratory Factor Analysis for Bystander Behaviour in Cyberbullying

Items

F1:

F2:

F3:

Pro-Bully Outsider Defender

1. I forwarded an embarrassing online post that was sent to me.

$\begin{array}{lll}.76 & -.09 & .12\end{array}$

2. I enjoyed reading mean online posts about others as it was fun and entertaining.

$\begin{array}{lll}.66 & .13 \quad-.01\end{array}$

3. I laughed and showed other friends the embarrassing online post of someone else.

$\begin{array}{lll}.84 & .07 & -.92\end{array}$

4. I forwarded a message to my friend about another person that I had received.

$.71 \quad-.01 \quad .06$

5. When I have read mean or offensive posts online, I did not respond or comment on the post.

$\begin{array}{lll}.15 & .44 & -.08\end{array}$

6. When I saw the embarrassing online post, I did not pass it on or show others.

$\begin{array}{lll}-.08 & .89 & .08\end{array}$

7. When I have seen an embarrassing online post or text message of someone, I tried to stop it from circulating.

8. When I have seen a mean message posted about someone, I reported the message or online post as 'inappropriate' or 'offensive'.

Note. Bolded values indicate significant loading on the factor $(p<.001)$ 
Table 8

Factor Loadings for Confirmatory Factor Analysis for Bystander Behaviour in Cyberbullying

\begin{tabular}{cccc}
\hline Items & F1: & F2: & F3: \\
& Pro- & F2: & Bully \\
& Outsider & Defender
\end{tabular}

1. I forwarded an embarrassing online post that was sent to me.

2. I enjoyed reading mean online posts about others as it was fun and entertaining.

3. I laughed and showed other friends the embarrassing online post of someone else.

4. I forwarded a message to my friend about another person that I had received.

5. When I have read mean or offensive posts online, I did not respond or comment on the post.

6. When I saw the embarrassing online post, I did not pass it on or show others.

7. When I have seen an embarrassing online post or text message of someone, I tried to stop it from circulating.

8. When I have seen a mean message posted about someone, I reported the message or online post as 'inappropriate' or 'offensive'.

Note. Bolded values indicate significant loading on the factor $(p<.001)$ 
Table 9

Factor Loadings for Confirmatory Factor Analysis for Bystander Behaviour in Cyberbullying

\begin{tabular}{ccc}
\hline & F1: & F2: \\
Items & Pro- & Bully \\
& Befender
\end{tabular}

1. I forwarded an embarrassing online post that was sent to me.

2. I enjoyed reading mean online posts about others as it was fun and entertaining.

3. I laughed and showed other friends the embarrassing online post of someone else.

4. I forwarded a message to my friend about another person that I had received.

5. When I have seen an embarrassing online post or text message of someone, I tried to stop it from circulating.

6. When I have seen a mean message posted about someone, I reported the message or online post as 'inappropriate' or 'offensive'.

Note. Bolded values indicate significant loading on the factor $(p<.001)$ 
measure (Henson \& Roberts, 2006); however, for the sake of comparison an orthogonal rotation was used (varimax method) and the same factor structures emerged.

Two factors corresponded to those identified in Thornberg and Jungert's (2013) measure: pro-bully behaviour (Cronbach's $\alpha=.82$ ), and defender bystander behaviour (Cronbach's $\alpha=$ .60). Pro-bully included four items (e.g. "I forwarded a message to my friend about another person that I had received"; "I enjoyed reading mean online posts about others as it was fun and entertaining."), representing the behaviours of bystanders who actively engage in perpetrating bullying behaviour. The second factor represented defender bystander behaviour factor (e.g. "When I have seen an embarrassing online post or text message of someone, I tried to stop it from circulating") encompassing the construct of defender behaviour, when a bystander actively intervenes to assist the victim. The two items that were hypothesized to represent the factor of 'outsider' behaviours were removed, as they did not load as a separate factor. This is believed to be due to the nature of online bullying. The behaviours characterized 'outsider bystanders' involves those who report passively standing by without helping the person who is victimized (Gini et al., 2008; Salmivalli et al., 1996; Sutton \& Smith, 1999). It is possible that due to the online environment, bystanders must be aware of the bullying and communicate by engaging in defending and pro-bully behaviours. High endorsement (extremely negatively skewed items with over $90 \%$ of participants reporting high use of this behaviour) also suggests that this is indeed not a distinct construct as seen in other forms of aggression.

\section{Development of the Defender Self-Efficacy Scale}

Exploratory factor analyses (EFA) were used to examine latent factors for the Defender Self-Efficacy Scale. Bivariate correlations between items were conducted to see if there was multicollinearity. An EFA was then used to explore latent factors for the remaining items. A 
cut-off of 0.8 was used (Tabachnick \& Fidell, 2007). All items were retained as all correlations were below $0.8(r=0.41-0.72)$. Further, to examine whether cyber and social defender selfefficacy items should be examined separately, items were assessed for frequency, distribution and mean scores (see Table 10). Overall there were no distinct differences between social and cyber defender self-efficacy and therefore the items were assessed as one construct, defender self-efficacy.

The complete 6 items were factor analyzed with maximum likelihood extraction and promax rotation. A one-factor solution was examined after observing the eigenvalues where only one factor reported a value of greater than one. This single factor accounted for $93.51 \%$ of the variance. Factor loadings of at least 0.35 were considered good indicators of the underlying concept and all items were retained. It was expected that a single factor model would best fit the model representing the defender self-efficacy behaviours (Thornberg \& Jungert, 2013).

A confirmatory factor analysis (CFA) was performed using the recommended singlefactor structure on the set of 9 items (see Table 11). The fit indices were good. The Comparative Fit Index (CFI) was 0.97, which indicates a good fit (Bentler, 1990) and the SRMR was .03 indicating good fit. To further support the single factor model, RSMEA was 0.05 (CI: [0.04 - 0.08]), the NFI assesses the model by comparing the chi-square value of the model to the chi-square of the null model that assumes all measured variables are uncorrelated and was .96 showing a good fit. Internal consistency reliability was .94 for the 9 -item scale.

In conclusion, total scores were calculated for defender self-efficacy for all social and cyberbullying items. All items pertaining to cyber and social aggression were used to assess defender self-efficacy. This is consistent with previous research (Thornberg \& Jungert, 2013) that found a single factor model for defender self-efficacy. 
Table 10

Means and Standard Deviations for the Defender Self-Efficacy Scale

\begin{tabular}{|c|c|c|c|c|}
\hline Items & & $\mathrm{N}$ & $M$ & $S D$ \\
\hline & $\begin{array}{l}\text { Tell a person who sends nasty messages to another person that it } \\
\text { is not okay. }\end{array}$ & 474 & 3.65 & 1.70 \\
\hline & $\begin{array}{l}\text { Tell a person who posts mean comments online via website, } \\
\text { social media chat forum to stop. }\end{array}$ & 474 & 3.19 & 1.85 \\
\hline & $\begin{array}{l}\text { Tell a person who sends embarrassing pictures of someone via } \\
\text { online or electronic device to stop. }\end{array}$ & 474 & 3.60 & 1.79 \\
\hline & $\begin{array}{l}\text { Tell a person who leaves others out intentionally that it is not } \\
\text { okay. }\end{array}$ & 473 & 3.55 & 1.68 \\
\hline & $\begin{array}{l}\text { Tell a person or friend who spreads rumours, or says mean things } \\
\text { about another person to stop. }\end{array}$ & 474 & 3.43 & 1.68 \\
\hline & $\begin{array}{l}\text { Tell a person or friend who talks behind other peoples back to } \\
\text { stop. }\end{array}$ & 474 & 3.30 & 1.68 \\
\hline
\end{tabular}

Table 11

Factor Loadings for Confirmatory Factor Analysis for the Defender Self-Efficacy Scale

\begin{tabular}{ll}
\hline Items & Defender Self-Efficacy
\end{tabular}

1. Tell a person who sends nasty messages to another person that it is not okay.

2. Tell a person who posts mean comments online via website, social media chat forum to stop.

3. Tell a person who sends embarrassing pictures of someone via online or electronic device to stop.

4. Tell a person who leaves others out intentionally that it is not okay.

5. Tell a person or friend who spreads rumours, or says mean things about another person to stop.

6. Tell a person or friend who talks behind other peoples back to stop.

Note. Bolded values indicate significant loading on the factor $(p<.001)$ 


\section{Exploring Sex Differences for all Variables}

It has been suggested in the literature that sex differences exist in moral disengagement (Almedia et al., 2010; Bandura et al., 1996, 2001; Barchia \& Bussey, 2010; Obermann, 2011) and bystander behaviour (Gini et al., 2008; O'Connell et al., 1999; Salmivalli et al., 1996; Salmivalli \& Voeten, 2004) therefore sex differences were explored for all variables. In the current study, sex was measured by asking participants to identify as male, female, or other. According to the American Psychological Association (2010) "sex refers to a person's biological status and is typically categorized as male, female, or intersex (i.e., atypical combinations of features that usually distinguish male from female)". Refer to Table 12 for the means and standard deviations for moral disengagement, defender self-efficacy, and bystander behaviours reported separately for males and females.

A set of 4 one-way ANOVAs testing sex differences revealed that males $(M=15.68, S D$ $=7.8$ ) reported significantly higher moral disengagement in using social aggression than females $(M=11.63, S D=7.86), F(1,469)=21.29, p<.001, d=.53$. Males also reported significantly higher moral disengagement in using cyber aggression $(M=11.14, S D=9.9)$ than females $(M=$ $6.47 S D=7.4), F(1,469)=27.27, p<.001, d=.52$ and significantly higher levels of general moral disengagement $(M=35.18, S D=18.57)$ as measured by Bandura than females $(M=$ 25.20, $S D=15.85, F(1,469)=29.19 p<.001, d=.58)$. There were no significant grade or sex differences in defender self-efficacy $(F(1,471)=3.77 p=.05, d=.21)$.

\section{Moral disengagement, Defender Self-Efficacy, and Bystander Behaviour}

Hierarchical linear and logistic regression models were used to examine the relationships between moral disengagement, defender self-efficacy and three forms of bystander behaviour. Demographic variables including age and sex were entered in Step 1, followed by moral 
Table 12

Means and Standard Deviations for all Variables for Males and Females

\begin{tabular}{lrrrrr}
\hline & \multicolumn{5}{c}{ Males } \\
\cline { 2 - 6 } Items & \multicolumn{1}{c}{$M$} & \multicolumn{1}{c}{$S D$} & \multicolumn{1}{c}{$M$} & $S D$ & $d$ \\
\hline MD Social & 11.14 & 9.91 & 6.47 & 7.38 & 0.53 \\
MD Cyber & 15.68 & 7.86 & 11.63 & 7.84 & 0.52 \\
MD Bandura & 35.19 & 18.58 & 25.20 & 15.85 & 0.58 \\
Defender Self-Efficacy & 30.16 & 13.2 & 32.89 & 12.43 & -0.21 \\
Pro-Bully Social & 5.88 & 3.74 & 5.79 & 3.27 & 0.03 \\
Outsider Social & 5.14 & 2.86 & 5.46 & 2.55 & -0.12 \\
Defender Social & 3.80 & 2.30 & 4.13 & 1.93 & -0.16 \\
Pro-Bully Cyber & 3.59 & 3.37 & 3.23 & 3.23 & 0.11 \\
Defender Cyber & 2.49 & 2.21 & 2.87 & 2.05 & -0.18 \\
\hline
\end{tabular}


disengagement in witnessing social or cyber aggression in Step 2. Defender self-efficacy was entered in Step 3 to examine the unique contribution of self-efficacy over and above that contributed by moral disengagement when predicting to bystander behaviour. The order of the variables entered into the regression model was determined based on previous research in order to determine how much defender self-efficacy would predict over and above moral disengagement and if it would account for a significant amount of variance in bystander behaviour (Thornberg \& Jungert, 2013).

Linear regression models for social bullying bystander behaviour. Three hierarchical regression models were performed, one for each form of bystander behaviour (pro-bully, outsider, defender) for social bullying behaviour. For each regression model, demographic variables including age and sex were entered in Step 1, followed by moral disengagement in witnessing social or cyber aggression in Step 2. Defender self-efficacy was entered in Step 3 to examine the unique contribution of self-efficacy over and above that contributed by moral disengagement when predicting bystander behaviour, as has been done with other recent researchers in the field (Thornberg \& Jungert, 2013). In the final step an interaction term of moral disengagement and defender self-efficacy was entered to determine if the interaction between moral disengagement and defender self-efficacy accounted for a significant amount of variance in bystander behaviour.

An examination of correlations (see Table 13) revealed that variables were highly correlated (all correlations were below $r=.80$ ) and the assumption of multicollinearity was deemed to have been met (Tabachnick \& Fidell, 2007). Further, all continuous independent variables were centered prior to analyses to improve interpretability of results, including the interaction term variables. 
Table 13

Means, Standard Deviations and Inter-Correlations Between all Variables

\begin{tabular}{llllllllll}
\hline Variable & 1 & 2 & 3 & 4 & 5 & 6 & 7 & 8 \\
\hline
\end{tabular}

1. MD Cyber

2. MD Social $.74^{* *}-$

3. Defender Self-Efficacy $\quad-.26^{* *}-.25^{* *} \quad-$

4. Pro-Bully Cyber $\quad .49^{* *} \quad .47^{* *} \quad-.15^{* *} \quad-$

5. Defender Cyber $\quad-.07 \quad-.18^{* *} \quad .35^{* *} \quad-.06 \quad-$

6. Pro-Bully Social $\quad .42^{* *} \quad .51^{* *} \quad-.23^{* *} \quad .65^{* *} \quad-.18^{* *} \quad-$

7. Outsider Social $\quad .20^{* *} \quad .20^{* *} \quad-.21^{* *} \quad .26^{* *} \quad-.13^{* *} \quad .39^{* *} \quad-$

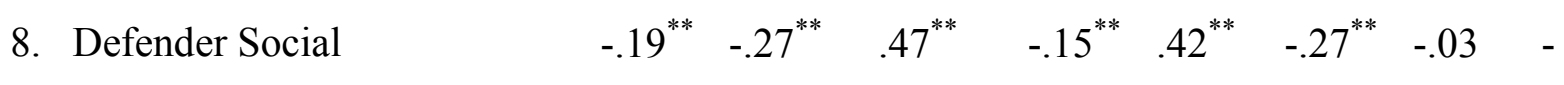

$\begin{array}{lllllllll}\text { Mean } & 7.50 & 12.53 & 32.29 & 3.33 & 2.79 & 5.83 & 5.40 & 4.06\end{array}$

$\begin{array}{lllllllll}\text { Standard Deviation } & 8.27 & 8.03 & 12.64 & 3.28 & 2.09 & 3.38 & 2.63 & 2.02\end{array}$

Note: $* p<.05,{ }^{* *} p<.01,{ }^{* * *} p<.001$ 
Pro-bully bystander behaviour. To test the hypothesis that moral disengagement and defender self-efficacy explain a significant amount of variance in pro-bully bystander behaviour, a hierarchical linear regression analysis was performed.

The hierarchical linear regression revealed that at Step 1, sex and age did not contribute significantly to the regression model, $F(2,465)=.240,(p=.79)$ and accounted for $3.2 \%$ of the variation in pro-bully behaviour (see Table 14). Interestingly, sex did not have an overall main effect, and did not contribute a significant amount of variance to pro-bully bystander behaviour.

Introducing moral disengagement in using social aggression in the Step 2 explained an additional $26.3 \%$ of variation in pro-bully behaviour and this change in $R^{2}$ was significant, $F(3$, $463)=164.84, p<.001$. Lower levels of defender self-efficacy predicted to pro-bully behaviour and explained an additional $0.8 \%$ of the variation in pro-bully behaviour. This change in $R^{2}$ was significant, $F(4,462)=5.32, p=.02$. The most important predictor of pro-bully behaviour was moral disengagement. The partial correlation coefficient indicated that moral disengagement uniquely contributed $23 \%$ of the variance in pro-bully bystander behaviour. Higher levels of moral disengagement were associated with an increase in reports of pro-bully behaviour. The interaction term was not significant $F(5,461)=3.65, p=.06$, therefore no further analysis was required. Together in the final model the five independent variables of age, sex, moral disengagement, defender self-efficacy, and the interaction term accounted for $27.7 \%$ of the variation in pro-bully bystander behaviour.

Outsider bystander behaviour. To test the hypothesis that moral disengagement and defender self-efficacy explained a significant amount of variance in outsider bystander behaviour, a hierarchical linear regression analysis was performed. The hierarchical linear regression revealed that at Step 1, sex and age did not contribute significantly to the regression 
Table 14

Hierarchical Regression Predicting Pro-Bully Bystander Behaviour in Social Bullying

\begin{tabular}{|c|c|c|c|c|c|c|c|}
\hline \multicolumn{8}{|c|}{ Adjusted } \\
\hline Predictor & $\mathrm{R}$ & $\mathrm{R}^{2}$ & $\mathrm{R}^{2}$ & $\Delta R^{2}$ & $\mathrm{~B}$ & SEB & $\beta$ \\
\hline Step 1 & .03 & .001 & -.003 & .001 & & & \\
\hline Sex & & & & & -.9 & .38 & -.01 \\
\hline Age & & & & & -.11 & .17 & -.03 \\
\hline Step 2 & .51 & .26 & .26 & $.26^{* *}$ & & & \\
\hline Sex & & & & & .81 & .33 & .10 \\
\hline Age & & & & & -.10 & .15 & -.03 \\
\hline Moral Disengagement & & & & & .22 & .02 & $.53 * *$ \\
\hline Step 3 & .52 & .27 & .26 & .008 & & & \\
\hline Sex & & & & & .84 & .33 & .10 \\
\hline Age & & & & & -.05 & .15 & -.01 \\
\hline Moral Disengagement & & & & & .21 & .02 & $.49 * *$ \\
\hline Defender Self-Efficacy & & & & & -.06 & .02 & $-.13 *$ \\
\hline Step 4 & .53 & .28 & .27 & .006 & & & \\
\hline Sex & & & & & .85 & .33 & .12 \\
\hline Age & & & & & -.05 & .15 & -.01 \\
\hline Moral Disengagement & & & & & .17 & .02 & $.49 * *$ \\
\hline Defender Self-Efficacy & & & & & -.04 & .02 & -.14 \\
\hline$M D X$ Defender $S E$ & & & & & .004 & .002 & .08 \\
\hline
\end{tabular}

Note: Age, moral disengagement, defender self-efficacy and the interaction term were centered at their means.

$* p<.01 . * * p<.001$. 
model, $F(2,460)=1.70, p=.18$ and accounted for $0.7 \%$ of the variation in outsider bystander behaviour (see Table 15).

Introducing the moral disengagement in using social aggression explained an additional $4 \%$ of variation in outsider behaviour and this change in $R^{2}$ was significant, $F(3,459)=19.26, p$ $<.001$. The addition of defender self-efficacy to the regression model explained an additional $3 \%$ of the variation in outsider behaviour and this change in $R^{2}$ was also significant, $F(1,463)=$ $14.65 p<.001$. Moral disengagement and defender self-efficacy accounted for a significant amount of variance in outsider behaviour. Higher levels of moral disengagement were associated with higher reports of outsider behaviour whereas higher defender self-efficacy was associated with lower reports of outsider behaviour. An examination of the partial correlation coefficients revealed that moral disengagement uniquely contributed $3 \%$ of the variance in outsider bystander behaviour and defender self-efficacy uniquely contributed $3.1 \%$ of the variance. The interaction between moral disengagement and defender self-efficacy was not significant therefore no further analysis was required. Together the five independent variables of age, sex, moral disengagement, defender self-efficacy, and the interaction term accounted for $8 \%$ of the variance in outsider behaviour.

Defender bystander behaviour. To test the hypothesis that variance in defender bystander behaviour could be explained by moral disengagement and defender self-efficacy, a hierarchical regression analysis was performed. The hierarchical linear regression revealed that at Step 1, sex and age did not contribute significantly to the regression model, $F(2,458)=8.33, p$ $=.13$, and accounted for $0.9 \%$ of the variation in defender behaviour (see Table 16). 
Table 15

Hierarchical Regression Predicting Outsider Bystander Behaviour in Social Bullying

\begin{tabular}{|c|c|c|c|c|c|c|c|}
\hline Predictor & $\mathrm{R}$ & $\begin{array}{c}\text { Adjusted } \\
\mathrm{R}^{2}\end{array}$ & $\mathrm{R}^{2}$ & $\Delta R^{2}$ & B & SEB & $\beta$ \\
\hline Step 1 & .09 & .007 & .003 & .007 & & & \\
\hline Sex & & & & & .31 & .29 & .05 \\
\hline Age & & & & & -.19 & .13 & -.07 \\
\hline Step 2 & .22 & .047 & .041 & $.04 * *$ & & & \\
\hline Sex & & & & & .58 & .29 & .09 \\
\hline Age & & & & & -.18 & .13 & -.06 \\
\hline Moral Disengagement & & & & & .07 & .02 & $.20 * *$ \\
\hline Step 3 & .28 & .077 & .069 & $.03 * *$ & & & \\
\hline Sex & & & & & .61 & .29 & .10 \\
\hline Age & & & & & -.13 & .13 & -.05 \\
\hline Moral Disengagement & & & & & .05 & .02 & $.16^{* *}$ \\
\hline Defender Self-Efficacy & & & & & -.07 & .02 & $-.19 * *$ \\
\hline Step 4 & .28 & .08 & .07 & .003 & & & \\
\hline Sex & & & & & .63 & .29 & .10 \\
\hline Age & & & & & -.14 & .13 & -.05 \\
\hline Moral Disengagement & & & & & .05 & .02 & $.16^{* *}$ \\
\hline Defender Self-Efficacy & & & & & -.07 & .02 & $-.19 * *$ \\
\hline$M D X$ Defender $S E$ & & & & & .002 & .002 & .05 \\
\hline
\end{tabular}

Note: Age, moral disengagement, defender self-efficacy and the interaction term were centered at their means.

$* p<.01 . * * p<.001$. 
Table 16

Hierarchical Regression Predicting Defender Bystander Behaviour in Social Bullying

\begin{tabular}{|c|c|c|c|c|c|c|c|}
\hline \multicolumn{8}{|c|}{ Adjusted } \\
\hline Predictor & $\mathrm{R}$ & $\mathrm{R}^{2}$ & $\mathrm{R}^{2}$ & $\Delta R^{2}$ & $\mathrm{~B}$ & SEB & $\beta$ \\
\hline Step 1 & .09 & .009 & .005 & .005 & & & \\
\hline Sex & & & & & .30 & .23 & .06 \\
\hline Age & & & & & -.15 & .10 & -.07 \\
\hline Step 2 & .28 & .08 & .074 & $.071 * *$ & & & \\
\hline Sex & & & & & .03 & .23 & .01 \\
\hline Age & & & & & -.15 & .10 & -.07 \\
\hline Moral Disengagement & & & & & -.07 & .01 & $-.27 * *$ \\
\hline Step 3 & .50 & .254 & .25 & $.17 * *$ & & & \\
\hline Sex & & & & & -.01 & .20 & -.003 \\
\hline Age & & & & & -.23 & .09 & -.11 \\
\hline Moral Disengagement & & & & & -.04 & .01 & $-.16 * *$ \\
\hline Defender Self-Efficacy & & & & & .13 & .01 & $.46^{* *}$ \\
\hline Step 4 & .51 & .26 & .25 & .002 & & & \\
\hline Sex & & & & & -.02 & .20 & -.005 \\
\hline Age & & & & & -.23 & .09 & -.11 \\
\hline Moral Disengagement & & & & & -.04 & .01 & $-.16 * *$ \\
\hline Defender Self-Efficacy & & & & & .13 & .01 & $.46^{* *}$ \\
\hline$M D X$ Defender $S E$ & & & & & -.001 & .001 & -.04 \\
\hline
\end{tabular}

Note: Age, moral disengagement, defender self-efficacy and the interaction term were centered at their means.

${ }^{*} p<.01 .{ }^{*} p<.001$. 
Introducing the moral disengagement in using social aggression explained an additional $8 \%$ of variation in defender behaviour and this change in $R^{2}$ was significant, $F(3,457)=35.46, p$ $<.001$. The addition of defender self-efficacy to the regression model explained an additional $24.8 \%$ of the variation in defender behaviour and this change in $R^{2}$ was also significant, $F$ $(4,456)=106.46, p<.001$. Moral disengagement and defender self-efficacy were both important predictors of outsider behaviour and explained a significant amount of variance in defender behaviour. Higher reports of moral disengagement were associated with lower reports of defender behaviour, whereas higher defender self-efficacy was associated with higher reports of defender behaviour. An examination of the partial correlation coefficients revealed that moral disengagement uniquely contributed $3 \%$ of the variance in pro-bully bystander behaviour and defender self-efficacy uniquely contributed $17.4 \%$ of the variance. The interaction between moral disengagement and defender self-efficacy was not significant therefore no further analysis was required.

Logistic regression models for cyberbullying bystander behaviour. Two logistic regression analyses were conducted in order to evaluate the independent contribution of moral disengagement and defender self-efficacy in bystander behaviour of cyberbullying. Logistic regression analyse were conducted to accommodate the severe non-normality in the dependent variables. Bystander behaviours were coded $(0,1)$ to compare children who reported engaging in bystander behaviour (1) to the reference category of those who reported low to no engagement in bystander behaviours (0). A cut-off score of students who were reported to exhibit behaviours at least sometimes or more on one or more items were coded 1. This cut-off was chosen based on the standard used in bullying literature where the cut-off representing discrete groups of those 
who participate sometimes or more are compared to those who report no engagement (e.g. Raskauskas \& Stoltz, 2007; Solberg \& Olweus, 2003; Wang et al., 2009).

To test the hypotheses that moral disengagement and defender self-efficacy predicted to the likelihood of reporting bystander behaviour, two logistic regression analyses were preformed for pro-bully and defender behaviour separately. All continuous independent variables were centered and the interaction term was calculated using the centered variables. Sex and age were the first variables entered in Step 1 to identify the contribution of descriptive characteristics. In Step 2 of the model, moral disengagement in using cyberbullying was entered and Step 3, defender self-efficacy was entered to examine the contribution over and above that of moral disengagement. In the final step an interaction term of moral disengagement and defender selfefficacy was entered to determine if there was a significant interaction between moral disengagement and defender self-efficacy.

Pro-bully bystander behaviour. A logistic regression was conducted to determine if sex, age, moral disengagement, and defender self-efficacy significantly predicted to pro-bully bystander behaviour. Sex and age did not significantly predict to pro-bully behaviour (see Table 17). After controlling for sex and age, the full model was statistically significant, $\chi^{2}(5, N=475)$ $=75.07, p<.001$, indicating that all predictors significantly distinguished between no reports of pro-bully bystander behaviour and reported pro-bully bystander behaviour. Classification was adequate, and predicted $68.1 \%$ of the responses correctly. According to the Wald criterion, only moral disengagement significantly predicted pro-bully bystander behaviour. Those who reported high levels of moral disengagement had 1.14 higher odds of engaging in pro-bully behaviour when witnessing cyberbullying. This confirmed the finding that moral disengagement was the only significant predictor of pro-bully behaviour among the four predictor variables. 
Table 17

Risk (Odds Ratio) for Pro-Bully Cyber Bystander Behaviour Predicted from Moral Disengagement and Defender Self-Efficacy

\begin{tabular}{|c|c|c|c|c|c|c|}
\hline \multirow{2}{*}{ Variable } & \multirow[b]{2}{*}{ B } & \multirow[b]{2}{*}{ S.E. } & \multirow[b]{2}{*}{$P$} & \multirow{2}{*}{$\begin{array}{l}\text { Odds Ratio } \\
\operatorname{EXP}(\mathrm{B})\end{array}$} & \multicolumn{2}{|c|}{ 95\% C.I. EXP(B) } \\
\hline & & & & & Lower & Upper \\
\hline \multicolumn{7}{|l|}{ Step 1} \\
\hline Sex & .05 & .23 & .83 & 1.05 & .68 & 1.63 \\
\hline Age & .08 & .10 & .44 & 1.08 & .89 & 1.32 \\
\hline \multicolumn{7}{|l|}{ Step 2} \\
\hline Sex & -.47 & .26 & .07 & .63 & .38 & 1.03 \\
\hline Age & .14 & .11 & .22 & 1.15 & .92 & 1.42 \\
\hline Moral Disengagement & .12 & .02 & .000 & 1.13 & 1.09 & 1.17 \\
\hline \multicolumn{7}{|l|}{ Step 3} \\
\hline Sex & -.47 & .26 & .07 & .63 & .38 & 1.03 \\
\hline Age & .14 & .11 & .22 & 1.15 & .92 & 1.42 \\
\hline Moral Disengagement & .12 & .02 & .000 & 1.13 & 1.09 & 1.17 \\
\hline Defender Self-Efficacy & -.001 & .02 & .97 & .99 & .96 & 1.04 \\
\hline \multicolumn{7}{|l|}{ Step 4} \\
\hline Sex & -.46 & .26 & .07 & .63 & .38 & 1.04 \\
\hline Age & .13 & .11 & .24 & 1.14 & .92 & 1.42 \\
\hline Moral Disengagement & .13 & .02 & .000 & 1.14 & 1.10 & 1.19 \\
\hline Defender Self-Efficacy & .01 & .02 & .56 & 1.01 & .97 & 1.06 \\
\hline$M D X$ Defender $S E$ & .01 & .004 & .06 & 1.01 & 1.00 & 1.01 \\
\hline
\end{tabular}


However, the odds ratio showed little change in the likelihood of pro-bully behaviour on the basis of a one-unit change in moral disengagement. The final model included defender self-efficacy but found there was no significant association between defender selfefficacy and pro-bully bystander behaviour. The interaction between moral disengagement and defender self-efficacy was not significant. Thus, moral disengagement distinguished between those who did and those who did not report engaging in pro-bully behaviour when witnessing cyber bullying, but the distinction was not very strong and the overall effect size of the model was small (Nagelkerke $\left.R^{2}=.197\right)$.

Defender bystander behaviour. A second logistic regression was conducted to examine the contribution of sex, age, moral disengagement, and defender self-efficacy to predicting the likelihood of engaging in defender bystander behaviour (see Table 18). Sex and age did not significantly predict to defender behaviour. After controlling for sex and age, the full model was statistically significant, $\chi^{2}(5, N=475)=31.58, p<.001$, indicating that all predictors significantly distinguished between reports of not engaging in defender bystander behaviour and reports of engaging in defender bystander behaviour. Classification was adequate, and predicted $61.9 \%$ of the responses correctly. According to the Wald criterion, only defender self-efficacy was found to significantly predict defender bystander behaviour. Those who reported higher levels of defender self-efficacy had 1.1 higher odds of intervening when witnessing cyberbullying behaviour. This confirms the finding that defender self-efficacy is the only significant predictor of defender behaviour among the four predictor variables. However, the odds ratio showed little change in the likelihood of defender behaviour on the basis of a one-unit change in defender self-efficacy. It was found that moral disengagement did not significantly 
Table 18

Risk (Odds Ratio) for Defender Cyber Bystander Behaviour Predicted from Moral Disengagement and Defender Self-Efficacy

\begin{tabular}{lcccccc}
\hline \multirow{2}{*}{ Variable } & & & & Odds Ratio & \multicolumn{2}{c}{$95 \%$ C.I. EXP(B) } \\
\cline { 6 - 7 } & B & S.E. & $P$ & EXP(B) & Lower & Upper \\
\hline Step 1 & & & & & & \\
Sex & -.61 & .23 & .007 & .54 & .35 & .85 \\
Age & .18 & .10 & .08 & 1.20 & .98 & 1.47 \\
Step 2 & & & & & & \\
$\quad$ Sex & -.52 & .23 & .03 & .59 & .37 & .94 \\
Age & .17 & .10 & .09 & 1.19 & .97 & 1.46 \\
$\quad$ Moral Disengagement & -.02 & .01 & .11 & .98 & .96 & 1.00 \\
Step 3 & & & & & & \\
Sex & -.46 & .24 & .06 & .63 & .40 & 1.01 \\
Age & .14 & .11 & .19 & 1.15 & .93 & 1.41 \\
Moral Disengagement & -.01 & .01 & .51 & .99 & .97 & 1.02 \\
Defender Self-Efficacy & .09 & .02 & .000 & 1.10 & 1.05 & 1.15 \\
Step 4 & & & & & & \\
Sex & -.45 & .24 & .06 & .64 & .40 & 1.02 \\
Age & .14 & .11 & .19 & 1.15 & .93 & 1.41 \\
Moral Disengagement & -.01 & .01 & .54 & .99 & .97 & 1.02 \\
& .09 & .02 & .000 & 1.10 & 1.05 & 1.15 \\
Defender Self-Efficacy & .001 & .00 & .82 & 1.00 & .99 & 1.01 \\
MD X Defender SE & .00 &
\end{tabular}


predict defender bystander behaviour. The interaction between moral disengagement and defender self-efficacy was not examined, as the main effect of moral disengagement was not significant.

Overall, defender self-efficacy distinguished between those who did and those who did not report engaging in defender behaviour when witnessing cyberbullying, but the distinction was weak and the overall effect size of the model was small (Nagelkerke $\left.R^{2}=.104\right)$.

\section{Discussion}

Research has consistently demonstrated that moral disengagement is associated with bullying participation (e.g. Gini 2006; Hymel et al. 2005; Thornberg \& Jungert 2013) in children and adults. However, little is known about whether the use of moral disengagement justifications are consistent across various forms of aggression, including indirect forms such as social bullying and cyberbullying. Moreover, the majority of the research to date has used the original or adapted version of the Bandura Moral Disengagement questionnaire (Bandura et al., 1996) that primarily addresses behaviours of physical aggression and deviant behaviours. To date, there have been no appropriate measures to assess moral disengagement mechanisms in the context of more covert and indirect forms of aggression. Before the goals of this study could be met it was necessary to develop two new measures of moral disengagement as well as two new measures of bystander behaviours relevant to the context of social bullying and cyberbullying.

\section{Development of Moral Disengagement Scales for Social Bullying and Cyberbullying}

Moral disengagement for social aggression. The current study used a newly developed scale in order to assess moral justifications and endorsement of social bullying behaviours as previous research in the field of bullying has suggested that moral disengagement measures should be specific to the behaviours of interest (Hymel et al., 2005; Pozzoli et al., 2012). Based 
on a review of the literature, it was expected that the measure of moral disengagement for social aggression would be comprised of a single factor consistent with the previous findings for general aggression (e.g. Bandura et al., 1996; Paciello et al., 2008). As expected, the items designed to assess the four underlying theoretical mechanisms of moral disengagement theorized by Bandura et al. (1996) for social aggression all loaded on a single factor. Overall this newly developed scale presented adequate fit indices, good internal reliability, and concurrent validity with Bandura's scale (1996).

Moral disengagement in using cyber aggression. To further add to the literature on moral disengagement justifications made in the context of online aggression, a moral disengagement scale that is relevant to the cyberbullying context and consistent with previous research (Bandura et al., 1996; Hymel et al., 2005) was developed. As expected, items designed to assess the four underlying theoretical mechanisms of moral disengagement (Bandura et al., 1996) all loaded on a single factor. This scale presented adequate fit indices, very good internal reliability, and concurrent validity with Bandura's scale (1996). Theoretically it appears that although there may be a variety of strategies used to justify immoral behaviour, these items all appear to reflect one underlying construct of moral disengagement in cyberbullying.

The cyber moral disengagement scale correlated with the social moral disengagement scale $(r$ $=.74$ ) but was not considered to overlap significantly (Tabachnick \& Fidell, 2007) and thus these two measures are believed to be measuring the same construct within two separate contexts. Further support for this argument was found by examining the average level of social moral disengagement compared to cyber moral disengagement. The mean level of cyber moral disengagement was significantly lower than the mean level of social moral disengagement. This finding indicates that although in theory the behaviours of cyberbullying were similar to those of 
social bullying, emerging adults justified the use of social bullying behaviours at a higher rate than cyberbullying. These findings support the argument that measures of justifications and behaviours should be constructed to address the specific context that is being examined (Barchia \& Bussey, 2011; Hymel et al., 3005; Osofsky, Bandura, \& Zimbardo, 2005; Poyhonen et al., 2012; Thornberg \& Jungert, 2013). Future research is suggested to determine whether these measures of moral disengagement can be used to accurately assess social and cyber moral disengagement within a younger age range.

\section{Development of the Student Bystander Behaviour Scale}

Research has demonstrated that students who observe bullying can assume a range of different bystander behaviours (Salmivalli, 1999; Salmivalli et al., 1996) including those who support the bullies, those who remain uninvolved and those who try to help or support the victim. To date there is no known research that has examined these three bystander behaviours in the context of social bullying and cyberbullying. The current study modified an existing measure of bystander behaviour (Thornberg \& Jungert, 2013) to develop measures of bystander behaviours for both social and cyberbullying. Items on each measure tapped possible prior experiences of bystander behaviours consistent with the theory of the participant role approach (Salmivalli, 1999; Salmivalli et al., 1996).

Social bullying bystander behaviour. The current study developed a scale for bystander behaviour in the context of social bullying that included 9 items that assessed three forms of bystander behaviour specific to social bullying (i.e. pro-bully, outsider and defender). Three underlying factors consistent with the three forms of bystander behaviours represented by Salmivalli (1999) were found. This scale showed adequate fit indices and good internal reliability. 
Cyberbullying bystander behaviour. Although cyberbullying is related and similar to traditional bullying (Ybarra \& Mitchell, 2004) the unique characteristics of the cyber world can influence bullying dynamics and consequently also bystander behaviour (Patchin \& Hinduja, 2010). For example, in online social interactions individuals can be confronted with cyberbullying within but also outside of their own social circle. A bystander can have several different types of relationships with the people involved in a cyberbullying incident resulting in a variety of factors that can influence the bystander's behaviour. Also, online bystanders have a variety of means to react to cyberbullying incidents such as text- and picture-based communications, by clicking a button (e.g. the "like" or "report" button), or simply by reading a post and exiting the screen. Taking this into consideration, the current study developed a bystander measure that addressed the variety of means by which a bystander can react based on the participant role approach of Salmivalli (1999).

It was hypothesized that this measure would tap into the three bystander behaviours that have been identified more generally for bullying (i.e. pro-bully, outsider, and defender); however, contrary to expectations, only two underlying factors were found (pro-bully and defender bystander behaviour). Contrary to what was expected, outsider bystander behaviour did not load as a separate construct. The cyber bystander measure was found to have good internal consistency and adequate fit indices.

Outsider behaviour is characterized as those who witness bullying but passively observe the behaviours without helping the person who is victimized (Gini et al., 2008; Salmivalli et al., 1996; Sutton \& Smith, 1999). It is possible that due to the online environment, one must be aware of the bullying and by interacting/communicating online they engage in behaviours characteristic of defending or pro-bully behaviours. All participants reported high engagement 
on items that represented outsider behaviours (i.e. When I have read mean or offensive posts online, I did not respond or comment on the post) and thus it did not load as a latent factor. This is consistent with recent research by Bastiaensens and colleagues (2014) who found that online bystanders only reported having had the intent to assist the victim or reinforce the bully.

Another possible explanation is that the nature of cyberbullying may impact bystander's behaviours differently from face-to-face bullying situations. Researchers have shown that there are a number of factors that can affect whether an individual defends a victim online including the severity of the incident, the involvement of other bystanders, the status of the bystanders, and the status of the victim (Bastiaensens et al., 2014). Another explanation may be that individuals who engage in outsider behaviour (not defending or perpetrating) do not use online mediums where cyberbullying occurs (i.e., social networking, instant messaging, or text messaging). It may also be that the concept of outsider behaviour does not translate into the cyber context given that there is such widespread high use of electronic technologies by adolescents (Li, 2007; Ybarra \& Mitchell, 2004; Smith et al., 2008). Further research is needed to examine and clarify the various behaviours of bystanders online and factors that may be related to these behaviours.

\section{Sex Differences in Moral Disengagement and Bystander Behaviour}

Females have been shown to report more positive attitudes toward victims (Menesini et al., 1997; Pozzoli \& Gini, 2010) and to be more likely to support or defend victims and less likely to reinforce bullies than males (Gini et al., 2008; O’Connell et al., 1999; Salmivalli et al., 1996; Salmivalli \& Voeten, 2004). Based on these findings, it was hypothesized that similar results would be found in the current sample of emerging adults. Surprisingly in this study, no significant sex differences in bystander behaviour were found for social bullying or 
cyberbullying. This may differ from previous research on children and adolescents due to the older sample of university students used.

A consistent finding across the literature is that males are higher in moral disengagement compared to females (e.g. Almedia et al., 2010; Bandura et al., 1996, 2001; Barchia \& Bussey, 2010; Obermann, 2011). Consistent with research to date in the current study males were higher on all forms of moral disengagement compared to females. This finding may help to expand our understanding of why research has shown that females are more likely to show positive attitudes towards victims of bullying (e.g., Menesini et al., 1997; Pozzoli \& Gini, 2010) and more likely to support or defend victims and less likely to reinforce bullies when compared to males (Gini et al., 2008; O’Connell et al., 1999; Salmivalli et al., 1996; Salmivalli \& Voeten, 2004). Caution should be used when interpreting these results due to the possibility that social cultural pressures on females to "be nice" and suppress anger may lead females to report more socially desirable responses than males (Brown \& Gilligan, 1993; Gilligan, 1993; Underwood, 2003). Results from the current study substantiate this possibility in that young women reported lower levels of moral disengagement for both cyber and social bullying but they did not report lower levels of pro-bully behaviour or higher levels of defender behaviour compared to young men. Pepler and Craig (2005) suggested that individual social-cognitive processes may explain sex differences in peer aggression. Given that children are aware of sex roles early in childhood, it is suggested that females experience inhibitory dissonance between aggressive behavior (particularly physical aggression) and stereotypes of appropriate female behaviour (Pepler \& Craig, 2005). This gender role socialization may result in females having more negative views of aggression than males and therefore are less likely to justify aggressive acts. 


\section{Moral Disengagement Defender Self-Efficacy and Social Bystander Behaviours}

This study was the first to examine the relationships between moral disengagement, defender self-efficacy and bystander behaviours specific to the context of social bullying. Moral disengagement for social bullying was found to be positively associated with pro-bully behaviour and negatively associated with outsider and defender behaviour, which confirmed the hypothesis and supported previous findings (Gini, 2006; Hymel et al., 2005; Menesini et al., 2003; Obermann, 2011). A significant positive relationship between defender self-efficacy and defender behaviour was found, consistent with the previous research (Barchia \& Bussey, 2011; Poyhonen et al., 2012; Thornberg \& Jungert, 2013). Over and above the contribution of moral disengagement, this study found that defender self-efficacy explained one quarter of the variance $(25.4 \%)$ in defender bystander behaviour suggesting that those who believed they could intervene to assist the victim were more likely to report having done so. Simply possessing a self-belief in one's ability to perform a specific behaviour is no guarantee that the behaviour will be performed; however, it does increase the probability of the behaviour occurring in that those who reported higher levels of self-efficacy also reported higher levels of intervention. It has been theorized that individuals may regulate their behaviour through the interplay of a variety of

cognitive factors with defender self-efficacy being a key mechanism in the regulatory process for defender bystanders (Thornberg \& Jungert, 2013). The results from this study suggest that both moral disengagement and defender self-efficacy are important factors for consideration when examining peer aggression and bystander behaviour in social bullying.

\section{Moral Disengagement and Defender Self-Efficacy and Cyber Bystander Behaviours}

A significant positive relationship between cyber moral disengagement and pro-bully behaviour was found. This is consistent with previous research that found a significant 
relationship between moral disengagement and traditional bullying behaviours (e.g. Almeida et al., 2010; Gini, 2006; Gini, Pozzoli, \& Bussey, 2014; Hymel et al., 2005; Menesini et al., 2003; Obermann, 2011; Pornari \& Wood, 2010; Thornberg \& Jungert, 2013). The current study was the first to investigate and find a significant relationship between cyberbullying bystander behaviours and moral disengagement and is consistent with Bussey, Fitzpatrick, and Raman (2014) who found that higher levels of moral disengagement were associated with higher levels of self-reported cyberbullying behaviours.

A recent meta-analysis had established that in cross-sectional and longitudinal research there is a strong relationship between moral disengagement and traditional bullying (Gini et al., 2014). However, this association has proved to be inconsistent when assessing the relationship between moral disengagement and cyberbullying when using a general measure of moral disengagement (Perren et al., 2012; Pornari \& Wood, 2010). The current study addressed this issue by developing a measure that asked about moral disengagement justifications specific to cyberbullying behaviours. When asked specifically about moral disengagement and pro-bully bystander behaviours for cyberbullying a strong relationship was found. This finding is consistent with Bandura's (2002) argument that moral disengagement occurs selectively and is invoked in some contexts and not in others. It also supports the need to ask about moral disengagement in reference to the specific context (i.e. traditional bullying or cyberbullying) that is of interest. Results were consistent with previous research (Barchia \& Bussey, 2011; Hymel et al., 3005; Poyhonen et al., 2012; Thornberg \& Jungert, 2013) and demonstrated that higher defender self-efficacy was related to higher reports of defender behaviour when witnessing cyberbullying. 
The findings suggested that moral disengagement aids in explaining mechanisms used by those who engage in pro-bully behaviour online and in social bullying. Unlike the results found for social bullying, moral disengagement was not associated with defender behaviour in cyberbullying. Consistent with the results found for social bullying, defender self-efficacy was significantly related to higher reports of defender behaviour. Overall effect sizes were relatively small suggesting that although these cognitive mechanisms are significantly associated with the use of bystander behaviours, other factors may be at play.

\section{Limitations and Future Directions}

The use of self-report measures in the current study may be susceptible to careless marking, social desirability, and intentionally exaggerated responses among participants. Nevertheless, self-report measures are the standard form of assessments used in the bullying literature and provide insight into the participant's own perceptions of their behaviours. It is important to use caution when generalizing the findings as this sample of emerging adults from a Canadian university may or may not be similar to other populations under consideration. The current sample consisted of $80 \%$ females and $70 \%$ identified as Caucasian, although representative of the university population, caution is warranted when generalizing the findings to other populations. Due to the cross-sectional design of this study, all variables were measured at the same time, and therefore this study was not able to pinpoint the direction of effects. Thus, caution should be taken before trying to draw causal conclusions from the associations identified. Longitudinal studies are needed to allow for an investigation into the development of moral disengagement over time and the nature of the relationship between moral disengagement, selfefficacy and bystander behaviours over time. 
The current study examined bystander behaviour using a social cognitive theory framework; however, it is important to note that there may be other pathways and theories that aid in the understanding of bystander behaviour including contextual, situational, and socioemotional factors.

Bastiaensens and colleagues (2014) examined contextual factors that were associated with bystander behaviour when witnessing cyberbullying including severity of the event and the behaviours of other bystanders. Results demonstrated that the more severe the bystanders evaluated the situation to be the greater the likelihood of assisting the victim. It has been speculated that intervention on behalf of the victim is influenced by situational factors and it is important to determine which situations influence the rates of intervention as well as the level of moral disengagement across types of bullying behaviour. Although this study has shown that bystanders who witness severe bullying events are willing to help the victim, future research is warranted in examining which type of defender behaviour adequately stops the bullying or buffers the negative effects on the victim.

The majority of bullying behaviour is witnessed by a group of people and it has been found that when many individuals are witnesses to an event, the likelihood of intervention decreases (Latane \& Nida, 1981). Individuals who witness bullying may expect others to take action and intervene, reducing some feelings of their responsibility to intervene. Furthermore, when there are multiple witnesses to bullying behaviour, bystanders may interpret other witnesses' inaction to mean that the behaviour between the victim and the bully may not be that serious and therefore they will not intervene. Another factor that may inhibit bystanders from intervening is the perpetrator's power or status. Status of the perpetrator as popular, powerful or threatening may intimidate a witness and prevent intervention on behalf of the victim 
(Salmivalli, 2010). Future research should include participant reports of situational factors that affect their role as a bystander including the relationship to the victim and perpetrator, the number of other bystanders present and the severity of the bullying episode.

Socio-emotional factors have also been found to be significantly related to bystander behaviour in that holding positive attitudes toward victims has been found to be related to higher personal responsibility for intervention. Moreover, research has pointed to the importance of considering the expectations of peers and parents which has been linked to both behaviour and individual attitudes, responsibility, and coping skills (Pozzoli \& Gini, 2012). Additionally, a recent study demonstrated that a low sense of loneliness and high levels of social support are significantly associated with providing help to victims of cyberbullying (Olenik-Shemesh, Heiman, \& Eden, 2015). In future studies it would be important to investigate reasons why bystanders who engage in outsider behaviour may not intervene, the effect of the presence of other witnesses on intervention rates as well as situational characteristic such as the severity of the event and the status of the perpetrator. Furthermore, it is important to examine how many witnesses are present during a bullying episode.

Research has also shown that genetics play an important role in understanding factors that account for chronic victimization (Ball et al., 2008; Bowes et al., 2013) and this may play an important role in who others defend. Previous experiences may impact the decision to intervene and assist the victim. Researchers have shown that children who were more likely to have been a victim of cyberbullying or traditional bullying in the past were more likely to defend and help the victim when witnessing cyberbullying (Van Cleemput, Vandebosch, \& Pabian, 2014). 


\section{Conclusion}

This was the first study to develop and pilot valid and reliable measures for moral disengagement justifications in the contexts of social bullying and cyberbullying among a sample of emerging adults. The current study adds valuable knowledge to the literature on bystander behaviour and highlights the important relationships between moral disengagement, defender self-efficacy, and bystander behaviour across social and cyber bullying contexts. Specifically, it was found that those who witnessed social bullying and cyberbullying behaviours and reported engaging in pro-bully behaviours also reported higher levels of moral disengagement justifications. This study expanded on previous research and went one step further to examine the relationship between defender self-efficacy and bystander behaviour. Consistent with previous research (Barchia \& Bussey, 2011; Poyhonen et al., 2012; Thornberg \& Jungert, 2013) it was found that defender self-efficacy was positively associated with defender bystander behaviour when witnessing social and cyber bullying.

The findings of the current study suggest that young adults who reported that they would stand up and defend the victim when witnessing social acts of aggression or hurtful acts on the internet also reported higher levels of the belief that they were capable of intervening. On the contrary, those who reported standing by or supporting the bully reported higher levels of morally disengaged justifications than were used to minimize or distort the impact of the bullying behaviour.

Implications of this study point to the potential importance of understanding the cognitive mechanisms related to bystander behaviours in emerging adulthood. Arnett (2004) argued that the developmental period that spans the ages between 18 and 25 is a transitional period between adolescence and adulthood, or a period of extended adolescence that is associated with 
characteristics more typical of adolescents than adults. The results of the present study are very similar to previous studies of adolescent populations (Thornberg \& Jungert, 2013). Results can inform intervention and prevention programs to focus on the behaviours of bystanders, as they are an important aspect of the bullying dynamic and can dramatically affect the prevalence and length of bullying episodes (Craig \& Pepler, 1997; O’Connell et al., 1999). This study demonstrates the necessity of investigating social bullying and cyberbullying across various developmental periods. Further research is essential so that we may more fully comprehend indirect forms of bullying in emerging adulthood and its similarities and differences of bullying behaviours and cognitions in childhood and adolescence. Future longitudinal research and controlled randomized designs are needed to develop successful intervention programs and must include evidence-based components that highlight attitudes and responsible actions when witnessing bullying situations. It is important for the larger community to encourage positive action and moral responsibility among youth. 


\section{References}

Almeida, A., Correia, I., \& Marinho, S. (2010). Moral disengagement, normative beliefs of peer group, and attitudes regarding roles in bullying. Journal of School Violence, 9, 23-36. doi:10.1080/15388220903185639

Archer, J., \& Côté, S. (2005). Sex differences in aggressive behavior: A developmental and evolutionary perspective. Developmental origins of aggression. Guilford Press, New York, NY.

Archer, J., \& Coyne, S. M. (2005). An integrated review of indirect, relational, and social aggression. Personality and Social Psychology Review, 9(3), 212-230. doi: 10.1207/s15327957pspr0903_2

Arnett, J. J. (2001). Adolescence and emerging adulthood: A cultural approach (2nd ed.) Pearson Education New Zealand, Auckland.

Arnett, J. J. (2004). Emerging adulthood: The winding road from the late teens through the twenties. New York: Oxford University Press.

Arnett, J. J. (2011). Emerging adulthood(s): The cultural psychology of a new life stage. Bridging cultural and developmental approaches to psychology: New syntheses in theory, research, and policy. (pp. 255-275) Oxford University Press, New York, NY

Ball, H., Arseneault, L., Taylor, A., Maughan, B., Caspi, A., \& Moffitt, T. E. (2008). Genetic and environmental influences on victims, bullies and bully-victims in childhood. Journal of Child Psychology and Psychiatry, 49, 104-112.

Bandura, A. (1986). Social foundations of thought and action: A social cognitive theory. Englewood Cliffs, NJ: Prentice-Hall, Inc. 
Bandura, A. (1990). Selective activation and the disengagement of moral control. Journal of Social Issues, 46(1), 27-46.

Bandura, A. (1999). Moral disengagement in the perpetration of inhumanities. Personality and Social Psychology Review, 3(3), 193-209.

Bandura, A. (2002). Selective moral disengagement in the exercise of moral agency. Journal of Moral Education, 31, 101-119. doi: 10.1080/0305724022014322

Bandura, A., Barbaranelli, C., Caprara, G. V., \& Pastorelli, C. (1996). Mechanisms of moral disengagement in the exercise of moral agency. Journal of Personality and Social Psychology, 71(2), 364-374. doi: 10.1037/0022-3514.71.2.364

Bandura, A., Caprara, V., Barbaranelli, C., Pastorelli, C., \& Regalia, C. (2001). Sociocognitive self-regulatory mechanisms governing transgressive behaviour. Journal of Personality and Social Psychology, 80, 125-135. doi: 10.10337/0022-3514.80.1.125

Barchia, K., \& Bussey, K. (2011). Individual and collective social cognitive influences on peer aggression: Exploring the contribution of aggression efficacy, moral disengagement, and collective efficacy. Aggressive Behaviour, 37(2), 107-120. doi: 10.1002/ab.20375

Barchia, K., \& Bussey, K. (2011). Predictors of student defenders of peer aggression victims: Empathy and social cognitive factors. International Journal of Behavioural Development, 35(4), 289-297. doi: 10.1177/0165025410396746

Bastiaensens, S., Vandebosch, H., Poels, K., Van Cleemput, K., DeSmet, A., \& De Bourdeaudhuij, I. (2014). Cyberbullying on social network sites. an experimental study into bystanders' behavioural intentions to help the victim or reinforce the bully. Computers in Human Behavior, 31, 259-271. doi:http://dx.doi.org/10.1016/j.chb.2013.10.036 
Bauman, S., \& Newman, M. L. (2013). Testing assumptions about cyberbullying: Perceived distress associated with acts of conventional and cyber bullying. Psychology of Violence, 3(1), 27-38. doi:http://dx.doi.org/10.1037/a0029867

Baumeister, R. F., \& Leary, M. R. (1995). The need to belong: Desire for interpersonal attachments as a fundamental human motivation. Psychological Bulletin, 117(3), 497529. doi: $10.1037 / 0033-2909.117 .3 .497$

Bentler, P.M. (1990), "Comparative Fit Indexes in Structural Models," Psychological Bulletin, $107(2), 238-46$.

Boulton, M. J., \& Smith, P. K. (1994). Bully/victim problems in middle-school children: Stability, self-perceived competence, peer perceptions and peer acceptance. British Journal of Developmental Psychology, 12(3), 315-329.

Bowes, L., Maughan, B., Ball, H., Shakoor, S., Ouellet-Morin, I., Caspi, A., . . Arseneault, L. (2013). Chronic bullying victimization across school transitions: The role of genetic and environmental influences. Development and Psychopathology, 25(2), 333-346. doi:10.1017/S0954579412001095

Brown, L. M., \& Gilligan, C. (1992). Meeting at the crossroads: Women's psychology and girls' development Harvard University Press, Cambridge, MA.

Campbell, M. A. (2005). Cyberbullying: An old problem in a new guise? Australian Journal of Guidance and Counselling, 15(1), 68-76. doi: 10.1375/ajgc.15.1.68

Cowie, H. (2000). Bystanding or standing by: Gender issues in coping with bullying in English schools. Aggressive Behaviour,26(1), 85-97. doi: 10.1002/(SICI)10982337(2000)26:1<85::AID-AB7>3.0.CO;2-5 
Coyne, S. M., Archer, J., \& Eslea, M. (2006). "We're not friends anymore! Unless...": The frequency and harmfulness of indirect, relational, and social aggression. Aggressive Behaviour, 32(4), 294-307. doi: 10.1002/ab.20126

Craig, W. M. \& Pepler, D. J. (1995). Peer processes in bullying and victimization: An observational study. Exceptionality Education in Canada, 5, 81-95.

Craig, W. M., \& Pepler, D. J. (1997). Observations of bullying and victimization in the school yard. Canadian Journal of School Psychology, 13, 41-59.

Craig, W. M., Pepler, D., \& Atlas, R. (2000). Observations of bullying in the playground and in the classroom. School Psychology International, 21, 22-36.

Crick, N., Bigabee, M. A., \& Howes, C. (1996). Gender differences in children's normative beliefs about aggression: How do I hurt thee? Let me count the ways. Child Development, $67,1003-1014$.

Crick, N. R., \& Grotpeter, J. K. (1995). Children's treatment by peers: Victims of relational and overt aggression. Developmental Psychopathology, 8, 367-380.

Dooley, J. J., Pyżalski, J., \& Cross, D. (2009). Cyberbullying versus face-to-face bullying: A theoretical and conceptual review. Zeitschrift Für Psychologie/Journal of Psychology, 217(4), 182-188. doi: 10.1027/0044-3409.217.4.182

Galen, B. R., \& Underwood, M. K. (1997). A developmental investigation of social aggression among children. Developmental Psychology, 33(4), 589-600.

Gilligan, C. (1993). In a different voice: Psychological theory and women's development (revised edition) Harvard University Press, Cambridge, MA.

Gini, G. (2006). Social cognition and moral cognition in bullying: What's wrong? Aggressive Behaviour, 32, 528-539. doi:10.1002/ab.20153 
Gini, G., Albeiro, P., Benelli, B., \& Altoe, G. (2008). Determinants of adolescents' active and passive bystanding behaviour in bullying. Journal of Adolescence, 31, 93-105. doi: 10.1002/ab.20204

Gini, G., Pozzoli, T., \& Hauser, M. (2011). Bullies have enhanced moral competence to judge relative to victims judge relative to victims, but lack moral compassion. Personality and Individual Differences, 50, 603-608. doi: 10.1016/j.paid.2010.12.002

Goldbaum, S., Craig, W. M., Pepler, D., \& Connolly, J. (2007). Developmental trajectories of victimization: Identifying risk and protective factors. New York, NY: Haworth Press.

Hawkins, D. L., Pepler, D. J., \& Craig, W. M. (2001). Naturalistic observations of peer interventions in bullying. Social Development, 10, 512-527.

Henson, R. K., \& Roberts, J. K. (2006). Use of exploratory factor analysis in published research: Common errors and some comment on improved practice. Educational and Psychological Measurement, 66(3), 393-416. doi:http://dx.doi.org/10.1177/0013164405282485

Hu, L., \& Bentler, P. M. (1995). Evaluating model fit. Structural equation modeling: Concepts, issues, and applications. (pp. 76-99) Sage Publications, Inc, Thousand Oaks, CA

Hymel, S., Rocke-Henderson, N., \& Bonanno, R. A. (2005). Moral disengagement: A framework for understanding bullying among adolescents. Journal of Social Sciences, 8, 1-11.

Hymel, S., Schonert-Reichl, K. A., Bonanno, R. A., Vaillancourt, T., \& Rocke-Henderson, N. (2010). Bullying and morality: Understanding how good kids can behave badly. In S. R. Jimerson, S. M. Swearer, \& D. L. Espelage (Eds.), Handbook of bullying in schools: An international perspective (pp. 101-117). New York, NY: Taylor and Francis. 
Kaiser, H. F. (1991). Coefficient alpha for a principal component and the kaiser-guttman rule. Psychological Reports, 68(3), 855-858.

Lagerspetz, K. M., Björkqvist, K., \& Peltonen, T. (1988). Is indirect aggression typical of females? Gender differences in aggressiveness in 11- to 12-year-old children. Aggressive Behaviour, 14(6), 403-414.

Latane, B., \& Nida, S. (1981). Ten years of research on group size and helping. Psychological Bulletin, 89, 308-324.

Law, D. M., Shapka, J. D., Domene, J. F., \& Gagné, M. H. (2012). Are cyberbullies really bullies? An investigation of reactive and proactive online aggression. Computers in Human Behaviour, 28(2), 664-672. doi: 10.1016/j.chb.2011.11.013

Lenhart, A., Madden, M., Smith, A., Purcell, K., Zickuhr, K., \& Rainie, L. (2011). Teens, kindness and cruelty on social network sites. Retrieved from http://www.pewinternet.org/Reports/2011/Teens-and-social-media.aspx

Li, Q. (2006). Cyberbullying in schools: A research of gender differences. School Psychology International, 27(2), 157-170. doi: 10.1177/014303430606454

Li, Q. (2007). New bottle but old wine: A research of cyberbullying in schools. Computers in Human Behaviour, 23, 1777-1791. doi: 10.1016/j.chb.2005.10.005

Li, Q. (2008). A cross-cultural comparison of adolescents' experiences related to cyberbullying. Educational Research, 50(3), 223-234. doi: 10.1080/00131880802309333

Li, Q. (2010). Cyberbullying in high schools: A study of students' behaviours and beliefs about this new phenomenon. Journal of Aggression, Maltreatment \& Trauma, 19, 372-392. doi: $10.1080 / 10926771003788979$ 
McCuaig Edge, H. J. (2012). Peer involvement in traditional and electronic bullying.

(Unpublished doctoral dissertation). Queen's University, Kingston, ON, Canada.

Menesini, E., Sanchez, V., Fonzi, A., Ortega, R., Costabile, A., \& Lo Feudo, G. (2003). Moral emotions and bullying: A cross national comparison of differences between bullies, victims and outsiders. Aggressive Behaviour, 29, 515-530. doi: 10.1002/ab.10060

Nansel, T., Overpeck, M., Pilla, R. S., Ruan, W. J., Simons-Morton, B., \& Scheidt, P. (2001). Bullying behaviours among U.S. youth: Prevalence and association with psychosocial adjustment. Journal of the American Medical Association, 285, 2094-2100.

Obermann, M. L. (2011a). Moral disengagement among bystanders to school bullying. Journal of School Violence, 10, 239-257. doi: 10.1080/15388220.2011.578276

Obermann, M. L. (2011b). Moral disengagement in self-reported and peer nominated school bullying. Aggressive Behaviour, 37, 133-144. doi: 10.1002/ab.20378

Obermann, M. (2013). Temporal aspects of moral disengagement in school bullying: Crystallization or escalation? Journal of School Violence, 12(2), 193-210. doi: $10.1080 / 15388220.2013 .766133$

O’Connell, P., Pepler, D., \& Craig, W. (1999). Peer involvement in bullying: Insights and challenges for intervention. Journal of Adolescence, 22, 437-452.

Olweus, D. (1993). Bullying at school. What we know and what we can do. Cambridge, UK: Blackwell.

Olweus, D. (1994). Bullying at school: Basic facts and an effective intervention programme. Promotion and Education, 1(4), 27-31. 
Olweus, D. (2010). Understanding and researching bullying: Some critical issues. In S. R. Jimerson, S. M. Swearer, \& D. L. Espelage (Eds.), Handbook of bullying in schools: An international perspective (pp. 9-33). New York, NY: Taylor \& Francis.

Osofsky, M. J., Bandura, A., \& Zimbardo, P. G. (2005). The role of moral disengagement in the execution process. Law and Human Behavior, 29(4), 371-393.

doi:http://dx.doi.org/10.1007/s10979-005-4930-1

Orr, J. M., Sackett, P. R., \& Dubois, C. L. (1991). Outlier detection and treatment in I/O psychology: A survey of researcher beliefs and an empirical illustration. Personnel Psychology, 44(3), 473-486.

Paciello, M., Fida, R., Tramontano, C., Lupinet, C., \& Caprara, G. V. (2008). Stability and change of moral disengagement and its impact on aggression and violence in late adolescence. Child Development, 79(5), 1288-1309. doi: 10.1111/j.14678624.2008.01189.x

Patchin, J. W., \& Hinduja, S. (2006). Bullies move beyond the schoolyard: A preliminary look at cyberbullying. Youth Violence and Juvenile Justice, 4(2), 148-169. doi:

$10.1177 / 1541204006286288$

Pepler, D., Craig, W., \& O'Connell, P. (2010). Peer process in bullying: Informing prevention and intervention strategies. In S. R. Jimerson, S. M. Swearer, \& D. L. Espelage (Eds.), Handbook of bullying in schools: An international perspective (pp. 469-479). New York, NY: Taylor \& Francis. 
Perren, S., \& Gutzwiller-Helfenfinger, E. (2012). Cyberbullying and traditional bullying in adolescence: Differential roles of moral disengagement, moral emotions, and moral values. European Journal of Developmental Psychology, 9(2), 195-209. doi: $10.1080 / 17405629.2011 .643168$

Pornari, C. D., \& Wood, J. (2010). Peer and cyber aggression in secondary school students: The role of moral disengagement, hostile attribution bias, and outcome expectancies. Aggressive Behaviour, 36(2), 81-94. doi: 10.1002/ab.20336

Pöyhönen, V., Juvonen, J., \& Salmivalli, C. (2010). What does it take to stand up for the victim of bullying? The interplay between personal and social factors. Merrill-Palmer Quarterly, 56(2), 143-163. doi: 10.1353/mpq.0.0046

Pozzoli, T., \& Gini, G. (2010). Active defending and passive bystanding behaviour in bullying: The role of personal characteristics and perceived peer pressure. Journal of Abnormal Child Psychology, 38, 815-827.

Pozzoli, T., Gini, G., \& Vieno, A. (2012). Individual and class moral disengagement in bullying among elementary school children. Aggressive Behaviour, 38(5), 378-388. doi: 10.1002/ab.21442

Pozzoli, T., \& Gini, G. (2013). Why do bystanders of bullying help or not? A multidimensional model. Journal of Early Adolescence, 33(3), 315-340. doi: 10.1177/0272431612440172

Raskauskas, J., \& Stoltz, A. D. (2007). Involvement in traditional and electronic bullying among adolescents. Developmental Psychology, 43(3), 564-575.

doi:http://dx.doi.org/10.1037/0012-1649.43.3.564 
Renati, R., Berrone, C., \& Zanetti, M. A. (2012). Morally disengaged and unempathic: Do cyberbullies fit these definitions? An exploratory study. Cyberpsychology, Behaviour, and Social Networking, 15(8), 391-398. doi: 10.1089/cyber.2012.0046

Renda, J., Vassallo, S., \& Edwards, B. (2011). Bullying in early adolescence and its association with anti-social behaviour, criminality and violence 6 and 10 years later. Criminal Behaviour and Mental Health, 21(2), 117-127. doi:http://dx.doi.org/10.1002/cbm.805

Rivers, I., Poteat, V. P., Noret, N., \& Ashurst, N. (2009). Observing bullying at school: The mental health implications of witness status. School Psychology Quarterly, 24, 211-223. doi:10.1037/a0018164

Robson, C., \& Witenberg, R. T. (2013). The influence of moral disengagement, morally based self-esteem, age, and gender on traditional bullying and cyberbullying. Journal of School Violence, 12(2), 211-231. doi: 10.1080/15388220.2012.762921

Salmivalli, C. (1999). Participant role approach to school bullying: Implications for intervention. Journal of Adolescence, 22(4), 453-459. doi: 10.1006/jado.1999.0239

Salmivalli, C., Lagerspetz, K., Bjorkqvist, K., Osterman, K., \& Kaukiainen, A. (1996). Bullying as a group process: Participant roles and their relations to social status within the group. Aggressive Behaviour, 22, 1-15.

Slonje, R., \& Smith, P. K. (2008). Cyberbullying: Another main type of bullying? Scandinavian Journal of Psychology, 49(2), 147-154. doi: 10.1111/j.1467-9450.2007.00611.x

Smith, P. K., Mahdavi, J., Carvalho, M., Fisher, S., Russell, S., \& Tippett, N. (2008). Cyberbullying: Its nature and impact in secondary school pupils. Journal of Child Psychology and psychiatry, 49(4), 376-385. doi: 10.1111/j.1469-7610.2007.01846.x 
Solberg, M. E., \& Olweus, D. (2003). Prevalence estimation of school bullying with the olweus Bully/Victim questionnaire. Aggressive Behavior, 29(3), 239-268. doi:http://dx.doi.org/10.1002/ab.10047

Summers N., Polihronis C., \& Daniels T. (2013) Examining how Attitudes Regarding Social Aggression Influence Bystander Intervention. Poster presented at PURE: Psychology Undergraduate Research Event (Carleton University, Ottawa, Ontario).

Tabachnick, B. G. \& Fidell, L. S. (2007). Using Multivariate Statistics (5th edition). Boston: Pearson Education.

Thornberg, R. (2010). A student in distress: Moral frames and bystander behaviour in school. The Elementary School Journal, 110(4), 585-608. doi: 10.1086/651197

Thornberg, R. (2010). School children's social representations on bullying causes. Psychology in the Schools, 47(4), 311-327

Thornberg, R., \& Jungert, T. (2013). Bystander behaviour in bullying situations: Basic moral sensitivity, moral disengagement and defender self-efficacy. Journal of Adolescence, 36(3), 475-483. doi: 10.1016/j.adolescence.2013.02.003

Trach, J., Hymel, S., Waterhouse, T., \& Neale, K. (2010). Bystander responses to school bullying: A cross-sectional investigation of grade and sex differences. Canadian Journal of School Psychology, 25, 114-130. doi: 10.1177/0829573509357553

Tremblay, R. E., \& Nagin, D. S. (2005). The developmental origins of physical aggression in humans. Developmental origins of aggression. (pp. 83-106) Guilford Press, New York, NY. 
Twemlow, S. W., Fonagy, P., \& Sacco, F. C. (2010). The etiological cast to the role of the bystander in the social architecture of bullying and violence in schools and communities. In S. R. Jimerson, S. M. Swearer, \& D. L. Espelage (Eds.), Handbook of bullying in schools: An international perspective (pp. 73-86). New York, NY: Taylor \& Francis.

Underwood, M. K. (2003). Social aggression among girls Guilford Press, New York, NY.

Vaillancourt, T. (2005). Indirect aggression among humans: Social construct or evolutionary adaptation? Developmental origins of aggression. (pp. 158-177) Guilford Press, New York, NY.

Vaillancourt, T., McDougall, P., Hymel, S., Krygsman, A., Miller, J., Stiver, K., \& Davis, C. (2008). Bullying: Are researchers and children/youth talking about the same thing? International Journal of Behavioural Development, 32, 486-495. doi: $10.1177 / 0165025408095553$

Vaillancourt, T., McDougall, P., Hymel, S., \& Sunderani, S. (2010). Respect or fear? The relationship between power and bullying behaviour. In S. R. Jimerson, S. M. Swearer, \& D. L. Espelage (Eds.), Handbook of bullying in schools: An international perspective (pp. 211-222). New York, NY: Taylor \& Francis.

Vaillancourt, T., Trinh, V., McDougall, P., Duku, E., Cunningham, L., Cunningham, C. \& Short, K. (2010). Optimizing population screening of bullying in school-aged children. Journal of School Violence, 9, 233-250. doi: 10.1080/15388220.2010.483182

Wang, J., Iannotti, R. J., \& Nansel, T. R. (2009). School bullying among adolescents in the United States: Physical, verbal, relational and cyber. Journal of Adolescent Health, 45, 368-375. 
Werner, N. E., \& Nixon, C. L. (2005). Normative beliefs and relational aggression: An investigation of the cognitive bases of adolescent aggressive behaviour. Journal of Youth and Adolescence, 34(3), 229-243. doi: 10.1007/s10964-005-4306-3

Whitney, I., \& Smith, P. K. (1993). A survey of the nature and extent of bullying in junior/middle and secondary schools. Educational Research, 35(1), 3-25.

Willard, N. (2005). An educator's guide to cyberbullying and cyberthreats. Retrieved from http://cyberbully.org/docs/cbcteducator.pdf

Ybarra, M. L., \& Mitchell, K. J. (2004). Youth engaging in online harassment: Associations with caregiver-child relationships, internet use, and personal characteristics. Journal of Adolescence, 27(3), 319-336. doi:http://dx.doi.org/10.1016/j.adolescence.2004.03.007

Zimmer-Gembeck, M., Geiger, T. C., \& Crick, N. R. (2005). Relational and physical aggression, prosocial behavior, and peer relations: Gender moderation and bidirectional associations.

The Journal of Early Adolescence, 25(4), 421-452.

doi:http://dx.doi.org/10.1177/0272431605279841 
Appendix A: Recruitment Poster

\section{Do You Stand By or Stand Up? Bystander Characteristics in Social and Cyberbullying}

Dear Carleton University students,

We are interested in expanding our knowledge and contributing to the body of research involving behaviours and justifications that commonly occur in childhood and may continue on into adulthood. In exchange for your participation, $0.50 \%$ will be added to your final mark in your psychology course (PSYC 1001, PSYC 1002, PSYC 2001, PSYC 2002; you must be currently enrolled in the course to receive participation percentage).

What is this study about? We are interested in your experience with friends and peers in university. We would like to gain insight into the types of experiences people have had and learn about their accompanying feelings, attitudes, and actions. To do this we will ask participants to spend approximately 45 minutes reflecting on their feelings about their friendship experiences and complete an online survey. You will not be asked for your name or any other identifying information after you have logged into SONA (which is only needed for the acknowledgement of your participation in exchange for the psychology credit). Your answers will be kept strictly confidential. Note that it is possible that thinking about peer relationships and reflecting on your own behaviour may cause you to feel mild temporary discomfort or concern when responding to some of the questionnaire items This is expected to be no more than would occur on a daily basis when talking or thinking about conflicts with friends.

Why participate? You will be contributing to research in which there is much room to gain knowledge; therefore there is potential for the researchers to learn many new things from the data. You will also earn $0.25 \%$ to your final grade. When the research is complete, we will be 
glad to share a summary of our results with you. If you are in the field of psychology, our results may get you thinking about what you would like to study in your future years as a student. This study has been approved by the Carleton University Ethics Committee for Psychological Research. The ethic approval number is 13-046.

If you would like to participate, click on this link. 
Appendix B: Informed Consent Form

\section{Informed Consent Form}

The purpose of an informed consent is to ensure that all participants fully understand and are aware of the nature of their involvement in the present study. The informed consent form must provide sufficient information such that each participant may have the opportunity to determine whether or not they wish to participate.

\section{Do You Stand By or Stand Up? Bystander Characteristics in Social and Cyberbullying}

Research personnel: The following people are involved in this research project and may be contacted at any time: Nicole Summers, (Psychology Graduate Student), Nicole_summers@carleton.ca, Christine Polihronis, MA (Psychology Graduate Student, Carleton U., Christine_polihronis@carleton.ca, Tina Daniels, Ph.D. Faculty Supervisor). (613) 520-2600 ext 2686, tina_daniels@carleton.ca

Ethical concerns: Should you have any ethical concerns about this questionnaire please contact Dr. Avi Parush, Chair, Carleton University Ethics Committee for Psychological Research (Avi_Parush@carleton.ca, 613-520-2600, ext. 6026). For any other concerns, please contact the department chair, Dr. Anne Bowker, (anne_bowker@carleton.ca, 613-520-2600, Ext. 8218).

Purpose: The purpose of this study is to examine the relationship between attitudes and beliefs about various bullying behaviours and the likelihood of intervening.

Task requirements: In this questionnaire, you will be asked to rate a number of statements as to how much you agree or disagree with them. All statements will address attitudes and justifications towards engaging in different forms of bullying behaviour. Please note that some personal and potentially sensitive information pertaining to your opinions of such behaviour and some potential justifications for them might be requested of you if you choose to fill out this questionnaire. You will not be asked for your name or any other identifying information after you have logged into SONA (which is only needed for the acknowledgement of your participation in exchange for the psychology credit). Your answers will be kept strictly confidential.

Duration and locale: The questionnaire will be completed online and will take approximately 
45 minutes.

Compensation: Participants will receive .50 bonus percent for 45 minutes of participation for qualifying courses.

Potential risk/discomfort: There are no potential physical risks associated with responding to this questionnaire. It is possible that thinking about your relationships with your friends and reflecting on your own behaviour when you have been in conflict may cause some mild temporary psychological discomfort or concern when responding to some of the questionnaire items. It is expected that this would be no more than that experienced in everyday life when talking or thinking about conflicts with friends. You may choose not to respond to any item or to withdraw from the study at any time, without penalty.

Anonymity/Confidentiality: All of the information provided by participants will be kept anonymous and confidential. All of the data will be collected and coded in such a way that the identity of the respondent will not be associated with any information that they provide. All of the questionnaire and demographic data collected here will be erased/destroyed within 5 years of the project being completed.

We collect data through the software Qualtrics, which uses servers with multiple layers of security to protect the privacy of the data (e.g., encrypted websites and pass-word protected storage). Please note that Qualtrics is hosted by a server located in the USA. The United States Patriot Act permits U.S. law enforcement officials, for the purpose of an anti-terrorism investigation, to seek a court order that allows access to the personal records of any person without that person's knowledge. In view of this we cannot absolutely guarantee the full confidentiality and anonymity of your data. With your consent to participate in this study you acknowledge this.

Right to withdraw: Your participation is entirely voluntary. At any point while filling out this questionnaire, you have the right to decline to respond to any questionnaire item or to stop responding to the questionnaire entirely.

This study has received clearance by the Carleton University Ethics Committee for Psychological Research (******) 
Consent: By clicking "Agree", you acknowledge that you have read and understand the description of this study and are allowing any information you provide to be used by the researchers for the purposes of the study. Your participation in this study is completely voluntary and you may choose to leave the study at any point. Any information you provide will be kept confidential. 


\title{
Appendix C
}

Student Bystander Behaviour Scale (SBBS)

\begin{abstract}
We say a student is being bullied when another student, or group of students, say nasty and unpleasant things to him or her. It is also bullying when a student is hit, kicked, threatened, or locked inside a room, sent nasty notes, when people don't talk to him or her and things like that. These things may take place frequently, and it is difficult for the student being bullied to defend him/herself. It is also bullying when a student is teased repeatedly in a negative way. But it is not bullying when students of the same strength quarrel or fight (p. 7).
\end{abstract}

Using the above definition, when you have witnessed these behaviours how often have you done the following in the past year?

\section{Pro-bully behaviour}

Usually

1. I joined in and began to tease the person too.
a) Never
b) Rarely
c) Sometimes
d) Usually
e) Always

2. I forwarded the embarrassing online post that was sent to me.
a) Never
b) Rarely
c) Sometimes
d) Usually
e) Always

3. When my friends ignored or excluded someone from our group, I excluded them too.
a) Never
b) Rarely
c) Sometimes
d) Usually
e) Always

4. I watched when someone was teased because it was fun and entertaining. 

a) Never
b) Rarely
c) Sometimes
d) Usually
e) Always

5. I enjoyed reading mean online posts about others as it was fun and entertaining.
a) Never
b) Rarely
c) Sometimes
d) Usually
e) Always

6. I joined in when friends gossiped because it was fun and entertaining
a) Never
b) Rarely
c) Sometimes
d) Usually
e) Always

7. I laughed and encouraged them to tease the person some more.
a) Never
b) Rarely
c) Sometimes
d) Usually
e) Always

8. I laughed and showed other friends the embarrassing online post of someone else.
a) Never
b) Rarely
c) Sometimes
d) Usually
e) Always

9. I laughed at the embarrassing gossip my friends told me.
a) Never
b) Rarely
c) Sometimes
d) Usually
e) Always

10. I started calling the person names too.
a) Never
b) Rarely
c) Sometimes 

d) Usually
e) Always

11. I forwarded a message to my friend about another person that I had received.
a) Never
b) Rarely
c) Sometimes
d) Usually
e) Always

12. I told the rumour I heard to another friend.
a) Never
b) Rarely
c) Sometimes
d) Usually
e) Always

Outsider behaviour

1. I watched and did nothing when my friends excluded another person.
a) Never
b) Rarely
c) Sometimes
d) Usually
e) Always

2. When I have read mean or offensive posts online, I did not respond or comment on the post.
a) Never
b) Rarely
c) Sometimes
d) Usually
e) Always

3. When my friends gossiped about others, I didn't do anything but I was quiet instead.
a) Never
b) Rarely
c) Sometimes
d) Usually
e) Always

4. I didn't do anything but I was quiet instead when my friends told rumours about others.
a) Never
b) Rarely
c) Sometimes
d) Usually 


\section{e) Always}

5. When I saw the embarrassing online post, I did not pass it on or show others.
a) Never
b) Rarely
c) Sometimes
d) Usually
e) Always

6. When I heard friends talking about other people, I didn't do anything but I was quiet instead.
a) Never
b) Rarely
c) Sometimes
d) Usually
e) Always

\section{Defender behaviour}

1. When I saw someone getting teased, I tried to get them to stop.
a) Never
b) Rarely
c) Sometimes
d) Usually
e) Always

2. When I have seen an embarrassing online post or text message of someone, I tried to stop it from circulating.
a) Never
b) Rarely
c) Sometimes
d) Usually
e) Always

3. When I have heard nasty rumours about someone, I have told people "it is not okay to talk like that".
a) Never
b) Rarely
c) Sometimes
d) Usually
e) Always

4. When I have seen people being treated unfairly, I stepped in and told everyone it was not okay. 

a) Never
b) Rarely
c) Sometimes
d) Usually
e) Always

5. When I have seen a mean message posted about someone, I reported the message or online post as 'inappropriate' or 'offensive'.
a) Never
b) Rarely
c) Sometimes
d) Usually
e) Always

6. When my friends have left someone out of the group on purpose, I asked them to join us and included them.
a) Never
b) Rarely
c) Sometimes
d) Usually
e) Always 
Appendix D

MODUSA Moral Disengagement in Using Social Aggression

Please indicate how much you agree with the following statements:

Minimizing Agency

1. Gossiping isn't that bad if all of your friends do it.

0) Completely Disagree 1) Slightly Disagree 2) Somewhat Agree 3) Moderately Agree 4)Totally agree

2. It's not my responsibility to include someone if my friends ignore that person.

0) Completely Disagree 1) Slightly Disagree 2) Somewhat Agree 3) Moderately Agree 4)Totally agree

3. If a rumour is being spread about someone, there is nothing I can do to stop it.

0) Completely Disagree 1) Slightly Disagree 2) Somewhat Agree 3) Moderately Agree 4)Totally agree

$\underline{\text { Cognitive Restructuring }}$

4. It's okay to give someone a dirty look because hitting them is worse.

0) Completely Disagree 1) Slightly Disagree 2) Somewhat Agree 3) Moderately Agree 4)Totally agree

5. It's okay to talk behind someone's back if they don't know who is doing it.

0) Completely Disagree 1) Slightly Disagree 2) Somewhat Agree 3) Moderately Agree 4)Totally agree

6. It's okay to tell a rumour about someone that my friends don't like.

0) Completely Disagree 1) Slightly Disagree 2) Somewhat Agree 3) Moderately Agree 4)Totally agree

\section{Distortion of Negative Events}

7. It's okay to give someone the silent treatment in order to teach that person a lesson.

0) Completely Disagree 1) Slightly Disagree 2) Somewhat Agree 3) Moderately Agree 4)Totally agree 
8. Rolling your eyes at someone gets them to know what is not appropriate in the group.

0) Completely Disagree 1) Slightly Disagree 2) Somewhat Agree 3) Moderately Agree 4)Totally agree

9. A rumour doesn't hurt if the person doesn't know about it.

0) Completely Disagree 1) Slightly Disagree 2) Somewhat Agree 3) Moderately Agree 4)Totally agree Dehumanizing/Blaming the Victim

10. Some people deserve to be left out from certain activities.

0) Completely Disagree 1) Slightly Disagree 2) Somewhat Agree 3) Moderately Agree 4)Totally agree

11. It's okay to give the cold shoulder to (or to turn away from) a person no one likes.

0) Completely Disagree 1) Slightly Disagree 2) Somewhat Agree 3) Moderately Agree 4)Totally agree

12. Most people who get gossiped about bring it on themselves.

0) Completely Disagree 1) Slightly Disagree 2) Somewhat Agree 3) Moderately Agree 4)Totally agree 13. Some people have rumours spread about them because they deserved it.

0) Completely Disagree 1) Slightly Disagree 2) Somewhat Agree 3) Moderately Agree 4)Totally agree 
Appendix E

Moral Disengagement in Cyberbullying

Please indicate how much you agree with the following statements:

Minimizing Agency

1. Posting mean comments online about another person is okay when all your friends are doing it.

0) Completely Disagree 1) Slightly Disagree 2) Somewhat Agree 3) Moderately Agree 4)Totally agree

2. If an embarrassing picture or video is being posted online of another person, there is nothing I can do to stop it.

0) Completely Disagree 1) Slightly Disagree 2) Somewhat Agree 3) Moderately Agree 4)Totally agree

3. If my friends are texting mean things to someone else, there is nothing I can do to stop them.

0) Completely Disagree 1) Slightly Disagree 2) Somewhat Agree 3) Moderately Agree 4)Totally agree

4. It is not my fault if someone gets upset about something funny I posted about them online.

0) Completely Disagree 1) Slightly Disagree 2) Somewhat Agree 3) Moderately Agree 4)Totally agree

Cognitive Restructuring

5. It's okay to post a mean comment online about someone because saying it to the person face to face is worse.

0) Completely Disagree 1) Slightly Disagree 2) Somewhat Agree 3) Moderately Agree 4)Totally agree

6. It's okay to post a nasty comment online about someone if they don't know who is doing it.

0) Completely Disagree 1) Slightly Disagree 2) Somewhat Agree 3) Moderately Agree 4)Totally agree

7. It's okay to post an embarrassing picture or video of someone else online if they don't know who is doing it.

0) Completely Disagree 1) Slightly Disagree 2) Somewhat Agree 3) Moderately Agree 4)Totally agree

8. It is okay to forward someone an embarrassing picture or video of someone nobody likes.

0) Completely Disagree 1) Slightly Disagree 2) Somewhat Agree 3) Moderately Agree 4)Totally agree 
9. When you post a status update online (via Facebook, Twitter, etc.) that includes all the friends you are with, it's not your fault if others feel excluded.

0) Completely Disagree 1) Slightly Disagree 2) Somewhat Agree 3) Moderately Agree 4)Totally agree

10. Posting something mean about someone online is okay if they did it to you first.

0) Completely Disagree 1) Slightly Disagree 2) Somewhat Agree 3) Moderately Agree 4)Totally agree

\section{Distortion of Negative Events}

11. Posting nasty comments online or through text messages is okay if they don't know who is doing it

0) Completely Disagree 1) Slightly Disagree 2) Somewhat Agree 3) Moderately Agree 4)Totally agree

12. It's okay to send a nasty comment to someone in order to teach that person a lesson.

0) Completely Disagree 1) Slightly Disagree 2) Somewhat Agree 3) Moderately Agree 4)Totally agree

13. A mean or hurtful online post about someone doesn't hurt if that person doesn't know about it.

0) Completely Disagree 1) Slightly Disagree 2) Somewhat Agree 3) Moderately Agree 4)Totally agree

\section{Dehumanizing/Blaming the Victim}

14. Some people deserve to have mean comments posted online about them.

0) Completely Disagree 1) Slightly Disagree 2) Somewhat Agree 3) Moderately Agree 4)Totally agree

15. It is okay to send mean messages to friends about a person no one likes.

0) Completely Disagree 1) Slightly Disagree 2) Somewhat Agree 3) Moderately Agree 4)Totally agree

16. People who have hurtful comments posted about them online bring it on themselves

0) Completely Disagree 1) Slightly Disagree 2) Somewhat Agree 3) Moderately Agree 4)Totally agree 


\section{Appendix F \\ Moral Disengagement (Bandura et al., 1996)}

Please indicate how much you agree with the following statements:

1. It is alright to fly off the handle to protect your friends.

0) Completely Disagree 1) Slightly Disagree 2) Somewhat Agree 3) Moderately Agree 4)Totally agree

2. Slapping and shoving someone is just a way of joking.

0) Completely Disagree 1) Slightly Disagree 2) Somewhat Agree 3) Moderately Agree 4)Totally agree

3. Damaging some property is no big deal when you consider that others are beating people up.

0) Completely Disagree 1) Slightly Disagree 2) Somewhat Agree 3) Moderately Agree 4)Totally agree

4. A member of a group should not be blamed for trouble the group causes.

0) Completely Disagree 1) Slightly Disagree 2) Somewhat Agree 3) Moderately Agree 4)Totally agree

5. If youth are living under bad conditions in their neighbourhood they cannot be blamed for behaving aggressively.

0) Completely Disagree 1) Slightly Disagree 2) Somewhat Agree 3) Moderately Agree 4)Totally agree

6. It is not serious to tell small lies because they don't hurt anybody.

0) Completely Disagree 1) Slightly Disagree 2) Somewhat Agree 3) Moderately Agree 4)Totally agree

7. Some people deserve to be treated like animals.

0) Completely Disagree 1) Slightly Disagree 2) Somewhat Agree 3) Moderately Agree 4)Totally agree

8. If people fight and misbehave in school or at work it is their teacher's /superior's fault. 
0) Completely Disagree 1) Slightly Disagree 2) Somewhat Agree 3) Moderately Agree 4)Totally agree 9. It is alright to beat someone who bad mouths your family.

0) Completely Disagree 1) Slightly Disagree 2) Somewhat Agree 3) Moderately Agree 4)Totally agree 10. To hit obnoxious friends is just giving them "a lesson."

0) Completely Disagree 1) Slightly Disagree 2) Somewhat Agree 3) Moderately Agree 4)Totally agree 11. Stealing some money is not too serious compared to those who steal a lot of money.

0) Completely Disagree 1) Slightly Disagree 2) Somewhat Agree 3) Moderately Agree 4)Totally agree 12. A person who only suggests breaking rules should not be blamed if others go ahead and do it.

0) Completely Disagree 1) Slightly Disagree 2) Somewhat Agree 3) Moderately Agree 4)Totally agree 13. If youth are not disciplined at home they should not be blamed for misbehaving.

0) Completely Disagree 1) Slightly Disagree 2) Somewhat Agree 3) Moderately Agree 4)Totally agree 14. People do not mind being teased because it shows interest in them.

0) Completely Disagree 1) Slightly Disagree 2) Somewhat Agree 3) Moderately Agree 4)Totally agree 15. It is okay to treat somebody badly who behaved like a "worm."

0) Completely Disagree 1) Slightly Disagree 2) Somewhat Agree 3) Moderately Agree 4)Totally agree 16. If people are careless about where they leave their things it is their own fault if they get stolen.

0) Completely Disagree 1) Slightly Disagree 2) Somewhat Agree 3) Moderately Agree 4)Totally agree 17. It is alright to fight when your group's honour is threatened.

0) Completely Disagree 1) Slightly Disagree 2) Somewhat Agree 3) Moderately Agree 4)Totally agree 
18. Taking someone's motorcycle or car without their permission is just "borrowing it."

0) Completely Disagree 1) Slightly Disagree 2) Somewhat Agree 3) Moderately Agree 4)Totally agree

19. It is not serious to insult a friend because beating him/her up is worse.

0) Completely Disagree 1) Slightly Disagree 2) Somewhat Agree 3) Moderately Agree 4)Totally agree

20. If a group decides together to do something harmful it is unfair to blame a single member of the group for it.

0) Completely Disagree 1) Slightly Disagree 2) Somewhat Agree 3) Moderately Agree 4)Totally agree

21. Youths cannot be blamed for using bad words when all their friends do it.

0) Completely Disagree 1) Slightly Disagree 2) Somewhat Agree 3) Moderately Agree 4)Totally agree

22. Teasing someone does not really hurt him/her.

0) Completely Disagree 1) Slightly Disagree 2) Somewhat Agree 3) Moderately Agree 4)Totally agree

23. Someone who is detestable does not deserve to be treated like a human being.

0) Completely Disagree 1) Slightly Disagree 2) Somewhat Agree 3) Moderately Agree 4)Totally agree

24. People who get mistreated usually do things that deserve it.

0) Completely Disagree 1) Slightly Disagree 2) Somewhat Agree 3) Moderately Agree 4)Totally agree

25. It is alright to lie to keep your friends out of trouble.

0) Completely Disagree 1) Slightly Disagree 2) Somewhat Agree 3) Moderately Agree 4)Totally agree 26. It is not a bad thing to "get drunk" once in a while.

0) Completely Disagree 1) Slightly Disagree 2) Somewhat Agree 3) Moderately Agree 4)Totally agree 
27. Compared to the illegal things people do, taking some things from a store without paying for them is not very serious.

0) Completely Disagree 1) Slightly Disagree 2) Somewhat Agree 3) Moderately Agree 4)Totally agree 28. It is unfair to blame a single person who had only a small part in the harm caused by a group.

0) Completely Disagree 1) Slightly Disagree 2) Somewhat Agree 3) Moderately Agree 4)Totally agree

29. Youth cannot be blamed for misbehaving if their friends pressured them to do it.

0) Completely Disagree 1) Slightly Disagree 2) Somewhat Agree 3) Moderately Agree 4)Totally agree

30. Insults among peers do not hurt anyone.

0) Completely Disagree 1) Slightly Disagree 2) Somewhat Agree 3) Moderately Agree 4)Totally agree

31. Some people have to be treated roughly because they lack feelings that can be hurt.

0) Completely Disagree 1) Slightly Disagree 2) Somewhat Agree 3) Moderately Agree 4)Totally agree

32. Youths are not at fault for misbehaving if their parents are too restrictive (severe, and they don't allow them any freedom).

0) Completely Disagree 1) Slightly Disagree 2) Somewhat Agree 3) Moderately Agree 4)Totally agree 


\section{Appendix $\mathrm{G}$}

Defender Self-Efficacy (Barchia \& Bussey, 2011)

How well can you:

1. Tell a person who slaps, punches, or pushes someone to stop.
Not well (1)
(2) (3)
(4) (5)
(6) (7) Very well

2. Tell a person who leaves others out, spreads rumors, or says mean things about another person behind their back to stop.
Not well (1)
(2) (3)
(4) (5)
(6) (7) Very well

3. Tell a person who calls someone mean names, teases, or says mean things to another person to stop.
Not well (1)
(2) (3)
(4) (5)
(6) (7) Very well

4. Tell a person who sends nasty messages to another person that it is not okay.
Not well (1)
(2) (3)
(4) (5)
(6) (7) Very well

5. Tell a person who posts mean comments online via website, social media chat forum to stop.
Not well (1)
(2) (3)
(4) (5)
(6)
(7) Very well

6. Tell a person who sends embarrassing pictures of someone via online or electronic device to stop.
Not well (1)
(2) (3)
(4) (5)
(6) (7) Very well

7. Tell a person who leaves others out intentionally that it is not okay.
Not well (1)
(2) (3)
(4) (5)
(6)
(7) Very well

8. Tell a person or friend who spreads rumors, or says mean things about another person to stop.
Not well (1)
(2) (3)
(4) (5)
(6) (7) Very well

9. Tell a person or friend who talks behind other peoples back to stop.
Not well (1)
(2) (3)
(4) (5)
(6) (7) Very well 
Appendix $\mathrm{H}$

Debriefing

\section{Debriefing}

\section{What are we trying to learn in this research?}

The primary goal of this study was to measure the extent to which individuals consider various social and physical bullying behaviours to be acceptable and how likely they are to intervene when witnessing these various forms of bullying behaviour.

\section{Why is this important to scientists or the general public?}

This research will help us understand why people may not intervene in incidents of bullying as well as help us to further understand the active role bystanders can play in bullying behaviour and the effects that attitudes \& beliefs may have on bystander's actions. These research findings can be used in the future by psychological researchers to determine what other kinds of individual attitudes might be related to engaging youth to intervene in actual bullying situations. It might also turn out to be useful to school psychologists as a measure for predicting things like a school or classroom climate that supports the use of socially aggressive behaviour.

\section{What are the hypotheses and predictions?}

It was hypothesized that all of the items on the scale, that asked about reasons for not doing something when witnessing incidents of social aggression, would be found to be reliable and consistent indicators of individual's attitudes \& beliefs. It was also hypothesized that if this scale is indeed a valid measure of attitudes, then higher levels of self-rated acceptance on this scale would be predictive of higher levels of acceptance towards using and observing these socially aggressive behaviours (i.e. gossip, rumours and non-verbal body language to harm a victim).

\section{Where can I learn more?}

If you would like to know more about current research in this area, the following references may be useful.

Hymel, S., Rocke-Henderson, N., \& Bonanno, R. A. (2005). Moral disengagement: A framework for understanding bullying among adolescents. Journal of Social Sciences, 8,1-11

Obermann, M. L. (2011a). Moral disengagement among bystanders to school bullying. Journal of School Violence, 10, 239-257. doi: 10.1080/15388220.2011.578276

Thornberg, R., \& Jungert, T. (2013). Bystander behaviour in bullying situations: Basic moral sensitivity, moral disengagement and defender self-efficacy. Journal of Adolescence, 36(3), 475 483. doi: 10.1016/j.adolescence.2013.02.003

\section{What if I have questions later?}

If you have any remaining concerns, questions, or comments about this questionnaire, please feel free to contact:

Tina Daniels, Ph.D. (Faculty Supervisor, Psychology Dept.tina_daniels@carleton.ca)

Christine Polihronis (Psychology Graduate Student, Carleton University,

Christine_polihronis@carleton.ca)

Nicole Summers (Psychology Graduate Student, Carleton University, 
Nicole_summers@carleton.ca)

Should you have any ethical concerns about this questionnaire please contact:

Dr. Avi Parush, Chair, Avi_Parush@carleton.ca. Carleton University Ethics Committee for Psychological Research , 613-520-2600, ext. 6026). For any other concerns, please contact the department chair, Dr. Anne Bowker (anne_bowker@carleton.ca, 613-520-2600, Ext. 8218). Please refer to the study's ethics approval number (provided by Carleton University Ethics Committee for Psychological Research) when making inquiries (13-046)

Is there anything that I can do if I found this questionnaire to be emotionally upsetting?

Yes. If you feel any distress or concern after participating in this study, please feel contact the Carleton University Health and Counselling Services at: 613-520-6674, or the Distress Centre of Ottawa and Region at 613-238-3311 (http://www.dcottawa.on.ca).

\section{THANK YOU FOR YOUR PARTICIPATION!}




\section{Appendix I}

Security of data collection. Data will be collected through the online survey tool Qualtrics. Qualtrics employs multiple layers of security to make sure that data remains private and secure. All surveys created are placed in a Secure Survey Environment (SSE) and the web pages are encrypted with secure socket layer (SSL). Only persons with authorized access to a survey account can download the data from this server. Qualtrics is SAS 70 certified and meets the rigorous privacy standards imposed on health care records by the Health Insurance Portability and Accountability Act (HIPAA). All Qualtrics accounts are protected by passwordaccess, and Qualtrics employees will not access the protected accounts without express permission by the account owner.

Survey responses collected will be anonymous. In addition, IP address collection will be removed from the options when creating the online survey. At the end of the survey, the participant will be encouraged to close the browser window with the following message: "For maximum confidentiality, please close this window". Throughout the survey, a "Quit" option will be included, which participants can select at any time and direct them to the debriefing form before exiting the window.

The Qualtrics server is located in the U.S. The United States Patriot Act permits U.S. law enforcement officials, for the purpose of an anti-terrorism investigation, to seek a court order that allows access to the personal records of any person without that person's knowledge. Participants will be informed of this on the consent form.

Security of data storage. The data collected will remain on the Qualtrics account until the end of the study and will then be deleted. No backups will be kept on the Qualtrics server after the deletion has been processed. In addition, the data will be downloaded upon completion 
of the study and stored on password protected lab computers at Carleton University. These files will not contain any personal identifying information. Data may be shared with trusted colleagues and with requests from competent professionals (APA guidelines 8.14). Each of the measures included in the on-line survey are described below. 


\section{Appendix J}

\section{Supplementary Results Tables}

Table

Means and Standard Deviations for the Moral Disengagement in Using Social Aggression Scale

Items
1. Gossiping isn't that bad if all of your friends do it.
2. It's not my responsibility to include someone if my friends ignore that
person.
3. If a rumour is being spread about someone, there is nothing I can do to
stop it.

4. It's okay to give someone a dirty look because hitting them is worse.

5. It's okay to talk behind someone's back if they don't know who is doing it.

6. It's okay to tell a rumour about someone that my friends don't like.

$\begin{array}{rrr}\mathrm{N} & M & S D \\ 474 & .73 & .89\end{array}$

$474 \quad 1.10 \quad 1.02$

$473 \quad 1.19 \quad 1.03$

$\begin{array}{lll}474 & 1.22 & 1.17\end{array}$

$474 \quad .55 \quad .80$

7. It's okay to give someone the silent treatment in order to teach that person a lesson.

$474 \quad .54 \quad .81$

$\begin{array}{lll}474 & 1.70 & 1.17\end{array}$

8. Rolling your eyes at someone gets them to know what is not appropriate in the group.

$\begin{array}{lll}474 & 1.35 & 1.09\end{array}$

9. A rumour doesn't hurt if the person doesn't know about it.

$\begin{array}{lll}473 & .53 & .83\end{array}$

10. Some people deserve to be left out from certain activities.

$474 \quad 1.00 \quad 1.09$

11. It's okay to give the cold shoulder to (or to turn away from) a person no one likes.

$473 \quad .59 \quad .80$

12. Most people who get gossiped about bring it on themselves. $\quad 474 \quad 1.13 \quad 1.03$

13. Some people have rumours spread about them because they deserved it. $\quad \begin{array}{llll}474 & .89 & .98\end{array}$ 
Table

Means and Standard Deviations for the Moral Disengagement Cyberbullying Scale

Items

$\mathrm{N} \quad M \quad S D$

1. Posting mean comments online about another person is okay when all your friends are doing it.

$\begin{array}{lll}472 \quad .57 & .54\end{array}$

2. If an embarrassing picture or video is being posted online of another person, there is nothing I can do to stop it.

$\begin{array}{lll}472 & 1.18 & 1.14\end{array}$

3. If my friends are texting mean things to someone else, there is nothing I can do to stop them.

$472 \quad .90 \quad .95$

4. It is not my fault if someone gets upset about something funny I posted about them online.

$472 \quad .51 \quad .81$

5. It's okay to post a mean comment online about someone because saying it to the person face to face is worse.

$472 \quad .30 \quad .64$

6. It's okay to post a nasty comment online about someone if they don't know who is doing it.

$\begin{array}{lll}472 \quad .62 & .62\end{array}$

7. It's okay to post an embarrassing picture or video of someone else online if they don't know who is doing it.

\begin{tabular}{lll}
$472 \quad .65$ \\
\hline
\end{tabular}

8. It is okay to forward someone an embarrassing picture or video of someone nobody likes.

$472 \quad .34 \quad .69$

9. When you post a status update online (via Facebook, Twitter, etc.) that includes all the friends you are with, it's not your fault if others feel excluded.

10. Posting something mean about someone online is okay if they did it to you first.

$472 \quad .75 \quad .95$

11. Posting nasty comments online or through text messages is okay if they don't know who is doing it

12. It's okay to send a nasty comment to someone in order to teach that person a lesson.

$471 \quad .48 \quad .79$

13. A mean or hurtful online post about someone doesn't hurt if that person doesn't know about it.

$472 \quad .40 \quad .76$

14. Some people deserve to have mean comments posted online about them.

$\begin{array}{lll}472 & .59 & .88\end{array}$

15. It is okay to send mean messages to friends about a person no one likes.

16. People who have hurtful comments posted about them online bring it on themselves 
Table

Means and Standard Deviations for the Student Bystander Behaviours in Social Aggression Scale

\begin{tabular}{|c|c|c|c|}
\hline Items & $\mathrm{N}$ & $M$ & $S D$ \\
\hline 1. I laughed at the embarrassing gossip my friends told me. & 466 & 1.82 & 1.10 \\
\hline $\begin{array}{l}\text { 2. I joined in when friends gossiped because it was fun and } \\
\text { entertaining }\end{array}$ & 470 & 1.53 & 1.15 \\
\hline $\begin{array}{l}\text { 3. When my friends ignored or excluded someone from our group, I } \\
\text { excluded them too. }\end{array}$ & 447 & 1.10 & 1.00 \\
\hline 4. I told the rumour I heard to another friend. & 465 & 1.57 & 1.09 \\
\hline $\begin{array}{l}\text { 5. I watched and did nothing when my friends excluded another } \\
\text { person. }\end{array}$ & 427 & 1.18 & 1.01 \\
\hline $\begin{array}{l}\text { 6. When I heard friends talking about other people, I didn't do } \\
\text { anything but I was quiet instead. }\end{array}$ & 462 & 1.91 & 1.03 \\
\hline $\begin{array}{l}\text { 7. When my friends gossiped about others, I didn't do anything but I } \\
\text { was quiet instead. }\end{array}$ & 456 & 1.96 & 1.00 \\
\hline $\begin{array}{l}\text { 8. I didn't do anything but I was quiet instead when my friends told } \\
\text { rumours about others. }\end{array}$ & 449 & 1.75 & 1.05 \\
\hline $\begin{array}{l}\text { 9. When I have heard nasty rumours about someone, I have told } \\
\text { people "it is not okay to talk like that". }\end{array}$ & 465 & 2.01 & 1.15 \\
\hline $\begin{array}{l}\text { 10. When my friends have left someone out of the group on purpose, } \\
\text { I asked them to join us and included them. }\end{array}$ & 434 & 2.25 & 1.16 \\
\hline
\end{tabular}


Table

Means and Standard Deviations for the Defender Self-Efficacy Scale

\begin{tabular}{|c|c|c|c|}
\hline Items & $\mathrm{N}$ & $M$ & $S D$ \\
\hline $\begin{array}{l}\text { 1. Tell a person who sends nasty messages to another person that it } \\
\text { is not okay. }\end{array}$ & 474 & 3.65 & 1.70 \\
\hline $\begin{array}{l}\text { 2. Tell a person who posts mean comments online via website, } \\
\text { social media chat forum to stop. }\end{array}$ & 474 & 3.19 & 1.85 \\
\hline $\begin{array}{l}\text { 3. Tell a person who sends embarrassing pictures of someone via } \\
\text { online or electronic device to stop. }\end{array}$ & 474 & 3.60 & 1.79 \\
\hline $\begin{array}{l}\text { 4. Tell a person who leaves others out intentionally that it is not } \\
\text { okay. }\end{array}$ & 473 & 3.55 & 1.68 \\
\hline $\begin{array}{l}\text { 5. Tell a person or friend who spreads rumours, or says mean things } \\
\text { about another person to stop. }\end{array}$ & 474 & 3.43 & 1.68 \\
\hline $\begin{array}{l}\text { 6. Tell a person or friend who talks behind other peoples back to } \\
\text { stop. }\end{array}$ & 474 & 3.30 & 1.68 \\
\hline
\end{tabular}

